\title{
Current Insight into Traditional and Modern Methods in Fungal Diversity Estimates
}

\author{
Ajay Kumar Gautam ${ }^{1, *}$, Rajnish Kumar Verma ${ }^{2, *}$, Shubhi Avasthi ${ }^{3}$, Sushma ${ }^{4}$, Yogita Bohra ${ }^{2} \mathbb{D}$, \\ Bandarupalli Devadatha ${ }^{5}$, Mekala Niranjan ${ }^{6}(\mathbb{D})$ and Nakarin Suwannarach $7, *(\mathbb{C})$
}

Citation: Gautam, A.K.; Verma, R.K.; Avasthi, S.; Sushma; Bohra, Y.; Devadatha, B.; Niranjan, M.; Suwannarach, N. Current Insight into Traditional and Modern Methods in Fungal Diversity Estimates. J. Fungi 2022, 8, 226. https://doi.org/ $10.3390 /$ jof 8030226

Academic Editors: Saowaluck Tibpromma and Samantha C. Karunarathna

Received: 30 January 2022

Accepted: 20 February 2022

Published: 24 February 2022

Publisher's Note: MDPI stays neutral with regard to jurisdictional claims in published maps and institutional affiliations.

Copyright: (c) 2022 by the authors. Licensee MDPI, Basel, Switzerland. This article is an open access article distributed under the terms and conditions of the Creative Commons Attribution (CC BY) license (https:/ / creativecommons.org/licenses/by/ $4.0 /)$.
1 School of Agriculture, Abhilashi University, Mandi 175028, Himachal Pradesh, India

2 Department of Plant Pathology, Punjab Agricultural University, Ludhiana 141004, Punjab, India; yogitabohra@pau.edu

3 School of Studies in Botany, Jiwaji University, Gwalior 474011, Madhya Pradesh, India; shubh.avasth@gmail.com

4 Department of Biosciences, Chandigarh University, Gharuan 140413, Punjab, India; smunihal@gmail.com

5 Fungal Biotechnology Lab, Department of Biotechnology, School of Life Sciences, Pondicherry University, Kalapet 605014, Pondicherry, India; devadatha796@gmail.com

6 Department of Botany, Rajiv Gandhi University, Rono Hills, Doimukh, Itanagar 791112, Arunachal Pradesh, India; neeru436@gmail.com

7 Research Center of Microbial Diversity and Sustainable Utilization, Chiang Mai University, Chiang Mai 50200, Thailand

* Correspondence: a2gautam2006@gmail.com (A.K.G.); vermarajnish1985@gmail.com (R.K.V.); suwan.462@gmail.com (N.S.); Tel.: +91-701-832-1256 (A.K.G.); +66-86-512-7518 (N.S.)

\begin{abstract}
Fungi are an important and diverse component in various ecosystems. The methods to identify different fungi are an important step in any mycological study. Classical methods of fungal identification, which rely mainly on morphological characteristics and modern use of DNA based molecular techniques, have proven to be very helpful to explore their taxonomic identity. In the present compilation, we provide detailed information on estimates of fungi provided by different mycologistsover time. Along with this, a comprehensive analysis of the importance of classical and molecular methods is also presented. In orderto understand the utility of genus and species specific markers in fungal identification, a polyphasic approach to investigate various fungi is also presented in this paper. An account of the study of various fungi based on culture-based and cultureindependent methods is also provided here to understand the development and significance of both approaches. The available information on classical and modern methods compiled in this study revealed that the DNA based molecular studies are still scant, and more studies are required to achieve the accurate estimation of fungi present on earth.
\end{abstract}

Keywords: classical and molecular methods; fungal diversity; fungal phylogeny; identification; taxonomy

\section{Introduction}

Biodiversity is one of the most interesting aspects of biology, which has attracted the attention of scientists and researchers for some time. Biological diversity generally represents the variety of living beings from all sources, including terrestrial, marine and other aquatic ecosystems, covering the diversity of plants, animals, insects, pests and microbes. The information on biodiversity yet to be fully discovered may be useful from many beneficial and harmful aspects of life. Based on available information, biodiversity can be of species which are genetic and ecological, and found to be distributed in a variety of environments. The various life forms are adapted to live in specific environments, referred to as terrestrial and aquatic. In addition, these diverse life forms show great variability based on the type of habitats [1]. Fungi is an important component of biodiversity, which play an important role in various ecological cycles [2,3]. 
Fungi present enormous species diversity with respect to morphological, ecological and nutritional modes. Fungi are considered the largest organismic group after insects [4], andareknown to exist in a wide variety of morphologies, lifestyles, developmental patterns anda wide range of habitats such as soil, water, air, animals, plants and in environments with extreme conditions such as low or high temperature, high concentration of metals and salts [5-7]. It has been estimated that 1.5 and 5.1 million species of fungi are believed to exist in various ecosystems of Earth, of which nearly 150,000 species of fungi have been described [8-10].

Fungi are an important and diverse component of biodiversity in various ecosystems. These organisms consist of a diverse range of all major fungal groups and play the role of both foe and friend. While some fungi may cause numerous diseases in humans, animals, plants and other biological substrates, others may play an important role in the nutrient cycle. In addition, fungi have beneficial applications in the agriculture, industrial and pharmaceutical sectors. The occurrence of fungi, however, varies greatly with respect to various ecosystems and environments. The study of fungi is not easy due to the extremely high level of diversity and difficulty in the prediction ofexact estimates. However, different researchers predicted fungal diversity on the planet and provided different estimates of fungal species $[3,11,12]$.

Identification based on morphological, phylogenetic or ecological characteristics is one of the most important aspectsof mycological studies. The classical methods of fungal identification which rely on direct observation of fungi either in a natural condition or after culturing on growth media are still most popularly in use. Despitethe use of molecular methods as more advanced modern techniques of fungal identification, the classical methods still have many advantages for studying fungal diversity. Some fungi produce visible structures useful in their identification. The culturing of some of the fungi is still not very successful; therefore, molecular techniques have proved to be very helpful in exploring their taxonomic identity $[13,14]$. The use of molecular methods along with conventional methods (morphological studies) helped mycologists to investigate the new fungal samples or reinvestigate the preserved ones. This has been led the fungal taxonomists to propose or establish many new taxa.

In the present paper, a general outline with current estimates of fungal diversity in all environments is presented. A complete section on general methods (classical and modern methods) used for fungal identification, along with their advantages and disadvantages, was also presentedin order to provide an updated account on fungal identification. Moreover, adetailed account of culture dependent and culture independent methods was providedin order to highlight their importancein fungal identification and their usefulness in finding updated fungal diversity estimates. Overall, this review will be a document containing present day information on various aspects of fungi.

\section{Fungal Diversity: General Outline with Updated Estimates}

Fungi constitute one of the largest groups of eukaryotes which play a significant role as decomposers, mutualists and pathogens. They are among the key components of global biodiversity, playing a powerful role in global biogeochemistry, recycling carbon and mobilizing nitrogen, phosphorus and other bio-elements. Besides performing this key role, fungi provide essential support to plant life in the form of endophytes and mycorrhizae, in addition to causing numerous plant and animal diseases. The industrial applications of various fungi nowadays are worth appreciating. Fungi as an important food source, and researchis still in progress to use fungal biomass to fulfil the basic needs of food, clothe and shelter $[15,16]$. Despite multiple uses, updated information of these organisms about the number of species are described, as well as global estimates of their diversitywhich are essential to accurately describe their taxonomic characteristics. Through the use of advanced methods of isolating and identifying fungi, a number of novel taxa have been established over the past decade, including new divisions, classes, orders and new families. 
Therefore, this section provides complete information on how to estimate fungal diversity based on the available literature.

Classification of fungi or their various groups is a continuous process because of the regular inclusion of data based on morpho-taxonomy and molecular studies. The frequent inclusion of data from DNA sequences in recent studies is updating fungal outlines and their estimates constantly. The outline of fungi classification provided by Wijayawardene et al. [17] is used here as a starting point for this section of the paper. An outline of fungi and fungus-like taxa provides a summary of the classification of the kingdom Fungi (including fossil fungi, i.e., dispersed spores, mycelia, sporophores and mycorrhizas). A total of 19 phyla were presented with the placement of all fungal genera with the described number of species per genus at the class-, order-and family-level [17]. Several earlier studies have also focused on fungal diversity. Some glimpses of different types of fungi found in various habitats are presented in Figures 1 and 2.

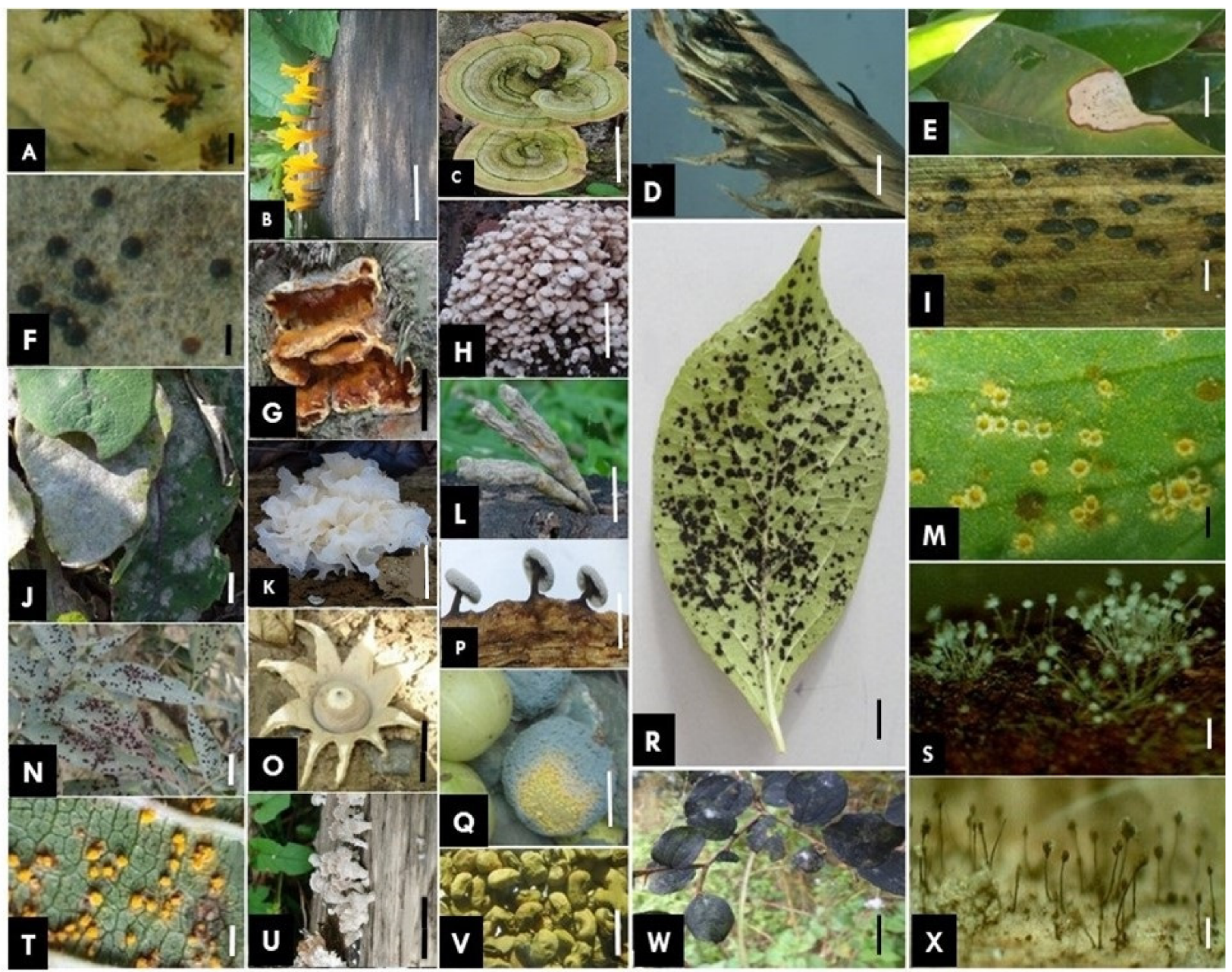

Figure 1. Diversity of different types of fungi. (A) Phragmidium sp. [rose rust], (B) Calocera sp., (C) Trametes sp., (D) Tilletia sp. [smut], (E) Colletotrichum sp. [Leaf spot], (F) Erysiphe sp. [Powdery mildew cleistothecia], (G) Inonotus sp., (H) Termitomyces sp., (I) Kweilingia sp. [rust], (J) Podosphaera sp. on Sonchus sp. [Powdery mildew], (K) Tremella sp., (L) Xylaria sp., (M) Uromyces sp. [aecia and telia], (N) Pileolaria sp. [rust], (O) Gaestrum sp., (P) Didymium sp., (Q) Penicillium sp. on Emblica sp., (R) Schiffnerula sp. [black mildew], (S) Aspergillus sp., (T) Coleosporium sp. [rust], (U) Schizophyllum sp., (V) Aspergillus sp. [on cow pea], (W) Mitteriella sp. [black mildew] and (X) Periconia sp. Scale bars $\mathrm{A}-\mathrm{X}=20 \mathrm{~mm}$. 


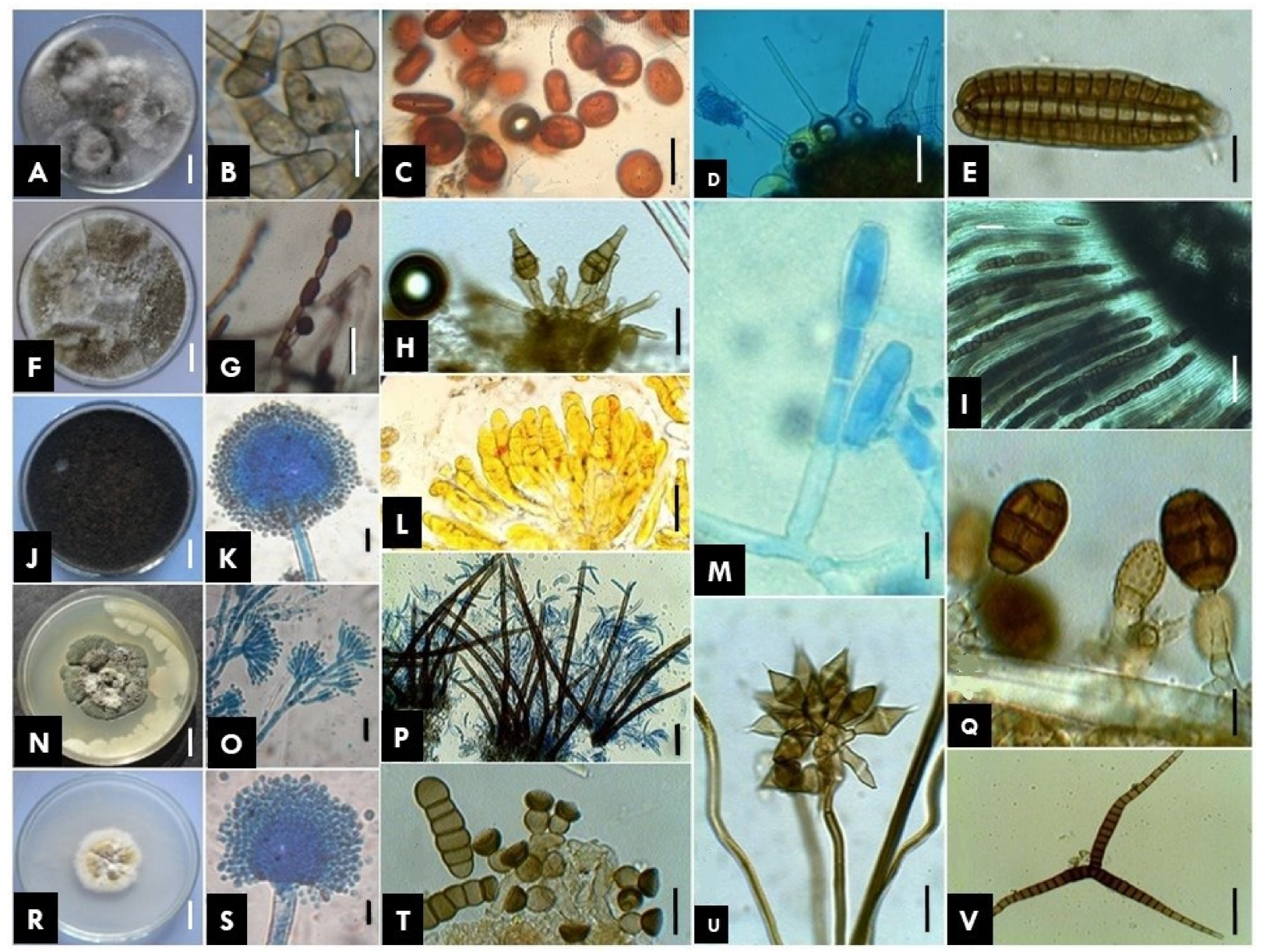

Figure 2. Diversity of different types of fungi. (A,B) Curvularia sp., (C) Pileolaria sp. [rust], (D) Phyllactinia sp. [powdery mildew], (E) Dictyosporium sp., (F,G) Sytalidium sp., (H) Alternaria alternata, (I) Hypoxylon sp., (J,K) Aspergillus niger, (L) Coleosporium sp. [rust], (M) Podosphaera sp. [powdery mildew], (N,O) Penicillium sp. on Emblica sp., (P) Colletotrichum sp., (Q) Pithomyces sp., (R,S) Aspergillus falvus, (T) Torula sp., (U) Beltrania sp., (V) Ceratosporium sp. Scale bars A,F,J,N,R = 1 mm; $\mathrm{B}-\mathrm{E}, \mathrm{G}-\mathrm{I}, \mathrm{K}-\mathrm{M}, \mathrm{O}-\mathrm{Q}, \mathrm{S}-\mathrm{V}=10 \mu \mathrm{m}$.

Based on phylogenies and the divergence time of particular taxa, Tedersoo et al. [18] proposed classification of kingdom Fungi into 18 phyla Ascomycota, Aphelidiomycota, Basidiobolomycota, Basidiomycota, Blastocladiomycota, Calcarisporiellomycota, Chytridiomycota, Entomophthoromycota, Entorrhizomycota, Glomeromycota, Kickxellomycota, Monoblepharomycota, Mortierellomycota, Mucoromycota, Neocallimastigomycota, Olpidiomycota, Rozellomycota and Zoopagomycota. Because this study was based on only 111 taxa, its universal acceptance remained a matter of thinking. In this agreement, Wijayawardene et al. [19] provided a revised classification system for basal clades of fungi from phyla to genera in the same year. A total of 16 phyla were accepted among the above-mentioned except viz. Ascomycota and Basidiomycota. The detailed information to fully resolved tree of life was reviewed by James et al. [20], where they provide detailed information on advancements in genomic technologies during the last 15 years to understand the revolution in fungal systematics in the phylogenomic era. However, the recently updated outline of fungi given by Wijayawardene et al. [17] revised the number of phyla upto 19 in addition to Caulochytriomycota. This group of researchers also included fungal-like taxa in this study and incorporated them in this outline. Similar studies on outlined fungal phyla were carried outoccasionally. These studies proved very useful for researchers engaged in updating fungal classification. A list of selected literature based on various taxonomical studies carried out by several researchers is presented in Table 1. 
These are studies on defining boundaries and providing the classification of different levels of fungal classification: Ascomycota [21-23], Diaporthales [24-29], Leotiomycetes [30], Magnaporthales [31], Orbiliaceae (Orbiliomycetes) [32], Discomycetes [33], Sordariomycetes [34-36], Sclerococcomycetidae [35,37], Xylariales [38], Xylariomycetidae [39] and Pezizomycetes [40]. Based on this, a brief outline of the classification of the kingdom Fungi (including fossil fungi, i.e., dispersed spores, mycelia, sporophores, mycorrhizas) given by Wijayawardene et al. [17] is provided herein tabulated form (Table 2).

Table 1. Selected literature on various taxonomical studies of fungi.

\begin{tabular}{|c|c|}
\hline Title & Reference \\
\hline Orders of Ascomycetes & [41] \\
\hline Laboulbeniales as a separate class of Ascomycota, Laboulbeniomycetes & [42] \\
\hline One hundred and seventeen clades of euagarics & [43] \\
\hline Toward resolving family-level relationships in rust fungi (Uredinales) & [44] \\
\hline $\begin{array}{l}\text { Higher level classification of Pucciniomycotina based on combined analyses of } \\
\text { nuclear large and small subunit rDNA sequences }\end{array}$ & [45] \\
\hline A phylogenetic overview of the family Pyronemataceae (Ascomycota, Pezizales) & [46] \\
\hline A higher-level phylogenetic classification of the Fungi & [47] \\
\hline Dictionary of the Fungi. (10th edn) & [48] \\
\hline Outline of Ascomycota & [49] \\
\hline Glomeromycota: two new classes and a new order & {$[50]$} \\
\hline $\begin{array}{c}\text { Entomophthoromycota: a new phylum and reclassification for } \\
\text { entomophthoroid fungi }\end{array}$ & [51] \\
\hline $\begin{array}{l}\text { Incorporating anamorphic fungi in a natural classification checklist and notes } \\
\text { for } 2011\end{array}$ & [52] \\
\hline Taxonomic revision of Ustilago, Sporisorium and Macalpinomyces & [53] \\
\hline Phylogenetic systematics of the Gigasporales & [54] \\
\hline $\begin{array}{l}\text { List of generic names of fungi for protection under the International Code of } \\
\text { Nomenclature for algae, fungi, and plants }\end{array}$ & [55] \\
\hline $\begin{array}{l}\text { A phylogeny of the highly diverse cup fungus family Pyronemataceae } \\
\text { (Pezizomycetes, Ascomycota) }\end{array}$ & [56] \\
\hline Families of Dothideomycetes & [57] \\
\hline $\begin{array}{c}\text { Taxonomic revision of the Lyophyllaceae (Basidiomycota, Agaricales) based on a } \\
\text { multigene phylogeny }\end{array}$ & [58] \\
\hline Recommended names for pleomorphic genera in Dothideomycetes & [27] \\
\hline Towards a natural classification and backbone tree for Sordariomycetes & [34] \\
\hline Phylogenetic classification of yeasts and related taxa within Pucciniomycotina & [59] \\
\hline Entomophthoromycota: a new overview of some of the oldest terrestrial fungi & {$[60]$} \\
\hline $\begin{array}{l}\text { Systematics of Kickxellomycotina, Mortierellomycotina, Mucoromycotina, and } \\
\text { Zoopagomycotina }\end{array}$ & {$[61]$} \\
\hline $\begin{array}{l}\text { A phylum-level phylogenetic classification of Zygomycete fungi based on } \\
\text { genome-scale data }\end{array}$ & [62] \\
\hline $\begin{array}{c}\text { Phylogenomics of a new fungal phylum reveals multiple waves of reductive } \\
\text { evolution across Holomycota }\end{array}$ & [63] \\
\hline Sequence-based classification and identification of fungi & [64] \\
\hline
\end{tabular}


Table 1. Cont.

\begin{tabular}{|c|c|}
\hline Title & Reference \\
\hline $\begin{array}{c}\text { Morphology-based taxonomic delusions: Acrocordiella, Basiseptospora, } \\
\text { Blogiascospora, Clypeosphaeria, Hymenopleella, Lepteutypa, Pseudapiospora, } \\
\text { Requienella, Seiridium and Strickeria }\end{array}$ & [65] \\
\hline Families of Sordariomycetes & [35] \\
\hline $\begin{array}{l}\text { Proposal to conserve the name Diaporthe eres, with a conserved type, against all } \\
\text { other competing names (Ascomycota, Diaporthales, Diaporthaceae) }\end{array}$ & [66] \\
\hline Taxonomy and phylogeny of dematiaceous Coelomycetes & [67] \\
\hline Multigene phylogeny of Endogonales & [68] \\
\hline $\begin{array}{l}\text { Classification of lichenized fungi in the Ascomycota and } \\
\text { Basidiomycota-Approaching one thousand genera }\end{array}$ & [69] \\
\hline $\begin{array}{c}\text { Taxonomy and phylogeny of the Auriculariales (Agaricomycetes, } \\
\text { Basidiomycota) with stereoid basidiocarps }\end{array}$ & [70] \\
\hline $\begin{array}{l}\text { An updated phylogeny of Sordariomycetes based on phylogenetic and } \\
\text { molecular clock evidence }\end{array}$ & [71] \\
\hline Families, genera, and species of Botryosphaeriales & [72] \\
\hline Ranking higher taxa using divergence times: a case study in Dothideomycetes & [73] \\
\hline A revised family-level classification of the Polyporales (Basidiomycota) & [74] \\
\hline Notes for genera: Ascomycota & [22] \\
\hline $\begin{array}{l}\text { Towards incorporating asexual fungi in a natural classification: checklist and } \\
\text { notes 2012-2016 }\end{array}$ & [23] \\
\hline $\begin{array}{l}\text { Notes for genera: basal clades of Fungi (including Aphelidiomycota, } \\
\text { Basidiobolomycota, Blastocladiomycota, Calcarisporiellomycota, } \\
\text { Caulochytriomycota, Chytridiomycota, Entomophthoromycota, Glomeromycota, } \\
\text { Kickxellomycota, Monoblepharomycota, Mortierellomycota, Mucoromycota, } \\
\text { Neocallimastigomycota, Olpidiomycota, Rozellomycota and Zoopagomycota) }\end{array}$ & [19] \\
\hline Outline of Ascomycota: 2017 & [75] \\
\hline $\begin{array}{l}\text { Classification of orders and families in the two major subclasses of } \\
\text { Lecanoromycetes (Ascomycota) based on a temporal approach }\end{array}$ & [76] \\
\hline A taxonomic summary and revision of Rozella (Cryptomycota) & [77] \\
\hline $\begin{array}{l}\text { Sexual and asexual generic names in Pucciniomycotina and Ustilaginomycotina } \\
\text { (Basidiomycota) }\end{array}$ & [78] \\
\hline Evolutionary complexity between rust fungi (Pucciniales) and their plant hosts & [79] \\
\hline $\begin{array}{l}\text { High-level classification of the Fungi and a tool for evolutionary } \\
\text { ecological analyses }\end{array}$ & [18] \\
\hline Taxonomy and phylogeny of operculate Discomycetes: Pezizomycetes & [33] \\
\hline Molecular phylogeny of the Laboulbeniomycetes (Ascomycota) & [80] \\
\hline Families in Botryosphaeriales & [81] \\
\hline $\begin{array}{l}\text { Natural classification and backbone tree for Graphostromataceae, Hypoxylaceae, } \\
\text { Lopadostomataceae and Xylariaceae }\end{array}$ & [82] \\
\hline Classification of the Dictyostelids & [83] \\
\hline Revisiting Salisapiliaceae & [84] \\
\hline Phylogenetic revision of Savoryellaceae & [85] \\
\hline Notes, outline and divergence times of Basidiomycota & [86] \\
\hline A new phylogenetic classification for the Leotiomycetes & [87] \\
\hline
\end{tabular}


Table 1. Cont.

\begin{tabular}{cc}
\hline Title & Reference \\
\hline Taxonomy and phylogeny of hyaline-spored Coelomycetes & {$[88]$} \\
\hline Refined families of Sordariomycetes & {$[36]$} \\
\hline Outline of Fungi and fungus-like taxa & {$[17]$} \\
\hline The genera of Coelomycetes & {$[89]$} \\
\hline A higher-rank classification for rust fungi, with notes on genera & {$[90]$} \\
\hline Indian Pucciniales: taxonomic outline with important descriptive notes & {$[91]$} \\
\hline Incorporating asexually reproducing fungi in the natural classification and notes \\
for pleomorphic genera & {$[92]$} \\
\hline How to publish a new fungal species, or name, version 3.0 & {$[93]$}
\end{tabular}

Table 2. A brief presentation on outline of fungi.

\begin{tabular}{|c|c|c|c|c|}
\hline Phylum & Class & Order & Family & Genera \\
\hline Aphelidiomycota & 1 & 1 & 1 & 4 \\
\hline Ascomycota & 21 & 148 & 624 & 4511 \\
\hline Basidiobolomycota & 1 & 1 & 1 & 2 \\
\hline Basidiomycota & 19 & 69 & 240 & 1521 \\
\hline Blastocladiomycota & 2 & 4 & 8 & 12 \\
\hline Calcarisporiellomycota & 1 & 1 & 1 & 2 \\
\hline Caulochytriomycota & 1 & 1 & 1 & 1 \\
\hline Chytridiomycota & 9 & 13 & 52 & 97 \\
\hline Entomophthoromycota & 2 & 2 & 5 & 20 \\
\hline Entorrhizomycota & 1 & 2 & 2 & 2 \\
\hline Glomeromycota & 3 & 5 & 16 & 49 \\
\hline Kickxellomycota & 6 & 6 & 7 & 61 \\
\hline Monoblepharomycota & 3 & 3 & 7 & 9 \\
\hline Mortierellomycota & 1 & 1 & 1 & 6 \\
\hline Mucoromycota & 3 & 3 & 17 & 62 \\
\hline Neocallimastigomycota & 1 & 1 & 1 & 11 \\
\hline Olpidiomycota & 1 & 1 & 1 & 4 \\
\hline Rozellomycota & 2 & 7 & 41 & 162 \\
\hline Zoopagomycota & 1 & 1 & 5 & 25 \\
\hline Total & 79 & 270 & 1031 & 6561 \\
\hline
\end{tabular}

As one of the ancient and most diverse branches of the tree of life, kingdom Fungi contains an estimated 4-5 million species distributed all across the globe and plays vital roles in terrestrial and aquatic ecosystems [94-97]. Of the total estimated number, so far, less than $2 \%$ of fungiis described [98]. Because of the vast diversity of these organisms and the addition of new fungi year by year, mycologists are facing major difficulties to define their boundaries accurately. The regular advancement in mycological techniques enables mycologists to describe new fungi all around the world every year based on decade evaluations. The description and addition of new species are estimated at 2626 from 2000 to 2012, while it was around 2326 between 1980 and 1999 [99-101]. This ongoing process of describing new fungi changes the overall estimate of fungi regularly. However, the suspense of undescribed fungi is still the same, which also added more uncertainty over 
defining their estimate exactly. In addition to natural habitats still waiting to explored, requirements of reassessment of dried herbarium samples based on molecular methods, along with morpho-taxonomy and lack of molecular facilities, still hinder mycologists in describing new fungi and attaining full estimate boundaries. Because of the importance of a total number of fungi estimates in their diversity and taxonomy (systematics, resources and classification) [12,102], many estimates have been put forward to elucidate the fungal species diversity in the world. Previous estimates of fungal diversity were based mainly on the plant-associated fungi [3]. Summarizing a comprehensive account of previous estimates of fungal diversity, we start with the estimate of about 100,000 presented by Bisby and Ainsworth [102]. Then, the number of fungi was estimated to be between 0.25-2.7 during the second half of the twentieth century. It was estimated (in millions) as follows: 0.25 [103], 2.7 [104], 1.5 [12,105,106], 1.0 [107-109], 1.3 [110], 0.27 [111] and 0.5 [112]. Similarly, the estimates on total described numbers of fungi during the twenty-first century were found to be between $2.3-5.1$ million. The fungal estimate (1.5 million) provided by Hawksworth [12] has been most widely accepted for two decades. However, updated estimates of fungal species were provided in the current century as 3.5-5.1 [113], 5.1 [10], 2.2-3.8 [11]. The updated estimates were provided based on DNA based molecular techniques and nextgeneration sequencing. However, Hyde et al. [114] pointed out that more than $90 \%$ of the collected samples of fungi were neglected by mycological taxonomists around the globe. The total number of described fungi may be increased many times after processing these samples. The fungal estimates provided by various mycologists are presented in detail in Figure 3.

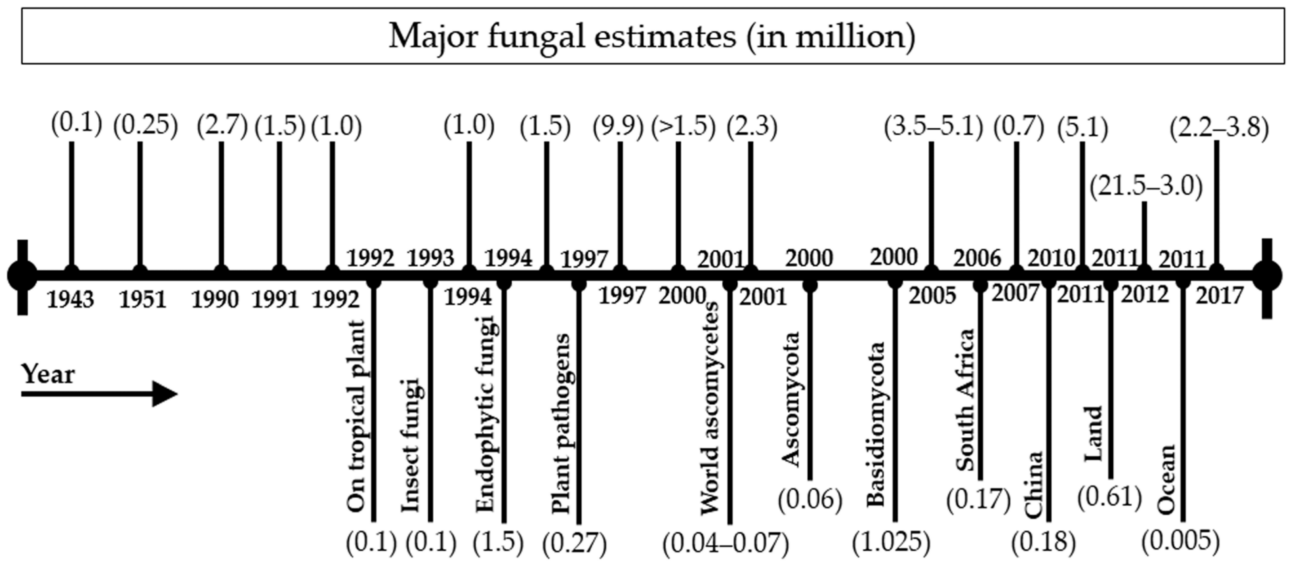

Figure 3. Estimations on the global number of fungal species.

In addition to estimating the total number of fungi, the global biodiversity of fungi has been extensively investigated for predicting their accurate estimate on earth. The number of advanced techniques, along with the number of numerical analytical methods, enabled researchers not only to identify and describe those fungi which are either not described, incorrectlyidentified or described incompletely, but also in understanding plant: fungus ratios [12,99], quantitative macroecological grid-based approaches [115-117], ecological scaling laws and methods based on environmental sequence data including plant: fungus ratios $[10,113]$. These studies on estimates proved fungi to be one of the largest groups of living organisms on this planet. An updated estimate of global fungal diversity is 2.2 to 3.8 million provided by Hawksworth and Lücking [11], however, also pointed out that this estimate would be a thousand times higher than the current highest estimate of 10 million species. A regression relationship between time and described fungal species by using Sigma State 3.5.SPSS (USA) was constructed and presented by Wu et al. [3]. With the help of this equation model, $\mathrm{Wu}$ et al. [3] presented the description rate of fungi. They indicated that 1.5 million fungal species, estimated by Hawksworth [12], could be described only by 
the year 2184, while the estimates of 2.2 and 3.8 million could be described by the years 2210 and 2245, respectively.

\section{General Methods of Fungal Identification}

The correct identification of fungi is one of the essential tools required for documenting fungi at the genus and species levels. There are several methods of fungal identification that differ in scope and content. However, the actual identification procedure is almost the same in each of the methods. Colonial morphological features, along with growth rate and microscopic observations, are some important criteria used to study different fungi. However, technological advancements have added more improved and sophisticated methods in this series. Generally, the fungal identification techniques are, broadly, three types, i.e., truly classical, culture and modern methods. While truly classical methods were based on the study of morphological features, the culture methods involved culture media technique. In modern methods, DNA-based techniques are utilized.

\subsection{Classical Methods}

Classical methods are most widely used in the documentation of fungi in relation to their identification and distribution on any substrate over a specific area. In general, these methods have been developed for studying any substratum or group of fungi [118]. Classical methods of fungal identification generally include incubation of substrata in moist chambers, direct sampling of fungal fruiting bodies, culturing of endophytes and particle plating. The following are basic types of classical methods.

\subsubsection{Opportunistic Approach}

In general, the opportunistic approach is one of the different types of classical methods used by mycologists to collect fruiting bodies of macromycetes. The availability of good condition fruiting bodies of macrofungi is generally a prerequisite for this efficient method of detecting new species or new records in a study area. The requirement of highly skilled mycologists for collection, processing and identification is a major limitation of this method, along with the risk of toxicity from these fungi [118].

\subsubsection{Substrate Based Approach}

The substrate-based protocols are another important approach used for the identification of fungi. The importance of these methods can be imagined because while some fungi fruit rather dependably, others fruit only sporadically. The substrate-based methods are mostly used for fungi that occur only on discrete, discontinuous or patchy resources, or are restricted to a particular host. The fungi forming sporocarps on soil, trees, large woody stumps, leaf litter, twigs and small branches are generally included in such methods. The fungi that form fruiting bodies on soil and ectomycorrhizal association with the trees provides a better understanding of their identification and diversity. The selection of a study plot is an important step that should be considered while using these methods $[119,120]$. In the case of fungi that form fruiting bodies on large woody debris, use of the log-based sampling method is generally preferred, keeping in view the substrate characteristics such as diameter, decay classes, upright, suspended, or grounded and host information [118,121]. Similarly, the use of a plot-based or band transect method is generally suggested in fungi, giving rise to fruiting bodies on fine debris (leaf litter, twigsand small branches). Here, size of the sample plot is generally kept in mind during the collection of fungal samples [119,120,122-124].

\subsubsection{Moist Chambers Techniques}

Moist Chambers Techniquesis one of the earliest and more effective methodsbeing utilized by mycologists in fungal taxonomy. This technique is used for fungi growing on leaves or small woody debris, such as ascomycetes, hyphomycetes and coelomycetes [124,125] and slime molds [126], and fungi growing on dung [127-130]. Here, the fungal samples 
collected from various substrates were processed for the production of fruiting bodies in a moist chamber for some duration and evaluated periodically for approximately 2 to 6 weeks.

\subsubsection{Culture Media Technique}

The use of culture media to inoculate fungi from the natural environment and incubate it to grow in controlled conditions for their isolation and identification is also one of the popular and widely used techniques. Numbers of artificial culture media are used here to provide growth substrate and required nutrition to inoculated fungi. Along with morphological characteristics, this technique proves quite useful in identifyinga fungal taxon. The easy and economic implication of this method has made it popular among mycologists. The numberof fungal groups such as endophytes, saprophytes and parasitesexcept obligate - can be isolated on various culture media from symptomless but fully expanded leaves, petioles, twigs, branches and roots, etc. [131]. Similarly, culturing of leaf washes is another culture media-based technique to assess the composition of spores on leaf surfaces. Commonly known as phylloplane fungi, these are considered to have good biocontrol potential $[132,133]$. Another culture based method known as the particle filtration method [134-136] is mainly meant for reducing the number of isolates derived from dormant spores in cultures taken from decomposing plant debris. Vegetatively active mycelia are generally cultured with the use of this method.

\subsubsection{Advantages and Disadvantages of Truly Classical and Culture Based Methods}

When we compare classical and culture based-methods with other advanced techniques, they still hold a key position in all the methods being utilized for assessing identification, diversity and distribution of fungi. Although these techniques are still in use globally, they also have certain disadvantages. In order tomake mycologistsaware of all aspects of basic methods (truly classical and culture based), a brief discussion on some of their important advantages/disadvantages is given below:

\section{Advantages of Truly Classical and Culture Based Methods}

- These methods are still considered as the sources which can provide complete information on fungal communities of different areas with variable habitats. Because of the non-availability of DNA-based sequence data of all the fungi, it is the only criteria to determine basic information about individual species, such as geographic range, host relationships and ecological distribution.

- The effects of abiotic variables ( $\mathrm{pH}$, soil nutrient content, weather-related variables) and biotic variables on fungi of the variable substrate and environmental conditions can be more easily studied by these methods.

- As compared to an advanced one, these methods are more economical and can be executed with less specialized equipment.

- Overall, the developing nations where adequate research funding is still a big challenge; these methods are important considerations for many investigators.

Disadvantages of Classical and Culture Based Methods

- For the fungi which are unable to grow or produce reproductive structures on culture or hardly reproduce naturally, these methods are not suitable and become a major limitation in identifying, classifying and outlining fungi of a specific area.

- The detailed procedure of sampling, culturing, isolation and identification methods are considerably more time consuming in comparison to more advanced techniques. The confirmation of new genera or species can be predicted more efficiently and accurately from the repeatedly sampled areas [120].

- Due to the above-mentioned disadvantages, classical taxonomists are now considered to be endangered, as the interests of young researchers in classical methods is considerably reducing. If one willing to peruse a career in classical mycology, it takes 
a long duration of training. Similarly, to identify all of the collections based on the classical approach increases the time duration to find out final results. In molecular methods, technical expertise is quite enough to carry out research which also poses a major limitation to classical methods.

\subsubsection{Advantages and Disadvantages of DNA Based Modern Methods}

Besides having many advantages, the DNA-based methods also have some limitations, while modern methods are proven to be more efficient in the confirmation of new genera or species inlesser in time consumption. When classical methods are not able to study the fungi more specifically due to overlapping characters, i.e., a high degree of phenotypic plasticity, cryptic species and occurrence of different morphs for the same taxa $[67,137,138]$, there are molecular methods which prove helpful to resolve such issues more accurately.

Like other methods, these methods also have certain disadvantages. The information we obtained with the help of this method is not so detailed as to be compared to classical methods; e.g., when we study basidiomata classically, we obtain a lot of information that we will never learn from DNA. Based on DNA-based techniques, numbers of new species are proposed, solely on the basis of unavailability of their sequences in the databases. Additionally, the submission of improper DNA sequences of many described fungi without proper editing is another drawback caused by molecular methods. Besides, poor taxon coverage in public depositories remains the principal impediment for successful species identification through molecular methods. The interpretation of BLAST results is regarded as the most important aspect in DNA-based methods of fungal identification. The availability of appropriate taxonomic and molecular experts in limited numbers is one of the major drawbacks of these methods. In addition, the contamination of DNA samples is another problem associated with molecular methods. Lastly, these methods are not cost effective in comparison to classical ones.

Keeping in view both advantages and disadvantages, it was found that mycological studies based on classical methods can perform better when combined with molecular analyses.

\section{Assessment of Fungal Taxonomy and Diversity}

Fungal taxonomy is the fundamental aspect of immense value utilized during mycological studies. The taxonomy of fungi based on morphological characters has been used for centuries and is still in use. Fungal taxonomy is generally required to identify and define existing and new fungi, andis ultimately useful in the assessment of their diversity and distribution. With the passage of time, the use of new and varied methods of fungal assessment came into existence which revolutionize the traditional methods based on morpho-taxonomy. However, both the methods based on morphology and molecular data care are still used equally and have their own levels of importance. It is primarily significant to use morphological-based methods and follow other approaches such as chemical, ecological, molecular or physiological analyses [139]. However, some technologies are expensive or inconvenient in terms ofuse in laboratories where the infrastructure is basic. Morphological analyses are, however, low-cost and results are acquired rapidly. These novel technologies have a relatively high cost. In cases wherethere is a limited quantity of a specimen or lack of sequence data, morphological data then play an important role in identification. In GenBank, there are many sequences which are wrongly named with errors. In such cases, detailed and extensive morphological characters help to resolve the taxonomy of them [140]. Therefore, morphology is still the most common technique to study fungi.

However, in recent times progress has driven taxonomic inferences towards DNAbased methods, and these procedures have parallel pros and cons. Modern mycotaxonomy has moved onward using morphological characters with a combination of chemotaxonomy, ecology, genetics, molecular biology and phylogeny [139,141-145]. The exploitation of sequence data for phylogenetic, biological, genetic and evolutionary analyses 
has offered a lot of understanding into the diversity and relationships of various fungal groups [71,139,146-148].

In DNA-based molecular characters, culture dependent and culture-independent methods are in practice nowadays to estimate fungal diversity. Culture-based approaches have been traditional, used to analyse microorganisms in indoor environments, including settled floor dust samples. However, this approach can be biased, for example, by microbial viability and/or culturability on a given nutrient medium. The advent of growth-independent molecular biology-based techniques, such as polymerase chain reaction (PCR) and DNA sequencing, has circumvented these difficulties. However, few studies have directly compared culture-based morphological identification methods with culture-independent DNA sequencing-based approaches. For example, a previous study compared the presence or absence of fungal species detected by a culture-based morphological identification method and a culture independent DNA sequencing method [149]. However, only a qualitative comparison was conducted between these two different approaches and a quantitative comparison was not conducted (Tables 3 and 4). A detailed account of general tools and repositories generally used in DNA-based identification of fungi are presented in Table 5 .

Table 3. An overview on DNA-based methods of fungal samples analyses.

\begin{tabular}{|c|c|c|c|c|c|c|}
\hline Global Fungi Study ID & Substrate & Samples & Method & $\begin{array}{l}\text { Sequencing } \\
\text { Platform }\end{array}$ & $\begin{array}{c}\text { ITS2 } \\
\text { Sequences }\end{array}$ & Reference \\
\hline Hartmann_2012_B1A3 & - & 6 & $\begin{array}{c}\text { Culture } \\
\text { independent }\end{array}$ & $\begin{array}{c}454- \\
\text { pyrosequencing }\end{array}$ & 2155088 & [150] \\
\hline Ihrmark_2012_3AE5 & $\begin{array}{l}\text { Soil, wood, wheat roots } \\
\text { and hay }\end{array}$ & 36 & $\begin{array}{c}\text { Culture } \\
\text { independent }\end{array}$ & $\begin{array}{c}454- \\
\text { pyrosequencing }\end{array}$ & 414896 & {$[151]$} \\
\hline Davey_2012_6F6A & $\begin{array}{c}\text { Shoots of Hylocomium } \\
\text { splendens, Pleurozium } \\
\text { schreberi, and Polytrichum } \\
\text { commune }\end{array}$ & 301 & $\begin{array}{l}\text { Culture } \\
\text { independent }\end{array}$ & $\begin{array}{c}454- \\
\text { pyrosequencing }\end{array}$ & 296964 & [152] \\
\hline Peay_2013_74BB & Soil & 36 & $\begin{array}{c}\text { Culture } \\
\text { independent }\end{array}$ & $\begin{array}{c}454- \\
\text { pyrosequencing }\end{array}$ & 86677 & [153] \\
\hline Davey_2013_7683 & $\begin{array}{c}\text { Shoots of Dicranum } \\
\text { scoparium, Hylocomium } \\
\text { splendens, Pleurozium } \\
\text { schreberi and Polytrichum } \\
\text { commune }\end{array}$ & $\begin{array}{l}454- \\
\text { pyrosequencing }\end{array}$ & $\begin{array}{l}\text { Culture } \\
\text { independent }\end{array}$ & $\begin{array}{l}\text { 454- } \\
\text { pyrosequencing }\end{array}$ & 313084 & [154] \\
\hline Talbot_2014_A187 & Soil & 555 & $\begin{array}{c}\text { Culture } \\
\text { independent }\end{array}$ & $\begin{array}{c}454- \\
\text { pyrosequencing }\end{array}$ & 16977 & {$[155]$} \\
\hline Tedersoo_2014_B9DD & Soil & 360 & $\begin{array}{l}\text { Culture } \\
\text { independent }\end{array}$ & $\begin{array}{c}454- \\
\text { pyrosequencing }\end{array}$ & 1979803 & {$[156]$} \\
\hline Kadowaki_2014_B85B & Soil & 46 & $\begin{array}{c}\text { Culture } \\
\text { independent }\end{array}$ & $\begin{array}{c}454- \\
\text { pyrosequencing }\end{array}$ & 66067 & [157] \\
\hline Geml_2014_2936 & Soil & 10 & $\begin{array}{c}\text { Culture } \\
\text { independent }\end{array}$ & $\begin{array}{c}454- \\
\text { pyrosequencing }\end{array}$ & 285031 & {$[158]$} \\
\hline Davey_2014_2252 & $\begin{array}{l}\text { Shoots of Hylocomium } \\
\text { splendens }\end{array}$ & 251 & $\begin{array}{c}\text { Culture } \\
\text { independent }\end{array}$ & $\begin{array}{c}454- \\
\text { pyrosequencing }\end{array}$ & 639746 & [159] \\
\hline McHugh_2015_CAE1 & Soil & 20 & $\begin{array}{c}\text { Culture } \\
\text { independent }\end{array}$ & $\begin{array}{c}454- \\
\text { pyrosequencing }\end{array}$ & 594424 & {$[160]$} \\
\hline DeBeeck_2014_14DC & Soil & 20 & $\begin{array}{c}\text { Culture } \\
\text { independent }\end{array}$ & $\begin{array}{c}454- \\
\text { pyrosequencing }\end{array}$ & 32778 & {$[161]$} \\
\hline Yamamoto_2014_C3F7 & Seedlings of Quercus sp. & 431 & $\begin{array}{c}\text { Culture } \\
\text { independent }\end{array}$ & $\begin{array}{c}454- \\
\text { pyrosequencing }\end{array}$ & 59021 & {$[162]$} \\
\hline Walker_2014_22C1 & Soil & 24 & $\begin{array}{l}\text { Culture } \\
\text { independent }\end{array}$ & $\begin{array}{l}\text { 454- } \\
\text { pyrosequencing }\end{array}$ & 34267 & {$[163]$} \\
\hline Veach_2015_7FDE & Soil & 91 & $\begin{array}{c}\text { Culture } \\
\text { independent }\end{array}$ & Illumina MiSeq & 579967 & {$[164]$} \\
\hline
\end{tabular}


Table 3. Cont.

\begin{tabular}{|c|c|c|c|c|c|c|}
\hline Global Fungi Study ID & Substrate & Samples & Method & $\begin{array}{l}\text { Sequencing } \\
\text { Platform }\end{array}$ & $\begin{array}{c}\text { ITS2 } \\
\text { Sequences }\end{array}$ & Reference \\
\hline Zhang_2015_A52F & $\begin{array}{l}\text { Seven lichens speciesViz. } \\
\text { Cetrariella delisei, Cladonia } \\
\text { borealis, C. arbuscula, } \\
\text { C. pocillum, Flavocetraria } \\
\text { nivalis, Ochrolechia frigida } \\
\text { and Peltigera canina }\end{array}$ & 22 & $\begin{array}{c}\text { Culture } \\
\text { independent }\end{array}$ & $\begin{array}{c}454- \\
\text { pyrosequencing }\end{array}$ & 11087 & [165] \\
\hline Elliott_2015_7CC2 & Soil & 16 & $\begin{array}{c}\text { Culture } \\
\text { independent }\end{array}$ & $\begin{array}{c}454- \\
\text { pyrosequencing }\end{array}$ & 3896 & [166] \\
\hline Geml_2015_1A45 & Soil & 10 & $\begin{array}{c}\text { Culture } \\
\text { independent }\end{array}$ & Ion Torrent & 1098472 & [167] \\
\hline Hoppe_2015_BE27 & Wood & 48 & $\begin{array}{c}\text { Culture } \\
\text { independent }\end{array}$ & $\begin{array}{c}454- \\
\text { pyrosequencing }\end{array}$ & 121459 & [168] \\
\hline Jarvis_2015_B613 & Roots of Pinus sylvestris & 32 & $\begin{array}{c}\text { Culture } \\
\text { independent }\end{array}$ & $\begin{array}{c}454- \\
\text { pyrosequencing }\end{array}$ & 112333 & [169] \\
\hline Chaput_2015_41F7 & Soil & 4 & $\begin{array}{c}\text { Culture } \\
\text { independent }\end{array}$ & $\begin{array}{c}\text { Tag-encoded FLX } \\
\text { amplicon } \\
\text { pyrosequencing }\end{array}$ & 1197 & [170] \\
\hline van_der_Wal_2015_1114 & $\begin{array}{l}\text { Sawdust from sapwood } \\
\text { and heartwood of Quercus } \\
\text { robur, Rubus fruticosus, } \\
\text { Sorbus aucuparia, Betula } \\
\text { pendula, } \\
\text { Pteridium aquilinum and } \\
\text { Amelanchier lamarckii }\end{array}$ & 42 & $\begin{array}{c}\text { Culture } \\
\text { independent }\end{array}$ & $\begin{array}{c}454- \\
\text { pyrosequencing }\end{array}$ & 543801 & [171] \\
\hline Clemmensen_2015_B0AE & Soil & 466 & $\begin{array}{c}\text { Culture } \\
\text { independent }\end{array}$ & $\begin{array}{c}454- \\
\text { pyrosequencing } \\
\text { GL FLX Titanium } \\
\text { system }\end{array}$ & 592836 & [172] \\
\hline Gao_2015_1CEF & Soil & 24 & $\begin{array}{c}\text { Culture } \\
\text { independent }\end{array}$ & $\begin{array}{c}454- \\
\text { pyrosequencing } \\
\text { GL FLX Titanium } \\
\text { system }\end{array}$ & 93683 & [173] \\
\hline Liu_2015_6174 & Soil & 26 & $\begin{array}{c}\text { Culture } \\
\text { independent }\end{array}$ & $\begin{array}{l}\text { Roche FLX 454- } \\
\text { pyrosequencing }\end{array}$ & 53978 & [174] \\
\hline Oja_2015_88D4 & $\begin{array}{c}\text { Cypripedium calceolus } \\
\text { (subfamily } \\
\text { Cypripedioideae) } \\
\text { Neottia ovata } \\
\text { (Epidendroideae) and Orchis } \\
\text { militaris (Orchidoideae) } \\
\text { and Soil } \\
\end{array}$ & 158 & $\begin{array}{c}\text { Culture } \\
\text { independent }\end{array}$ & $\begin{array}{c}454- \\
\text { pyrosequencing }\end{array}$ & 63045 & [175] \\
\hline Goldmann_2015_EA26 & Soil & 48 & $\begin{array}{c}\text { Culture } \\
\text { independent }\end{array}$ & $\begin{array}{c}454- \\
\text { pyrosequencer }\end{array}$ & 140966 & [176] \\
\hline Tedersoo_2015_ED81 & Soil & 11 & $\begin{array}{c}\text { Culture } \\
\text { independent }\end{array}$ & Illumina MiSeq & 261751 & [177] \\
\hline Rime_2015_89DE & Soil & 36 & $\begin{array}{c}\text { Culture } \\
\text { independent }\end{array}$ & $\begin{array}{c}454- \\
\text { pyrosequencing } \\
\text { GL FLX Titanium } \\
\text { system }\end{array}$ & 227118 & [178] \\
\hline Sterkenburg_2015_5E14 & Soil & 56 & $\begin{array}{c}\text { Culture } \\
\text { independent }\end{array}$ & $\begin{array}{c}454- \\
\text { pyrosequencing }\end{array}$ & 350560 & [179] \\
\hline Stursova_2016_D385 & Soil & 96 & $\begin{array}{c}\text { Culture } \\
\text { independent }\end{array}$ & Illumina MiSeq & 452546 & [180] \\
\hline Semenova_2016_576B & Soil & 10 & $\begin{array}{c}\text { Culture } \\
\text { independent }\end{array}$ & $\begin{array}{l}\text { Ion Torrent } \\
\text { sequencing }\end{array}$ & 1007509 & [181] \\
\hline Santalahti_2016_74FC & Soil & 117 & $\begin{array}{c}\text { Culture } \\
\text { independent }\end{array}$ & $\begin{array}{c}454- \\
\text { pyrosequencing }\end{array}$ & 739877 & [182] \\
\hline
\end{tabular}


Table 3. Cont.

\begin{tabular}{|c|c|c|c|c|c|c|}
\hline Global Fungi Study ID & Substrate & Samples & Method & $\begin{array}{l}\text { Sequencing } \\
\text { Platform }\end{array}$ & $\begin{array}{c}\text { ITS2 } \\
\text { Sequences }\end{array}$ & Reference \\
\hline Rime_2016_E0E4 & Soils and sediments & 2 & $\begin{array}{c}\text { Culture } \\
\text { independent }\end{array}$ & $\begin{array}{c}454- \\
\text { pyrosequencing }\end{array}$ & 35937 & [183] \\
\hline RoyBolduc_2016_E50C & Root and soil & 63 & $\begin{array}{c}\text { Culture } \\
\text { independent }\end{array}$ & $\begin{array}{c}454- \\
\text { pyrosequencing }\end{array}$ & 248325 & [184] \\
\hline RoyBolduc_2016_F11B & Soil & 77 & $\begin{array}{c}\text { Culture } \\
\text { independent }\end{array}$ & $\begin{array}{c}454- \\
\text { pyrosequencing }\end{array}$ & 280272 & [185] \\
\hline Tedersoo_2016_TDEF & Soil & 136 & $\begin{array}{c}\text { Culture } \\
\text { independent }\end{array}$ & $\begin{array}{c}454- \\
\text { pyrosequencing }\end{array}$ & 788372 & [186] \\
\hline UOBC_2016_5CA6 & Soil & 655 & $\begin{array}{c}\text { Culture } \\
\text { independent }\end{array}$ & Illumina HiSeq & 7138323 & [187] \\
\hline Urbina_2016_CE8E & Soil & 21 & $\begin{array}{c}\text { Culture } \\
\text { independent }\end{array}$ & $\begin{array}{l}\text { Ion Torrent } \\
\text { sequencing }\end{array}$ & 564332 & [188] \\
\hline Valverde_2016_5E5C & $\begin{array}{c}\text { Soil from the rhizosphere } \\
\text { of Welwitschia mirabilis }\end{array}$ & 8 & $\begin{array}{c}\text { Culture } \\
\text { independent }\end{array}$ & $\begin{array}{c}454- \\
\text { pyrosequencing } \\
\end{array}$ & 2677 & [189] \\
\hline Nacke_2016_8F49 & $\begin{array}{c}\text { Soil from the rhizosphere } \\
\text { Fagus sylvatica and } \\
\text { Picea abies }\end{array}$ & 160 & $\begin{array}{c}\text { Culture } \\
\text { independent }\end{array}$ & $\begin{array}{l}\text { 454- } \\
\text { pyrosequencing }\end{array}$ & 386432 & [190] \\
\hline Newsham_2016_191B & Soil & 29 & $\begin{array}{c}\text { Culture } \\
\text { independent }\end{array}$ & $\begin{array}{c}454- \\
\text { pyrosequencing }\end{array}$ & 509483 & [191] \\
\hline Nguyen_2016_D8E8 & $\begin{array}{l}\text { Shoots of Picea abies, Abies } \\
\text { alba, Fagus sylvatica, Acer } \\
\text { pseudoplatanus, Fraxinus } \\
\text { excelsior, Quercus robur, } \\
\text { Pinus sylvestris, Betula } \\
\text { pendula, Carpinus betulus } \\
\text { and Quercus robur }\end{array}$ & 221 & $\begin{array}{c}\text { Culture } \\
\text { independent }\end{array}$ & $\begin{array}{l}454- \\
\text { pyrosequencing }\end{array}$ & 63853 & [192] \\
\hline Goldmann_2016_0757 & $\begin{array}{l}\text { Root and soil samples } \\
\text { from beech-dominated } \\
\text { plots }\end{array}$ & 29 & $\begin{array}{c}\text { Culture } \\
\text { independent }\end{array}$ & $\begin{array}{c}454- \\
\text { pyrosequencing }\end{array}$ & 85867 & [193] \\
\hline Bahram_2016_7246 & Soil & 123 & $\begin{array}{c}\text { Culture } \\
\text { independent }\end{array}$ & $\begin{array}{c}454- \\
\text { pyrosequencing } \\
\end{array}$ & 213249 & [194] \\
\hline Gehring_2016_E395 & $\begin{array}{l}\text { Roots and root-associated } \\
\text { (rhizosphere) soil of } \\
\text { sagebrush, cheatgrass, } \\
\text { and rice grass plants }\end{array}$ & 60 & - & - & 1161117 & [195] \\
\hline Gourmelon_2016_9281 & Soil & 32 & $\begin{array}{c}\text { Culture } \\
\text { independent }\end{array}$ & Illumina MiSeq & 91814 & [196] \\
\hline Bissett_AAAA_2016 & Soil & 2061 & $\begin{array}{c}\text { Culture } \\
\text { independent }\end{array}$ & Illumina MiSeq & 50810033 & [197] \\
\hline Cox_2016_EDC5 & Soil & 135 & $\begin{array}{c}\text { Culture } \\
\text { independent }\end{array}$ & $\begin{array}{c}454- \\
\text { pyrosequencing } \\
\end{array}$ & 886200 & [198] \\
\hline Oh_2016_DEBA & Soil & 12 & $\begin{array}{c}\text { Culture } \\
\text { independent }\end{array}$ & $\begin{array}{c}454- \\
\text { pyrosequencing }\end{array}$ & 98376 & [199] \\
\hline Frey_2016_5D5C & Soil & 12 & $\begin{array}{c}\text { Culture } \\
\text { independent }\end{array}$ & $\begin{array}{l}\text { Illumina MiSeq } \\
\text { v3 }\end{array}$ & 500999 & [200] \\
\hline Gannes_2016_5E98 & Soil & 23 & $\begin{array}{c}\text { Culture } \\
\text { independent }\end{array}$ & $\begin{array}{l}\text { Illumina MiSeq } \\
\text { system }\end{array}$ & 218946 & [201] \\
\hline Li_2016_1EBC & Soil & 21 & $\begin{array}{c}\text { Culture } \\
\text { independent }\end{array}$ & $\begin{array}{c}\text { Illumina MiSeq } \\
\text { system }\end{array}$ & 129184 & [202] \\
\hline Kielak_2016_1110 & Wood of Pinus sylvestris & 75 & $\begin{array}{c}\text { Culture } \\
\text { independent }\end{array}$ & $\begin{array}{c}454- \\
\text { pyrosequencing }\end{array}$ & 1281356 & [203] \\
\hline Ji_2016_C06E & Soil & 13 & $\begin{array}{c}\text { Culture } \\
\text { independent }\end{array}$ & $\begin{array}{c}454- \\
\text { pyrosequencing }\end{array}$ & 277 & [204] \\
\hline Baldrian_2016_DE02 & Sawdust & 118 & $\begin{array}{c}\text { Culture } \\
\text { independent }\end{array}$ & llumina MiSeq & 1205580 & [205] \\
\hline
\end{tabular}


Table 3. Cont.

\begin{tabular}{|c|c|c|c|c|c|c|}
\hline Global Fungi Study ID & Substrate & Samples & Method & $\begin{array}{l}\text { Sequencing } \\
\text { Platform }\end{array}$ & $\begin{array}{c}\text { ITS2 } \\
\text { Sequences }\end{array}$ & Reference \\
\hline Barnes_2016_0042 & Roots of Cinchona calisaya & 21 & $\begin{array}{c}\text { Culture } \\
\text { independent }\end{array}$ & llumina MiSeq & 239387 & [206] \\
\hline Porter_2016_CD8D & Soil & 2 & $\begin{array}{c}\text { Culture } \\
\text { independent }\end{array}$ & $\begin{array}{c}454- \\
\text { pyrosequencing }\end{array}$ & 20123 & [207] \\
\hline Zhou_2016_A8F1 & Soil & 126 & $\begin{array}{c}\text { Culture } \\
\text { independent }\end{array}$ & Illumina MiSeq & 3542416 & [208] \\
\hline Zhang_2016_1DA0 & Soil & 13 & $\begin{array}{c}\text { Culture } \\
\text { independent }\end{array}$ & $\begin{array}{c}454- \\
\text { pyrosequencing }\end{array}$ & 2362 & [209] \\
\hline Wang_2016_6223 & $\begin{array}{l}\text { Roots, stems, and sprouts } \\
\text { of rice plant }\end{array}$ & 1 & $\begin{array}{c}\text { Culture } \\
\text { independent }\end{array}$ & Illumina MiSeq & 1850 & [210] \\
\hline Zifcakova_2016_4C03 & Soil & 24 & $\begin{array}{c}\text { Culture } \\
\text { independent }\end{array}$ & $\begin{array}{l}\text { ILLUMINA } \\
\text { HISEQ2000 }\end{array}$ & 123869 & [211] \\
\hline VanDerWal_2016_4C9C & $\begin{array}{l}\text { Sawdust from sapwood } \\
\text { and heartwood }\end{array}$ & 130 & $\begin{array}{c}\text { Culture } \\
\text { independent }\end{array}$ & $\begin{array}{c}454- \\
\text { pyrosequencing }\end{array}$ & 1215932 & [212] \\
\hline Varenius_2017_BCFB & Soil & 517 & $\begin{array}{c}\text { Culture } \\
\text { independent }\end{array}$ & $\begin{array}{l}\text { PacBio RSII } \\
\text { platform by } \\
\text { SciLifeLab }\end{array}$ & 186474 & [213] \\
\hline van_der_Wal_2017_2D0D & $\begin{array}{l}\text { Sawdust samples of Larix } \\
\text { stumps, and Quercus } \\
\text { stumps }\end{array}$ & 88 & $\begin{array}{c}\text { Culture } \\
\text { independent }\end{array}$ & Illumina MiSeq & 877425 & [214] \\
\hline Wang_2017_7E18 & Soil & 6 & $\begin{array}{c}\text { Culture } \\
\text { independent }\end{array}$ & $\begin{array}{c}454- \\
\text { pyrosequencing }\end{array}$ & 53737 & [215] \\
\hline van_der_Wal_2017_3070 & Soil & 135 & $\begin{array}{c}\text { Culture } \\
\text { independent }\end{array}$ & Illumina MiSeq & 1572834 & [216] \\
\hline Vasutova_2017_3070 & Soil & 28 & $\begin{array}{c}\text { Culture } \\
\text { independent }\end{array}$ & $\begin{array}{l}\text { GS Junior } \\
\text { sequencer }\end{array}$ & 9370 & [217] \\
\hline Vaz_2017_C16E & Woody debris & 2 & $\begin{array}{c}\text { Culture } \\
\text { independent }\end{array}$ & $\begin{array}{l}\text { Personal Genome } \\
\text { Machine }\end{array}$ & 11817 & [218] \\
\hline Yang_2017_2AFC & Soil & 180 & $\begin{array}{c}\text { Culture } \\
\text { independent }\end{array}$ & $\begin{array}{l}\text { llumina MiSeq } \\
\text { platform PE250 }\end{array}$ & 12688168 & [219] \\
\hline Wicaksono_2017_3B9E & $\begin{array}{l}\text { Root samples of } \text { Alnus } \\
\text { acuminata }\end{array}$ & 24 & $\begin{array}{c}\text { Culture } \\
\text { independent }\end{array}$ & Ion Torrent & 3596531 & [220] \\
\hline Yang_2017_EB1D & Soil & 26 & $\begin{array}{c}\text { Culture } \\
\text { independent }\end{array}$ & $\begin{array}{l}\text { Illumina MiSeq } \\
\text { platform PE250 }\end{array}$ & 1450233 & [221] \\
\hline Zhang_2017_02C2 & Plant litter and soil & 54 & $\begin{array}{c}\text { Culture } \\
\text { independent }\end{array}$ & Illumina MiSeq & 2904476 & [222] \\
\hline Zhang_2017_F933 & Peat soil & 9 & $\begin{array}{c}\text { Culture } \\
\text { independent }\end{array}$ & $\begin{array}{l}\text { Illumina } \\
\text { HiSeq2000 }\end{array}$ & 320199 & [223] \\
\hline Purahong_2017_8EFD & Wood sample & 116 & $\begin{array}{c}\text { Culture } \\
\text { independent }\end{array}$ & $\begin{array}{c}\text { Genome } \\
\text { Sequencer } \\
\text { 454-FLX System }\end{array}$ & 299831 & [224] \\
\hline Poosakkannu_2017_B342 & $\begin{array}{l}\text { Bulk soil, rhizosphere soil, } \\
\text { and D. flexuosa Leaf }\end{array}$ & 43 & $\begin{array}{c}\text { Culture } \\
\text { independent }\end{array}$ & IonTorrent & 259743 & [225] \\
\hline Bergottini_2017_02C2 & Roots of Ilex paraguariensis & 11 & $\begin{array}{c}\text { Culture } \\
\text { independent }\end{array}$ & $\begin{array}{c}454- \\
\text { pyrosequencing }\end{array}$ & 189048 & [226] \\
\hline Dean_2017_F5A5 & $\begin{array}{c}\text { Roots of Glycine max } \\
\text { (soybean) and Thlaspi } \\
\text { arvense }\end{array}$ & 12 & $\begin{array}{c}\text { Culture } \\
\text { independent }\end{array}$ & 454-FLX titanium & 12596 & [227] \\
\hline $\begin{array}{c}\text { Fernandez_Martinez_ } \\
\text { 2017_14C3 }\end{array}$ & Soil & 11 & $\begin{array}{c}\text { Culture } \\
\text { independent }\end{array}$ & $\begin{array}{c}454- \\
\text { pyrosequencing }\end{array}$ & 138524 & [228] \\
\hline Ge_2017_4DC8 & $\begin{array}{l}\text { Roots of Quercus nigra, } Q \text {. } \\
\text { virginiana, Q. laevis, Carya } \\
\text { cf. glabra, Carya cf. } \\
\text { tomentosa as well as several } \\
\text { Carya and Quercus spp. }\end{array}$ & 9 & $\begin{array}{c}\text { Culture } \\
\text { independent }\end{array}$ & $\begin{array}{c}454- \\
\text { pyrosequencing }\end{array}$ & 44 & [229] \\
\hline
\end{tabular}


Table 3. Cont.

\begin{tabular}{|c|c|c|c|c|c|c|}
\hline Global Fungi Study ID & Substrate & Samples & Method & $\begin{array}{l}\text { Sequencing } \\
\text { Platform }\end{array}$ & $\begin{array}{c}\text { ITS2 } \\
\text { Sequences }\end{array}$ & Reference \\
\hline Gomes_2017_2AFC & Roots of Thismia sp. & 61 & $\begin{array}{c}\text { Culture } \\
\text { independent }\end{array}$ & Ion Torrent & 4067438 & [230] \\
\hline Almario_2017_2082 & $\begin{array}{l}\text { Root and rhizosphere of } \\
\text { Arabis alpina }\end{array}$ & 26 & $\begin{array}{c}\text { Culture } \\
\text { independent }\end{array}$ & Illumina Miseq & 805679 & [231] \\
\hline Anthony_2017_647F & Soil & 142 & $\begin{array}{c}\text { Culture } \\
\text { independent }\end{array}$ & Illumina Miseq & 12453259 & [232] \\
\hline Grau_2017_E29A & Soil & 27 & $\begin{array}{c}\text { Culture } \\
\text { independent }\end{array}$ & Ion Torrent & 960177 & [233] \\
\hline Hiiesalu_2017_E29A & Soil & 1 & $\begin{array}{c}\text { Culture } \\
\text { independent }\end{array}$ & $\begin{array}{c}454- \\
\text { pyrosequencing }\end{array}$ & 4616 & [234] \\
\hline Nguyen_2017_6F2C & $\begin{array}{l}\text { Leaf samples of Betula } \\
\text { pendula }\end{array}$ & 20 & $\begin{array}{c}\text { Culture } \\
\text { independent }\end{array}$ & $\begin{array}{c}454- \\
\text { pyrosequencing }\end{array}$ & 1318 & [235] \\
\hline Kolarikova_2017_EB1D & $\begin{array}{c}\text { Roots of Salix caprea and } \\
\text { Betula pendula }\end{array}$ & 24 & $\begin{array}{c}\text { Culture } \\
\text { independent }\end{array}$ & $\begin{array}{c}454- \\
\text { pyrosequencing }\end{array}$ & 47543 & [236] \\
\hline Kyaschenko_2017_89D4 & Soil & 30 & $\begin{array}{c}\text { Culture } \\
\text { independent }\end{array}$ & $\begin{array}{c}\text { PacBio } \\
\text { sequencing }\end{array}$ & 64010 & [237] \\
\hline Oja_2017_AD29 & $\begin{array}{l}\text { Roots and rhizosphere soil } \\
\text { of }\end{array}$ & 333 & $\begin{array}{c}\text { Culture } \\
\text { independent }\end{array}$ & $\begin{array}{c}454- \\
\text { pyrosequencing }\end{array}$ & 446296 & [238] \\
\hline Miura_2017_2BE5 & $\begin{array}{l}\text { Leaves and berries of } \\
\text { grapes }\end{array}$ & 36 & $\begin{array}{c}\text { Culture } \\
\text { independent }\end{array}$ & Illumina MiSeq & 2250530 & [239] \\
\hline Oono_2017_B342 & Needles of Pinus taeda & 143 & $\begin{array}{c}\text { Culture } \\
\text { independent }\end{array}$ & Illumina MiSeq & 9755183 & [240] \\
\hline Kamutando_2017_6F2C & Soil & 3 & $\begin{array}{c}\text { Culture } \\
\text { independent }\end{array}$ & Illumina MiSeq & 4 & [241] \\
\hline Shen_2017_C7F4 & Soil & 1 & $\begin{array}{c}\text { Culture } \\
\text { independent }\end{array}$ & Illumina MiSeq & 1 & [242] \\
\hline Smith_2017_2AFC & Root of Dicymbe corymbosa & 8 & $\begin{array}{c}\text { Culture } \\
\text { independent }\end{array}$ & $\begin{array}{c}454- \\
\text { pyrosequencing }\end{array}$ & 94 & [243] \\
\hline Tian_2017_F933 & Soil & 3 & $\begin{array}{c}\text { Culture } \\
\text { independent }\end{array}$ & $\begin{array}{c}\text { 454-GS } \\
\text { FLX+pyrosequencing } \\
\text { machine }\end{array}$ & 25001 & [244] \\
\hline Tu_2017_BCFB & Soil & 60 & $\begin{array}{c}\text { Culture } \\
\text { independent }\end{array}$ & Illumina MiSeq & 696557 & [245] \\
\hline $\begin{array}{c}\text { Sharma_Poudyal_ } \\
\text { 2017_F933 }\end{array}$ & Soil & 53 & $\begin{array}{c}\text { Culture } \\
\text { independent }\end{array}$ & 454-FLX titanium & 7680 & [246] \\
\hline Cross_2017_2AFC & $\begin{array}{l}\text { Leaflet, petiole upper and } \\
\text { petiole base tissues of ash } \\
\text { leaves of Fraxinus excelsior } \\
\text { (common ash) }\end{array}$ & 27 & $\begin{array}{c}\text { Culture } \\
\text { independent }\end{array}$ & $\begin{array}{c}454- \\
\text { pyrosequencing }\end{array}$ & 171094 & [247] \\
\hline Kazartsev_2018_1115 & Bark of Picea abies & 20 & $\begin{array}{c}\text { Culture } \\
\text { independent }\end{array}$ & $\begin{array}{c}454- \\
\text { pyrosequencing }\end{array}$ & 22918 & [248] \\
\hline Bickford_2018_2EE0 & Roots of Phragmites spp. & 3 & $\begin{array}{c}\text { Culture } \\
\text { independent }\end{array}$ & PacBio-RS II & 66439 & [249] \\
\hline Cline_2018_0BCC & Wood of Betula papyrifera & 15 & $\begin{array}{c}\text { Culture } \\
\text { independent }\end{array}$ & 454-FLX titanium & 660 & [250] \\
\hline Cregger_2018_added & $\begin{array}{c}\text { Roots, stems, and leaves } \\
\text { of Populus deltoides and } \\
\text { the Populus trichocarpa } \times \\
\text { deltoides hybrid }\end{array}$ & 290 & $\begin{array}{c}\text { Culture } \\
\text { independent }\end{array}$ & Illumina MiSeq & 14767409 & [251] \\
\hline Marasco_2018_DBE1 & $\begin{array}{c}\text { Rhizosheath-root system } \\
\text { of Stipagrostis sabulicola, S. } \\
\text { seelyae and Cladoraphis } \\
\text { spinosa }\end{array}$ & 49 & $\begin{array}{c}\text { Culture } \\
\text { independent }\end{array}$ & Illumina MiSeq & 4694085 & [252] \\
\hline Glynou_2018_445A & $\begin{array}{l}\text { Roots of nonmycorrhizal } \\
\text { Microthlaspi spp. }\end{array}$ & 5 & $\begin{array}{c}\text { Culture } \\
\text { independent }\end{array}$ & Illumina Miseq & 7 & [253] \\
\hline
\end{tabular}


Table 3. Cont.

\begin{tabular}{|c|c|c|c|c|c|c|}
\hline Global Fungi Study ID & Substrate & Samples & Method & $\begin{array}{c}\text { Sequencing } \\
\text { Platform }\end{array}$ & $\begin{array}{c}\text { ITS2 } \\
\text { Sequences }\end{array}$ & Reference \\
\hline Montagna_2018_E316 & Soil & 24 & $\begin{array}{c}\text { Culture } \\
\text { independent }\end{array}$ & Illumina Miseq & 2475767 & [254] \\
\hline Schlegel_2018_A231 & $\begin{array}{l}\text { Leaves of Fraxinus spp. } \\
\text { and Acer pseudoplatanus }\end{array}$ & 353 & $\begin{array}{c}\text { Culture } \\
\text { independent }\end{array}$ & Illumina MiSeq & 24198214 & [255] \\
\hline $\begin{array}{c}\text { SchneiderMaunoury_ } \\
\text { 2018_51AB }\end{array}$ & Different plant species & 78 & $\begin{array}{c}\text { Culture } \\
\text { independent }\end{array}$ & Ion Torrent & 352332 & [256] \\
\hline Schon_2018_01F4 & Soil & 18 & $\begin{array}{c}\text { Culture } \\
\text { independent }\end{array}$ & Illumina MiSeq & 235709 & [257] \\
\hline Rasmussen_2018_C8E6 & Root samples & 228 & $\begin{array}{c}\text { Culture } \\
\text { independent }\end{array}$ & Illumina MiSeq & 428044 & [258] \\
\hline Rogers_2018_147F & Hemlock stems & 6 & $\begin{array}{c}\text { Culture } \\
\text { independent }\end{array}$ & Illumina MiSeq & 675067 & [259] \\
\hline Purahong_2018_14C0 & Deadwood logs & 297 & $\begin{array}{c}\text { Culture } \\
\text { independent }\end{array}$ & $\begin{array}{c}454- \\
\text { pyrosequencing }\end{array}$ & 2034928 & [260] \\
\hline Qian_2018_2B1E & $\begin{array}{l}\text { Leaves of Mussaenda } \\
\text { shikokiana }\end{array}$ & 20 & $\begin{array}{c}\text { Culture } \\
\text { independent }\end{array}$ & Illumina MiSeq & 449179 & [261] \\
\hline Park_2018_569C & $\begin{array}{c}\text { Calanthe species: } \\
\text { C. aristulifera, C. bicolor, } \\
\text { C. discolor, C. insularis and } \\
\text { C. striata }\end{array}$ & 12 & $\begin{array}{c}\text { Culture } \\
\text { independent }\end{array}$ & $\begin{array}{l}\text { 454-GS FLX } \\
\text { +System }\end{array}$ & 65867 & [262] \\
\hline Mirmajlessi_2018_765D & Soil & 40 & $\begin{array}{c}\text { Culture } \\
\text { independent }\end{array}$ & Illumina MiSeq & 1077125 & [263] \\
\hline Purahong_2018_9F2E & Wood samples & 96 & $\begin{array}{c}\text { Culture } \\
\text { independent }\end{array}$ & $\begin{array}{c}454- \\
\text { pyrosequencing }\end{array}$ & 656682 & [264] \\
\hline Si_2018_53B6 & Soil & 27 & $\begin{array}{c}\text { Culture } \\
\text { independent }\end{array}$ & Illumina MiSeq & 692169 & [265] \\
\hline Saitta_2018_51C8 & Soil & 16 & $\begin{array}{c}\text { Culture } \\
\text { independent }\end{array}$ & Illumina MiSeq & 4923667 & [266] \\
\hline Santalahti_2018_3794 & Soil & 38 & $\begin{array}{c}\text { Culture } \\
\text { independent }\end{array}$ & $\begin{array}{c}454- \\
\text { pyrosequencing }\end{array}$ & 218387 & [267] \\
\hline Sukdeo_2018_1DF4 & Soil & 126 & $\begin{array}{c}\text { Culture } \\
\text { independent }\end{array}$ & Illumina MiSeq & 32336646 & [268] \\
\hline Zhu_2018_1E38 & Soil & 12 & $\begin{array}{c}\text { Culture } \\
\text { independent }\end{array}$ & Illumina MiSeq & 1031479 & [269] \\
\hline Zhang_2018_F81F & Soil & 106 & $\begin{array}{c}\text { Culture } \\
\text { independent }\end{array}$ & Illumina HiSeq & 1673070 & [270] \\
\hline Zhang_2018_491A & $\begin{array}{c}\text { Bare sand, algal crusts, } \\
\text { lichen crusts, and moss } \\
\text { crusts }\end{array}$ & 17 & $\begin{array}{c}\text { Culture } \\
\text { independent }\end{array}$ & Illumina Miseq & 442056 & [271] \\
\hline Sun_2018_1B01 & Soil & 36 & $\begin{array}{c}\text { Culture } \\
\text { independent }\end{array}$ & Illumina Miseq & 1188520 & [272] \\
\hline Weissbecker_2019_6A75 & Soil & 394 & $\begin{array}{c}\text { Culture } \\
\text { independent }\end{array}$ & $\begin{array}{l}\text { GS-FLX + 454 } \\
\text { pyrosequencer }\end{array}$ & 1109208 & [273] \\
\hline Purahong_AD_2019 & $\begin{array}{l}\text { Wood chips of rotted } \\
\text { heartwood deadwood } \\
\text { from C. carlesii }\end{array}$ & 3 & $\begin{array}{c}\text { Culture } \\
\text { independent }\end{array}$ & $\begin{array}{l}\text { PacBio RS II } \\
\text { system }\end{array}$ & 22886 & [274] \\
\hline Egidi_AD_2019 & Soil & 161 & $\begin{array}{c}\text { Culture } \\
\text { independent }\end{array}$ & Illumina MiSeq & 14131987 & [275] \\
\hline Froeslev_2019_CA74 & Soil & 276 & $\begin{array}{c}\text { Culture } \\
\text { independent }\end{array}$ & Illumina MiSeq & 6114124 & [276] \\
\hline Ogwu_2019_38FE & Soil & 13 & $\begin{array}{c}\text { Culture } \\
\text { independent }\end{array}$ & Illumina Miseq & 724483 & [277] \\
\hline
\end{tabular}


Table 3. Cont.

\begin{tabular}{|c|c|c|c|c|c|c|}
\hline Global Fungi Study ID & Substrate & Samples & Method & $\begin{array}{l}\text { Sequencing } \\
\text { Platform }\end{array}$ & $\begin{array}{c}\text { ITS2 } \\
\text { Sequences }\end{array}$ & Reference \\
\hline Ovaskainen_2019_air & $\begin{array}{c}\text { Soil particles, spores, } \\
\text { pollen, bacteria, and small } \\
\text { insects }\end{array}$ & 75 & $\begin{array}{c}\text { Culture } \\
\text { independent }\end{array}$ & Illumina Miseq & 935812 & [278] \\
\hline Qian_2019_9691 & Leaves and soil & 30 & $\begin{array}{c}\text { Culture } \\
\text { independent }\end{array}$ & Illumina HiSeq & 2133292 & [279] \\
\hline Ramirez_2019_D0B2 & Soil & 810 & $\begin{array}{c}\text { Culture } \\
\text { independent }\end{array}$ & Illumina Miseq & 6555903 & [280] \\
\hline Pellitier_2019_82BC & $\begin{array}{l}\text { Bark of black oak (Quercus } \\
\text { velutina), white oak (Q. } \\
\text { alba), red pine (Pinus } \\
\text { resinosa), eastern white } \\
\text { pine (P. strobus) and red } \\
\text { maple (Acer rubrum) }\end{array}$ & 15 & $\begin{array}{c}\text { Culture } \\
\text { independent }\end{array}$ & Illumina MiSeq & 10649956 & [281] \\
\hline $\begin{array}{c}\text { Semenova- } \\
\text { Nelsen_2019_add }\end{array}$ & $\begin{array}{l}\text { Litter and the uppermost } \\
\text { soil }\end{array}$ & 121 & $\begin{array}{c}\text { Culture } \\
\text { independent }\end{array}$ & Illumina MiSeq & 3205748 & [282] \\
\hline Sheng_2019_66AC & Soil & 16 & $\begin{array}{c}\text { Culture } \\
\text { independent }\end{array}$ & Illumina MiSeq & 447840 & [283] \\
\hline Shigyo_2019_5B19 & Soil & 144 & $\begin{array}{c}\text { Culture } \\
\text { independent }\end{array}$ & Illumina MiSeq & 4353704 & [284] \\
\hline Schroter_2019_1B64 & Fine roots and soil & 3 & $\begin{array}{c}\text { Culture } \\
\text { independent }\end{array}$ & $\begin{array}{l}\text { Roche GS-FLX+ } \\
\text { pyrosequencer }\end{array}$ & 144 & [285] \\
\hline Singh_2019_EA7F & Fine roots and soil & 96 & $\begin{array}{c}\text { Culture } \\
\text { independent }\end{array}$ & Illumina MiSeq & 3138303 & [286] \\
\hline Song_2019_ad2 & Soil & 46 & $\begin{array}{c}\text { Culture } \\
\text { independent }\end{array}$ & Illumina MiSeq & 920391 & [287] \\
\hline U’Ren_2019_add & $\begin{array}{l}\text { Fresh, photosynthetic } \\
\text { tissues of a diverse range } \\
\text { of plants and lichens }\end{array}$ & 486 & $\begin{array}{l}\text { Culture-based } \\
\text { sampling and } \\
\text { culture- } \\
\text { independent }\end{array}$ & Illumina MiSeq & 5671834 & [288] \\
\hline Unuk_2019_567A & Fine roots and soil & 30 & $\begin{array}{c}\text { Culture } \\
\text { independent }\end{array}$ & Ilumina MiSeq & 470786 & [289] \\
\hline Araya_2019_add & Soil & 36 & $\begin{array}{c}\text { Culture } \\
\text { independent }\end{array}$ & Illumina MiSeq & 8083471 & [290] \\
\hline $\begin{array}{c}\text { Alvarez- } \\
\text { Garrido_2019_add }\end{array}$ & $\begin{array}{l}\text { Root tips from A. pinsapo } \\
\text { trees following the trunk } \\
\text { to the superficial } \\
\text { secondary roots }\end{array}$ & 76 & $\begin{array}{c}\text { Culture } \\
\text { independent }\end{array}$ & Illumina MiSeq & 1795423 & [291] \\
\hline Wei_2019_3796 & Soil & 1 & $\begin{array}{c}\text { Culture } \\
\text { independent }\end{array}$ & Illumina HiSeq & 18 & [292] \\
\hline Pan_2020_addZ & $\begin{array}{l}\text { Soil from the rhizosphere } \\
\text { of potato }\end{array}$ & 1 & $\begin{array}{c}\text { Culture } \\
\text { independent }\end{array}$ & Illumina MiSeq & 2 & [293] \\
\hline Detheridge_2020_Z & Soil & 70 & $\begin{array}{c}\text { Culture } \\
\text { independent }\end{array}$ & & 1832454 & [294] \\
\hline Li_2020_AS & Soil & 19 & $\begin{array}{c}\text { Culture } \\
\text { independent }\end{array}$ & Illumina MiSeq & 116660 & [295] \\
\hline
\end{tabular}


Table 4. An overview on culture dependentand culture independent analyses of fungal samples with respect to location, source, sequencing, observation method and target gene.

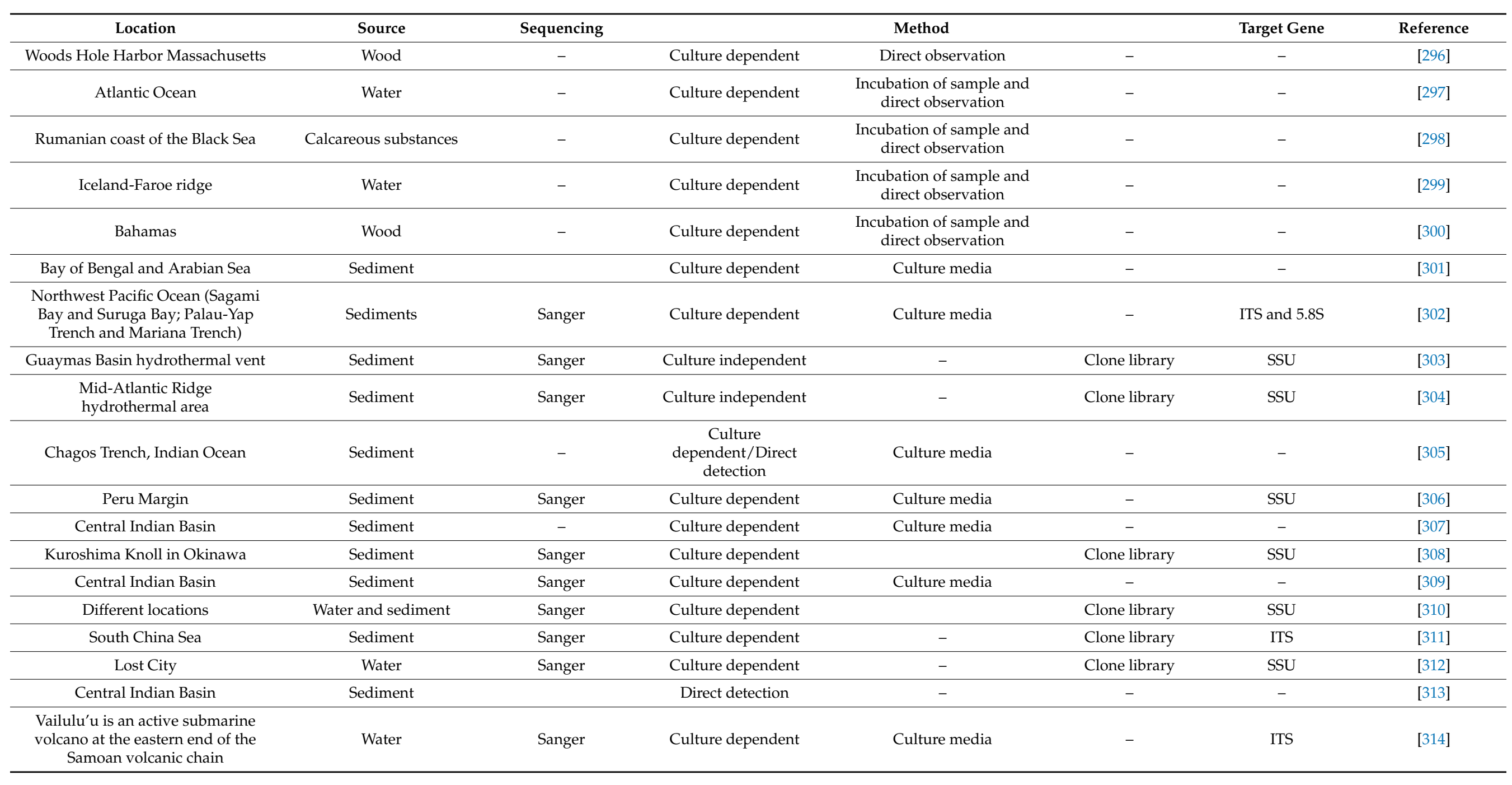


Table 4. Cont.

\begin{tabular}{|c|c|c|c|c|c|c|c|}
\hline Location & Source & Sequencing & & Method & & Target Gene & Reference \\
\hline Vanuatu archipelago & $\begin{array}{c}\text { Deepsea water, wood and } \\
\text { debris }\end{array}$ & Sanger & Culture dependent & Culture media & - & SSU and LSU & [315] \\
\hline $\begin{array}{l}\text { East Pacific Rise, Mid-Atlantic Ridge } \\
\text { and Lucky Strike }\end{array}$ & $\begin{array}{l}\text { Deepsea hydrothermal } \\
\text { ecosystem }\end{array}$ & Sanger & $\begin{array}{l}\text { Culture depen- } \\
\text { dent/Cultureindependent }\end{array}$ & Culture media & Clone library & SSU & [316] \\
\hline Southwest Pacific & $\begin{array}{l}\text { Deepsea hydrothermal } \\
\text { ecosystems }\end{array}$ & Sanger & Culture dependent & Culture media & - & SSU & [317] \\
\hline Different locations & $\begin{array}{l}\text { Deep-sea hydrothermal } \\
\text { ecosystems }\end{array}$ & Sanger & Culture dependent & Culture media & - & LSU & [318] \\
\hline Southern East Pacific Rise & Water and bivalves & Sanger & Culture independent & - & Clone library & SSU & [320] \\
\hline Central Indian Basin & Sediment & Sanger & Culture dependent & Culture media & & Full ITS and SSU & [321] \\
\hline Southern Indian Ocean & Sediment & Sanger & Culture independent & - & Clone library & SSU & {$[322]$} \\
\hline Peru Margin and the Peru Trench & Sediment & Sanger & Culture independent & - & Clone library & SSU & {$[323]$} \\
\hline Puerto Rico Trench & Water & Sanger & Culture independent & - & Clone library & SSU & [324] \\
\hline Marmara Sea & Sediment & $\begin{array}{l}\text { Sanger and } 454- \\
\text { pyrosequencing }\end{array}$ & Culture independent & - & Clone library & SSU & [326] \\
\hline $\begin{array}{c}\text { Central Indian Basin - Several } \\
\text { stations }\end{array}$ & Sediment & Sanger & Culture independent & - & Clone library & Full ITS and SSU & [327] \\
\hline $\begin{array}{l}\text { Central Indian Basin - Several } \\
\text { stations }\end{array}$ & Sediment & Sanger & $\begin{array}{c}\text { Culture } \\
\text { dependent/Culture } \\
\text { independent }\end{array}$ & Culture media & Clone library & $\begin{array}{c}\text { SSU (Fungal } \\
\text { isolates)/ITS (DNA } \\
\text { sediment) }\end{array}$ & [328] \\
\hline $\begin{array}{l}\text { Central Indian Basin - Several } \\
\text { stations }\end{array}$ & Sediment & Sanger & $\begin{array}{l}\text { Culture independent } \\
\text { cloning }\end{array}$ & - & Clone library & Full ITS and SSU & [328] \\
\hline $\begin{array}{l}\text { Alaminos Canyon } 601 \text { methane seep } \\
\text { in the Gulf of Mexico }\end{array}$ & Methane seeps sediment & Sanger & Culture independent & - & Clone library & ITS and LSU & [329] \\
\hline
\end{tabular}


Table 4. Cont.

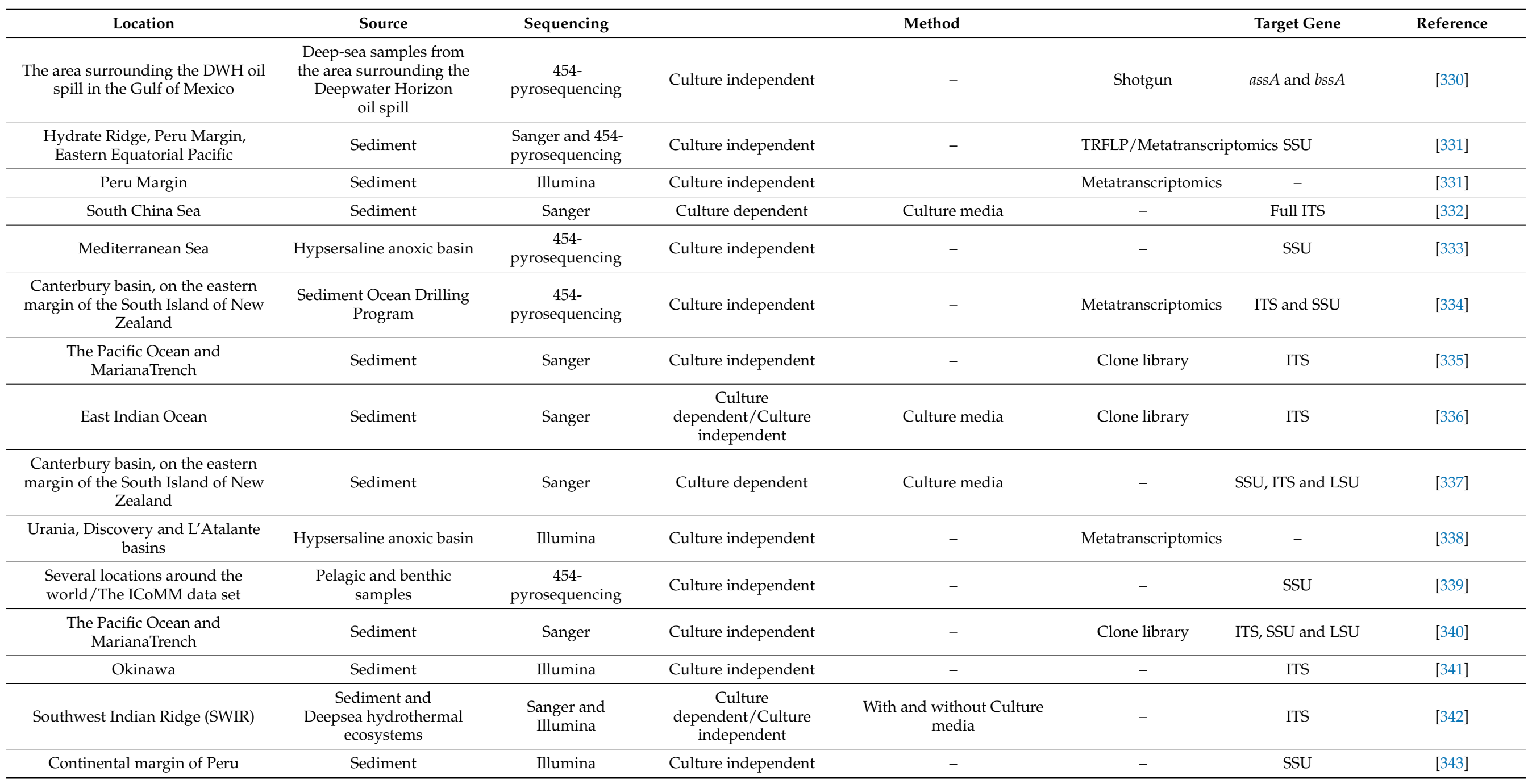


Table 4. Cont.

\begin{tabular}{|c|c|c|c|c|c|c|c|}
\hline Location & Source & Sequencing & & Method & & Target Gene & Reference \\
\hline North Atlantic and Arctic Basin & Marine snow & & Culture independent & - & CARD-FISH & - & [344] \\
\hline Northern Chile & Water & Sanger & Culture dependent & - & - & Full ITS & [345] \\
\hline The Sao Paulo Plateau & Asphalt seeps & Ion Torrent & Culture independent & - & - & ITS & [346] \\
\hline Peru Margin & Sediment & Illumina & Culture independent & - & Metatranscriptomics & & [347] \\
\hline East Pacific & Sediment & Sanger & Culturedependent & Culture media & & Full ITS & [348] \\
\hline $\begin{array}{l}\text { The Ionian Sea (Central } \\
\text { Mediterranean Sea) }\end{array}$ & Sediment & Illumina & Culture independent & - & FISH & ITS & [349] \\
\hline South-central western Pacific Ocean & Water & Illumina & Culture independent & - & - & SSU & [350] \\
\hline Challenger deep & Water & Illumina & Culture independent & - & - & ITS & [351] \\
\hline $\begin{array}{l}\text { Mexican Exclusive Economic } \\
\text { Zone-Gulf of Mexico }\end{array}$ & Sediment & Illumina & Culture independent & - & - & ITS & [352] \\
\hline Yap Trench & Sediment & $\begin{array}{l}\text { Sanger and } \\
\text { Illumina }\end{array}$ & $\begin{array}{c}\text { Culture } \\
\text { dependent/Culture } \\
\text { independent }\end{array}$ & - & - & ITS & [353] \\
\hline $\begin{array}{l}\text { Mexican Exclusive Economic } \\
\text { Zone-Gulf of Mexico }\end{array}$ & Sediment & Sanger & Culture dependent & Culture media & - & Full ITS and tub & [354] \\
\hline
\end{tabular}


Table 5. Databases and tools for sequence-based classification and identification.

\begin{tabular}{|c|c|}
\hline \multicolumn{2}{|c|}{ General Identification Tools and Data Repositories } \\
\hline BOLD & http:/ / www.boldsystems.org/ (accessed on 6 November 2021) \\
\hline Westerdijk Fungal BiodiversityInstitute & https:/ / wi.knaw.nl/page/Collection (accessed on 6 November 2021) \\
\hline CIPRES & https://www.phylo.org/ (accessed on 6 November 2021) \\
\hline Dryad & http:/ / datadryad.org/ (accessed on 6 November 2021) \\
\hline FUSARIUM-ID & http:/ / isolate.fusariumdb.org/ (accessed on 6 November 2021) \\
\hline One Stop Shop Fungi & http:/ / onestopshopfungi.org/ (accessed on 6 November 2021) \\
\hline GreenGenes & $\begin{array}{l}\text { http:/ /greengenes.lbl.gov/cgi-bin/nph-index.cgi (accessed on } \\
6 \text { November 2021) }\end{array}$ \\
\hline MaarjAM & http:/ / maarjam.botany.ut.ee/ (accessed on 6 November 2021) \\
\hline Mothur & http:/ / www.mothur.org/ (accessed on 6 November 2021) \\
\hline Naïve Bayesian Classifier & $\begin{array}{l}\text { http: / / aem.asm.org/content } / 73 / 16 / 5261 . \text { short? } r s s=1 \& \text { ssource }=\mathrm{mfc} \\
\text { (accessed on } 6 \text { November 2021) }\end{array}$ \\
\hline Open Tree of Life & $\begin{array}{l}\text { http: / / www.opentreeoflife.org/ } \\
\text { QIIME http:/ / qiime.org/ (accessed on } 6 \text { November 2021) }\end{array}$ \\
\hline PHYMYCO database & http:/ / phymycodb.genouest.org/ (accessed on 6 November 2021) \\
\hline RefSeq Targeted Loci & $\begin{array}{l}\text { http:/ / www.ncbi.nlm.nih.gov/refseq/targetedloci/ (accessed on } \\
6 \text { November 2021) }\end{array}$ \\
\hline Ribosomal Database Project (RDP) & http:/ / rdp.cme.msu.edu/ (accessed on 6 November 2021) \\
\hline Silva & http://www.arb-silva.de/ (accessed on 6 November 2021) \\
\hline TreeBASE & http:/ / treebase.org/ (accessed on 6 November 2021) \\
\hline TrichoBLAST & http:/ / www.isth.info/tools/blast/ (accessed on 6 November 2021) \\
\hline UNITE & http:/ / unite.ut.ee/ (accessed on 6 November 2021) \\
\hline United Kingdom National Culture Collection & http:/ / www.ukncc.co.uk/ (accessed on 6 November 2021) \\
\hline \multicolumn{2}{|r|}{ Data standards } \\
\hline $\mathrm{BIOM}$ & http:/ /biom-format.org/ (accessed on 6 November 2021) \\
\hline MIMARKS & $\begin{array}{l}\text { http://www.nature.com/nbt/journal/v29/n5/full/nbt/1823.html } \\
\text { (accessed on 6 November 2021) }\end{array}$ \\
\hline Darwin & Core http:/ / rs.tdwg.org/dwc/ (accessed on 6 November 2021) \\
\hline \multicolumn{2}{|c|}{ Genomics databases and tools } \\
\hline AFTOL & http:/ / aftol.umn.edu/ (accessed on 6 November 2021) \\
\hline 1000 Fungal Genomes Project (1KFG) & http:/ /1000.fungalgenomes.org/home/ (accessed on 6 November 2021) \\
\hline FungiDB & http:/ / fungidb.org/fungidb/ (accessed on 6 November 2021) \\
\hline GEBA & $\begin{array}{l}\text { http://jgi.doe.gov/our-science/science-programs/microbial-genomics / } \\
\text { phylogenetic-diversity/ (accessed on } 6 \text { November 2021) }\end{array}$ \\
\hline MycoCosm & $\begin{array}{l}\text { http:/ / genome.jgi.doe.gov/programs/fungi/index.jsf (accessed on } \\
6 \text { November 2021) }\end{array}$ \\
\hline \multicolumn{2}{|r|}{ Functional database } \\
\hline FUNGuild & http:/ /github.com/UMNFuN/FUNGuild (accessed on 6 November 2021) \\
\hline
\end{tabular}


Table 5. Cont.

\begin{tabular}{|c|c|}
\hline \multicolumn{2}{|c|}{ Nomenclature and nomenclatural databases and organizations } \\
\hline Catalogue of Life (COL) & http:/ / www.catalogueoflife.org/ (accessed on 6 November 2021) \\
\hline EPPO-Q-bank & http:/ / qbank.eppo.int/ (accessed on 6 November 2021) \\
\hline Faces of Fungi & http:/ / www.facesoffungi.org/ (accessed on 6 November 2021) \\
\hline Index Fungorum & http:/ / www.indexfungorum.org/ (accessed on 6 November 2021) \\
\hline $\begin{array}{l}\text { International code of nomenclature for algae, fungi, } \\
\text { and plants (ICNAFP) }\end{array}$ & $\begin{array}{l}\text { http://www.iapt-taxon.org/nomen/main.php (accessed on } \\
6 \text { November 2021) }\end{array}$ \\
\hline $\begin{array}{l}\text { International Commission on the Taxonomy of Fungi } \\
\text { (ICTF) }\end{array}$ & http:/ / www.fungaltaxonomy.org/ (accessed on 6 November 2021) \\
\hline $\begin{array}{l}\text { List of prokaryotic names with standing in } \\
\text { nomenclature (LPSN) }\end{array}$ & http:/ / www.bacterio.net/ (accessed on 6 November 2021) \\
\hline MycoBank & http:/ / www.mycobank.org/ (accessed on 6 November 2021) \\
\hline Outline of fungi & http:/ / www.outlineoffungi.org / (accessed on 6 November 2021) \\
\hline \multicolumn{2}{|c|}{ Biodiversity collections databases } \\
\hline Global Biodiversity Information Facility (GBIF) & http:/ / www.gbif.org/ (accessed on 6 November 2021) \\
\hline iDigBio & http:/ / www.idigbio.org/ (accessed on 6 November 2021) \\
\hline MycoPortal & http:/ / mycoportal.org/portal/index.php (accessed on 6 November 2021) \\
\hline World Federation of Culture Collections (WFCC) & http:/ /www.wfcc.info/ (accessed on 6 November 2021) \\
\hline
\end{tabular}

Likewise, a listing of Sequence Independent methodsand High-throughput sequencing platforms are summarized in Table 6. The pictorial overview on different molecular techniques, as well as the general protocol of culture dependent and culture independent DNA-based molecular techniques used in fungal sample analyses, is also present here (Figures 4 and 5).

Table 6. Sequence Independent methods and High-throughput sequencing platforms.

\begin{tabular}{cc}
\hline Sequencing Independent Methods & High-Throughput Sequencing Platforms \\
\hline ARDRA (Amplified Ribosomal DNA Restriction Analysis) & 454 Pyrosequencing (second-generation platform) \\
\hline ARISA (Amplified Intergeneric Spacer Analysis) & Illumina MiSeq sequencing (second-generation) \\
\hline DGGE (Denaturing Gradient Gel Electrophoresis) & Ion Torrent PGM and GeneStudio \\
\hline FISH (Fluorescence in Situ Hybridization) & $\begin{array}{c}\text { PacBio RSII and Sequel } \\
\text { (This third-generation HTS platform) }\end{array}$ \\
\hline LAMP (Loop-Mediated Isothermal Amplification) & - \\
\hline MT-PCR (Multiplexed tandem PCR) & Oxford Nanopore MinION, GridION and PrometION \\
\hline RCA (Rolling Circle Amplification) & - \\
\hline RDBH (Reverse Dot Blot Hybridization) & - \\
\hline RFLP (Restriction Fragment Length Polymorphism)
\end{tabular}




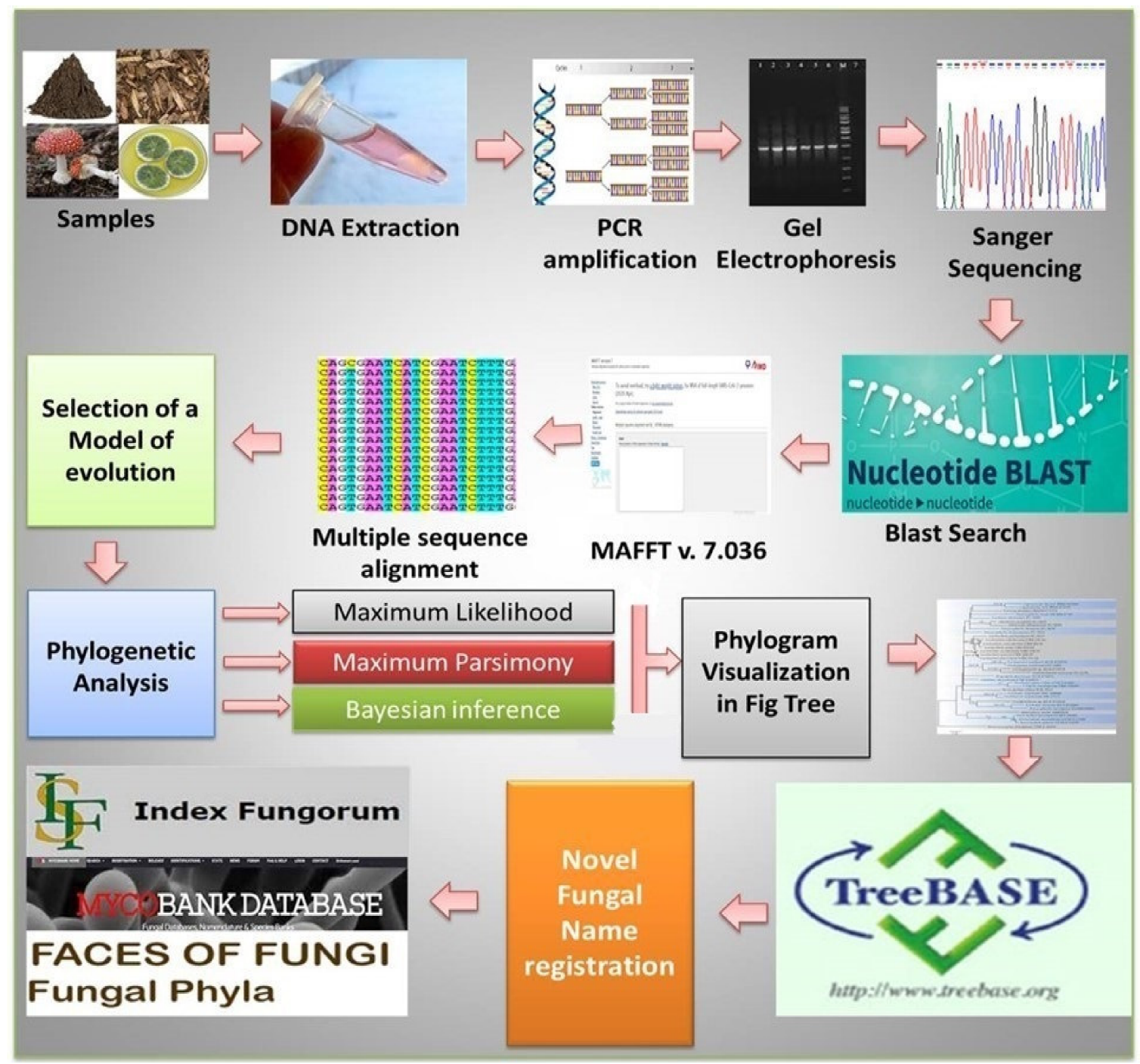

Figure 4. An overview of DNA-based molecular techniques used in fungal sample analyses.

\section{Molecular techniques}

\begin{tabular}{|c|c|c|}
\hline \multicolumn{3}{|c|}{ RNA Seq based next generation sequencing } \\
\hline \multicolumn{3}{|l|}{ PCR Base methods } \\
\hline \begin{tabular}{|l} 
- Conventional PCR \\
Nested PCR \\
\end{tabular} & $\begin{array}{l}\text { - RT PCR, Real time PCR } \\
\text { - SAGE }\end{array}$ & - Barcoding \\
\hline \multicolumn{2}{|c|}{ DNA/RNA probe based methods } & \\
\hline \begin{tabular}{|l} 
In-situ hybridization \\
$\therefore$ FISH
\end{tabular} & * Northern blotting & \\
\hline \multicolumn{2}{|c|}{ Post amplification techniques } & \\
\hline$\cdot$ Microarray & - Macroarray & \\
\hline \multicolumn{2}{|c|}{ Isothermal amplification base methods } & \\
\hline$\leadsto$ RCA & $\triangle$ NASBA & \\
\hline
\end{tabular}

Figure 5. Different molecular techniques used in DNA-based analyses of different fungi. 


\section{Polyphasic Identification}

The correct identification of species is a crucial goal in taxonomy. Information about each identified fungal species (e.g., biochemical properties, ecological roles, morphological description, physiological and societal risks or benefits) is a vital component in this process. Identification is a never-ending and apparently lengthy process with several amendments of the taxonomic outlines.

The polyphasic approaches comprise the use of varied procedures based on the grouping of scientific information. Various approaches such as biochemical, micro-and macromorphology, and molecular biology studies are applied (Figure 6). Microbial spectral analysis based on mass spectrometry (particularly matrix assisted laser desorption/ionization time-of-flight mass spectrometry//MALDI-TOF MS) has been developed and used as an important step in the polyphasic identification of fungi [355].

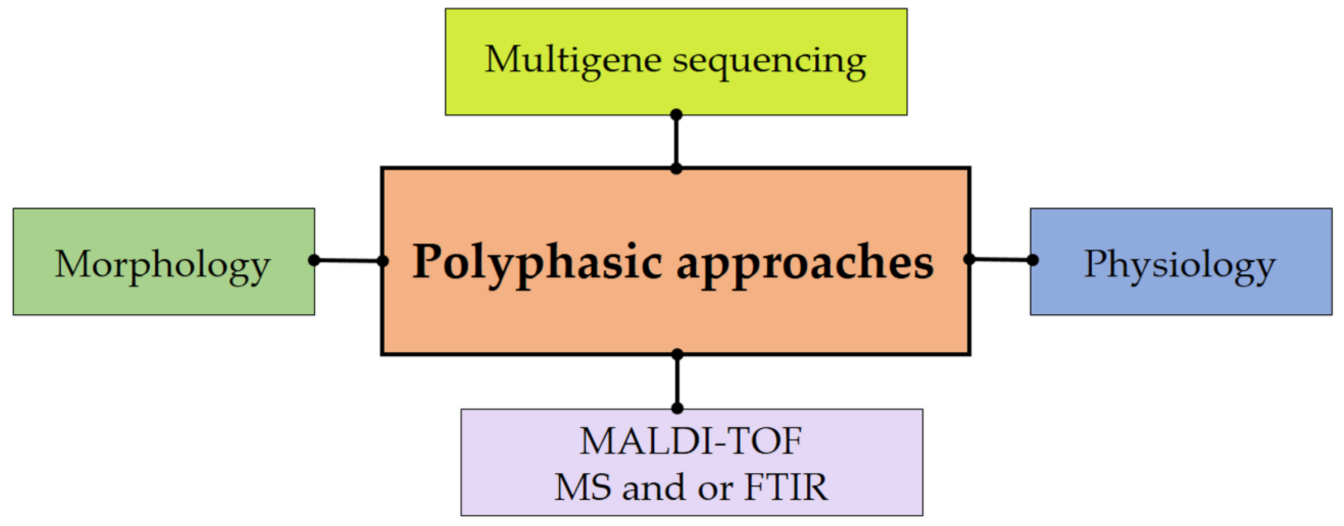

Figure 6. Modern polyphasic methodology of fungal identification.

A polyphasic method based on ecology, morphology and molecular data based techniques (multigene sequencing) is highly advocated to identify the fungal species precisely. Phylogenetic analyses have been comprehensively used to interpret species limitations in several fungal genera $[356,357]$ shown in Table 7 . There are several fungal species that have not been correctly identified. However, there are numerous boundaries associated with phylogenetic analyses for species identification [358,359]. There is an absence of molecular data for many fungal species, including reference sequences, and few species only have ITS sequences, which obstructs molecular-based techniques [360,361]. Moreover, phylogenetic analyses do not account for hybridization events and horizontal gene transfer [359]. The internal transcribed spacer (ITS) region has been accepted as a nearly universal barcode for fungi owing to the ease of amplification and its wide utility across the kingdom; however, it can often only be used for placement of taxa up to the genus level [361,362]. There is also a lack of ex-type or authenticated sequences for several pathogenic genera [355]. The identification of species boundaries is, thus, important to better understand genetic variation in nature to develop sustainable control measures [363].

It is also recommended to use diverse methods, including Bayesian inference, maximum likelihood, maximum parsimony coupled with automatic barcode gap discovery, coalescent-based methods or genealogical concordance phylogenetic species recognition to explore species boundaries in various fungal genera [358,360,364]. 
Table 7. An overview of polyphasic approach on analyses of plant pathogenic fungi.

\begin{tabular}{|c|c|c|c|c|}
\hline Family & Genus & $\begin{array}{l}\text { Genetic Marker for } \\
\text { Genus Level }\end{array}$ & $\begin{array}{l}\text { Genetic Markers for } \\
\text { Species Level }\end{array}$ & References \\
\hline Pleosporaceae & Alternaria & LSU and SSU & $\begin{array}{c}\text { ITS, GAPDH, rpb2 and } \\
\text { tef1- } \alpha\end{array}$ & [365-368] \\
\hline Physalacriaceae & Armillaria & ITS & ITS, IGS1 and tef1- $\alpha$ & {$[369,370]$} \\
\hline Botryosphaeriaceae & Barriopsis & ITS & tef1- $\alpha$ & {$[371,372]$} \\
\hline Didymellaceae & $\begin{array}{c}\text { Ascochyta, Boeremia, } \\
\text { Didymella, Epicoccum, } \\
\text { Phoma }\end{array}$ & LSU and ITS & $r p b 2$, tub2 and tef1- $\alpha$ & [373-376] \\
\hline Pleosporaceae & Bipolaris & GPDH & ITS, tef1- $\alpha$ and GPDH & [377] \\
\hline Botryosphaeriaceae & Botryosphaeria & LSU, SSU and ITS & tub and tef1- $\alpha$ & {$[378,379]$} \\
\hline Nectriaceae & $\begin{array}{c}\text { Calonectria, } \\
\text { Cylindrocladium }\end{array}$ & LSU and ITS & $\begin{array}{c}\text { ITS, tub, tef1- } \alpha, c m d A, \text { His3 } \\
\text { and } A C T\end{array}$ & [380-384] \\
\hline Mycosphaerellaceae & Cercospora & LSU and ITS & $\begin{array}{l}\text { ITS, tef1- } \alpha, A C T, C A L, H I S, \\
\text { tub2, rpb2 and GAPDH }\end{array}$ & [385-389] \\
\hline Cryptobasidiaceae & Clinoconidium & ITS and LSU & ITS and LSU & [390-392] \\
\hline Choanephoraceae & Choanephora & ITS & ITS & [393] \\
\hline Glomerellaceae & Colletotrichum & $\begin{array}{c}\text { GPDH, tub; } \\
\text { ApMat-Intergenic region of } \\
\text { apn2 and MAT1-2-1 genes } \\
\text { can resolve within the } \\
\text { C. gloeosporioides complex }\end{array}$ & $\begin{array}{c}\text { GS-glutamine } \\
\text { synthetase-CHS-1, } \\
\text { HIS3-Histone3 and } \\
\text { ACT-Actin-Placement } \\
\text { within the genus and also } \\
\text { some species-level } \\
\text { delineation }\end{array}$ & [394-396] \\
\hline Schizoparmaceae & Coniella & LSU and ITS & $\begin{array}{c}\text { ITS, LSU, tef1- } \alpha, r p b 2 \text { and } \\
\text { His3 }\end{array}$ & [397-401] \\
\hline Pleosporaceae & Curvularia & LSU & GDPH & [402-404] \\
\hline Nectriaceae & Cylindrocladiella & ITS and LSU & HIS, tef1- $\alpha$ and tub2 & {$[405,406]$} \\
\hline Cyphellophoraceae & Cyphellophora & LSU and SSU & ITS, LSU, tub2 and $r p b 1$ & {$[407,408]$} \\
\hline Botryosphaeriaceae & Diplodia & ITS, tef1- $\alpha$ and $t u b$ & LSU and SSU & {$[378,409]$} \\
\hline Botryosphaeriaceae & Dothiorella & $t u b$ & tef1- $\alpha$ & {$[378,410]$} \\
\hline Elsinoaceae & Elsinoe & ITS & $r p b 2$ and tef1- $\alpha$ & {$[411,412]$} \\
\hline Xylariaceae & Entoleuca & LSU and ITS & $r p b 2$ and $t u b 2$ & [413] \\
\hline Entylomataceae & Entyloma & ITS & ITS & {$[80,414,415]$} \\
\hline Corticiaceae & Erythricium & LSU & ITS & [416] \\
\hline Botryosphaeriaceae & Eutiarosporella & LSU and SSU & ITS and LSU & {$[372,417,418]$} \\
\hline Hymenochaetaceae & Fomitiporia & ITS & LSU, ITS, tef1- $\alpha$ and $r p b 2$ & {$[419-423]$} \\
\hline Hymenochataceae & Fulvifomes & LSU & ITS, tef1- $\alpha$ and $r p b 2$ & {$[424,425]$} \\
\hline Nectriaceae & Fusarium & $\begin{array}{l}\text { ATP citrate lyase (Acl1), } \\
\text { tef1- } \alpha \text { and ITS }\end{array}$ & $\begin{array}{l}\text { Calmodulin encoding gene } \\
(C m d A), t u b 2, t e f 1-\alpha, r p b 1 \\
\text { and } r p b 2\end{array}$ & [426-428] \\
\hline Ganodermataceae & Ganoderma & ITS & $r p b 2$ and tef1- $\alpha$ & {$[429-435]$} \\
\hline Erysiphaceae & Golovinomyces & ITS and LSU & $\begin{array}{c}\text { ITS and LSU, IGS, rpb2 } \\
\text { and CHS }\end{array}$ & [436-440] \\
\hline Bondarzewiaceae & Heterobasidion & LSU & $r p b 1$ and $r p b 2$ & [441] \\
\hline
\end{tabular}


Table 7. Cont.

\begin{tabular}{|c|c|c|c|c|}
\hline Family & Genus & $\begin{array}{l}\text { Genetic Marker for } \\
\text { Genus Level }\end{array}$ & $\begin{array}{l}\text { Genetic Markers for } \\
\text { Species Level }\end{array}$ & References \\
\hline Nectriaceae & Ilyonectria & ITS, LSU, tef1- $\alpha$ and tub2 & tef1- $\alpha$, tub2 and His3 & {$[442-446]$} \\
\hline Corticiaceae & Laetisaria, Limonomyces & LSU & ITS & {$[447,448]$} \\
\hline Botryosphaeriaceae & Lasiodiplodia & SSU and LSU & ITS, tef1- $\alpha$ and $t u b 2$ & {$[378,449]$} \\
\hline Botryosphaeriaceae & Macrophomina & LSU and SSU & $\begin{array}{c}\text { ITS, tef1- } \alpha, A C T, C m d A \text { and } \\
t u b 2\end{array}$ & {$[378,450]$} \\
\hline Medeolariaceae & Medeolaria & ITS & ITS & [451] \\
\hline Caloscyphaceae & Caloscypha & SSU and LSU & SSU, LSU & [452] \\
\hline Meliolaceae & Meliola & LSU and SSU & ITS & {$[453,454]$} \\
\hline Mucoraceae & Mucor & LSU and SSU & ITS and $r p b 1$ & [455-459] \\
\hline Erysiphaceae & Neoerysiphe & ITS and LSU & ITS & {$[460-462]$} \\
\hline Dermataceae & Neofabraea & LSU & ITS, LSU, $r p b 2$ and $t u b 2$ & {$[463]$} \\
\hline Botryosphaeriaceae & Neofusicoccum & SSU, LSU & ITS, tef1- $\alpha, t u b 2$ and $r p b 2$ & {$[464]$} \\
\hline Nectriaceae & Neonectria & LSU, ITS, tef1- $\alpha$ and tub2 & ITS, tef1- $\alpha$ and $t u b 2$ & [446] \\
\hline Sporocadaceae & Neopestalotiopsis & LSU & ITS, tub2 and tef1- $\alpha$ & {$[465-467]$} \\
\hline Didymellaceae & Nothophoma & LSU and ITS & tub2 and $r p b 2$ & [468-471] \\
\hline Sporocadaceae & Pestalotiopsis & LSU & ITS, tub2 and tef1- $\alpha$ & {$[472,473]$} \\
\hline Togninicaceae & Phaeoacremonium & SSU and LSU & $A C T$ and $t u b 2$ & {$[474-476]$} \\
\hline Hymenochataceae & Phellinotus & LSU & ITS, tef1- $\alpha$ and $r p b 2$ & [477] \\
\hline Hymenochaetaceae & Phellinus & LSU & ITS, tef1- $\alpha$ and $r p b 2$ & {$[478-481]$} \\
\hline Phyllostictaceae & Phyllosticta & ITS & $\begin{array}{c}\text { ITS, LSU, tef1- } \alpha, \text { GAPDH } \\
\text { and } A C T\end{array}$ & {$[57,482,483]$} \\
\hline Peronosporacae & Phytophthora & LSU, SSU and COX2 & LSU, tub2 and COX2 & {$[484,485]$} \\
\hline Peronosporaceae & Plasmopara & LSU & LSU & [486] \\
\hline Leptosphaeriaceae & Plenodomus & LSU & ITS, $t u b 2$ and $r p b 2$ & [487] \\
\hline Sporocadaceae & Pseudopestalotiopsis & LSU & ITS, tub2 and tef1- $\alpha$ & {$[488,489]$} \\
\hline Pyriculariaceae & Pseudopyricularia & LSU and $r p b 1$ & $A C T, r p b 1$, ITS and $C A L$ & {$[490,491]$} \\
\hline Saccotheciaceae & Pseudoseptoria & LSU & LSU, ITS and $r p b 2$ & {$[492,493]$} \\
\hline Rhizopodaceae & Rhizopus & ITS and $r p b 1$ & SSU, LSU and $A C T$ & [494-496] \\
\hline Xylariaceae & Rosellinia & LSU and ITS & ITS & [497-500] \\
\hline Didymellaceae & Stagonosporopsis & ITS & tub2 and $r p b 2$ & {$[373,501,502]$} \\
\hline Pleosporaceae & Stemphylium & ITS & $C m d A$ and $G A P D H$ & {$[503-506]$} \\
\hline Dothidotthiaceae & Thyrostroma & LSU & ITS, tef1- $\alpha, r p b 2$ and $t u b 2$ & {$[507,508]$} \\
\hline Tilletiaceae & Tilletia & LSU & ITS & {$[509-512]$} \\
\hline Ustilaginaceae & Ustilago & LSU & ITS & {$[53,513]$} \\
\hline Venturiaceae & Venturia & LSU and SSU & ITS & {$[514,515]$} \\
\hline
\end{tabular}

\section{Conclusions and Future Perspectives}

After compiling this manuscript, it was concluded thatabout 4-5 million species of fungi are distributed all across the globe, and less than $2 \%$ of them have been described to date. Different estimates of fungal species ranging between 0.1-9.9 million have been provided by different mycologists working continuously on the taxonomy and diversity of fungi. The addition of new fungal taxa (genera and species) is an ongoing process, as a 
number of natural environments and a variety of habitatsare still waiting to be explored in terms of their fungal diversity. Based on a regression relationship between time and described fungal species, the description rate of fungi was calculated, and new proposed estimates were also presented. As per the description rate observed after this regression relationship, the estimation of 1.5 million fungal species could be achieved by the year 2184, while the estimation of 2.2 million could be achieved by 2210 and 5.1 million by 2245 .

Both classical and DNA-based methods to study fungi have their own utility and importance. While classical methods are still used widely due to low cost, ease of identifying species and ability to sample wide areas or many pieces of substrata, modern methods have also gained popularity due to their accuracy in characterizing the fungi which are not possible with traditional classical methods. When traditional morphology based species identification utilizes the overall morphology of an organism, DNA-based modern techniques require a very small amount of fungal sample. However, modern mycologists have accepted integrated approaches using both morphological and molecular data.

In the integral approach of traditional and modern methods of fungal analyses, fungal culture plays an important role. Production of different morphs on culture and other accessory structures are important for identification and characterization. Due to this non sporulation of many fungi neither on the natural substrate nor artificial culture media, the modern DNA-based technique proved to be more efficient to understand their taxonomy. New generation sequencing or metagenomic techniques are of much use to analyze the fungal diversity of different environments. There area large number of sequences from environmental samples (unculturable and dark taxa) available in GenBank which signifies the use of modern methods to describe many important fungi. The advancement in sequencing technologies of DNA and RNA is regularly helping researchers to study fungi in an integrative way and understand their biology, ecology and taxonomy in a better way. More than a billion HTS-derived ITS reads are available publicly in available databases and can be used by researchers during various mycological studies. It is important to use this data to assemble evidence hitherto overlooked, as well as new hypotheses, research questions and theories. If cultures of all fungi are deposited in culture collections and made easily available to researchers, it may perhaps add value to basic taxonomy research.

The future of fungal taxonomy is challenging, as fungal systematics research requires well-trained mycologists with good expertise in traditional fungal classification, molecular systematics and bioinformatics/genomics. In order to produce experienced mycologists, the number of training programmers on fungal systematics should be organized more frequently for younger researchers. Molecular systematics training is comparatively expensive in nature and requires a decent facility for sequencing and/orcomputation. Research funding is not so uniform for taxonomic studies and is one of the possible reasons for declining fungal taxonomists. If this all goes at the same pace, the lack of well-trained fungal taxonomists will be a problem not only in the field of fungal taxonomy, but other scientific fields that rely on knowledge of fungal biodiversity and evolutionary biology. Therefore, adequate funding for research on taxonomic work is necessary to come out of this deprived situation. For young minds in college or plant pathology departments, more field research and highly advanced training programs should be organized to stimulate their interest in mycology.

Author Contributions: Conceptualization, A.K.G. and R.K.V.; methodology, A.K.G. and S.A.; software, R.K.V., A.K.G., B.D. and M.N.; validation, A.K.G., R.K.V., N.S. and S.A.; formal analysis, A.K.G., N.S., Y.B. and M.N.; investigation, A.K.G. and R.K.V.; resources, A.K.G., R.K.V., S. and N.S.; data curation, A.K.G., R.K.V. and N.S.; writing-original draft preparation, A.K.G., R.K.V. and N.S.; writing-review and editing, N.S. and A.K.G.; visualization, N.S., R.K.V. and A.K.G.; supervision, A.K.G. and N.S.; project administration, A.K.G., R.K.V. and N.S.; funding acquisition, N.S. All authors have read and agreed to the published version of the manuscript.

Funding: This research received no external funding.

Institutional Review Board Statement: Not applicable. 
Informed Consent Statement: Not applicable.

Data Availability Statement: Not applicable.

Acknowledgments: Authors wish to thank their respective organizations for providing the necessary laboratory facilities and valuable support during the study. The publication of this article was support by Chiang Mai University, Thailand.

Conflicts of Interest: The authors declare no conflict of interest.

\section{References}

1. Tsioumani, E.; Tsioumanis, A. International Institute for Sustainable Development Photo: NASA (CC0 1.0) STILL ONLY ONE EARTH: Lessons from 50 Years of UN Sustainable Development Policy Biological Diversity: Protecting the Variety of Life on Earth Key Messages. 2020. Available online: https://www.iisd.org/system/files/2020-09/still-one-earth-biodiversity.pdf (accessed on 15 October 2021).

2. Schmit, J.P.; Mueller, G.M. An estimate of the lower limit of global fungal diversity. Biodivers. Conserv. 2007, 16, 99-111. [CrossRef]

3. Wu, B.; Hussain, M.; Zhang, W.; Stadler, M.; Liu, X.; Xiang, M. Current insights into fungal species diversity and perspective on naming the environmental DNA sequences of fungi. Mycology 2019, 10, 127-140. [CrossRef] [PubMed]

4. Hasan, S.; Gupta, G. Fungal Biodiversity: Evolution \& Distribution-A Review. Int. J. Appl. Res. Stud. 2012, 1, 1-8.

5. Cox, R.J. Polyketides, proteins and genes in fungi: Programmed nano-machines begin to reveal their secrets. Org. Biomol. Chem. 2007, 5, 2010-2026. [CrossRef]

6. Devi, R.; Kaur, T.; Kour, D.; Rana, K.L.; Yadav, A.; Yadav, A.N. Beneficial fungal communities from different habitats and their roles in plant growth promotion and soil health. Microb. Biosyst. 2020, 5, 21-47. [CrossRef]

7. Rana, K.L.; Kour, D.; Sheikh, I.; Yadav, N.; Yadav, A.N.; Kumar, V.; Singh, B.P.; Dhaliwal, H.S.; Saxena, A.K. Biodiversity of endophytic fungi from diverse niches and their biotechnological applications. In Advances in Endophytic Fungal Research; Springer International Publishing: Cham, Switzerland, 2019; pp. 105-144.

8. Berbee, M.L.; James, T.Y.; Strullu-Derrien, C. Early Diverging Fungi: Diversity and Impact at the Dawn of Terrestrial Life. Annu. Rev. Microbiol. 2017, 71, 41-60. [CrossRef]

9. $\quad$ Lücking, R.; Aime, M.C.; Robbertse, B.; Miller, A.N.; Aoki, T.; Ariyawansa, H.A.; Cardinali, G.; Crous, P.W.; Druzhinina, I.S.; Geiser, D.M.; et al. Fungal taxonomy and sequence-based nomenclature. Nat. Microbiol. 2021, 6, 540-548. [CrossRef]

10. Blackwell, M. The fungi: 1, 2, 3 .. 5.1 million species? Am. J. Bot. 2011, 98, 426-438. [CrossRef]

11. Hawksworth, D.L.; Lücking, R. Fungal diversity revisited: 2.2 to 3.8 million species. Microbiol. Spectr. 2017, 5. [CrossRef]

12. Hawksworth, D.L. The fungal dimension of biodiversity: Magnitude, significance, and conservation. Mycol. Res. 1991, 95, 641-655. [CrossRef]

13. Peršoh, D. Plant-associated fungal communities in the light of meta'omics. Fungal Divers. 2015, 75, 1-25. [CrossRef]

14. Bálint, M.; Bahram, M.; Eren, A.M.; Faust, K.; Fuhrman, J.; Lindahl, B.; O’Hara, R.B.; Öpik, M.; Sogin, M.L.; Unterseher, M.; et al. Millions of reads, thousands of taxa: Microbial community structure and associations analyzed via marker genes. FEMS Microbiol. Rev. 2016, 40, 686-700. [CrossRef] [PubMed]

15. Wojciechowska, I. The Leather Underground: Biofabrication Offers New Sources for Fabrics. AATCC Rev. 2017, 17, 18-23. [CrossRef]

16. Jones, M.; Bhat, T.; Huynh, T.; Kandare, E.; Yuen, K.K.R.; Wang, C.-H.; John, S. Waste-derived low-cost mycelium composite construction materials with improved fire safety. Fire Mater. 2018, 42, 816-825. [CrossRef]

17. Wijayawardene, N.N.; Hyde, K.; Al-Ani, L.; Tedersoo, L.; Haelewaters, D.; Rajeshkumar, K.; Zhao, R.; Aptroot, A.; Leontyev, D.; Saxena, R.K.; et al. Outline of fungi and fungus-like taxa. Mycosphere 2020, 11, 1060-1456. [CrossRef]

18. Tedersoo, L.; Sánchez-Ramírez, S.; Kõljalg, U.; Bahram, M.; Döring, M.; Schigel, D.; May, T.; Ryberg, M.; Abarenkov, K. High-level classification of the Fungi and a tool for evolutionary ecological analyses. Fungal Divers. 2018, 90, 135-159. [CrossRef]

19. Wijayawardene, N.N.; Pawłowska, J.; Letcher, P.M.; Kirk, P.M.; Humber, R.A.; Schüßler, A.; Wrzosek, M.; Muszewska, A.; Okrasińska, A.; Istel, Ł.; et al. Notes for genera: Basal clades of fungi (including Aphelidiomycota, Basidiobolomycota, Blastocladiomycota, Calcarisporiellomycota, Caulochytriomycota, Chytridiomycota, Entomophthoromycota, Glomeromycota, Kickxellomycota, Monoblepharomycota, Mortierellomycota, Mucoromycota, Neocallimastigomycota, Olpidiomycota, Rozellomycota and Zoopagomycota). Fungal Divers. 2018, 92, 43-129.

20. James, T.Y.; Stajich, J.E.; Hittinger, C.T.; Rokas, A. Toward a Fully Resolved Fungal Tree of Life. Annu. Rev. Microbiol. 2020, 74, 291-313. [CrossRef]

21. Rossman, A.Y.; Allen, W.C.; Braun, U.; Castlebury, L.; Chaverri, P.; Crous, P.W.; Hawksworth, D.L.; Hyde, K.D.; Johnston, P.; Lombard, L.; et al. Overlooked competing asexual and sexually typified generic names of Ascomycota with recommendations for their use or protection. IMA Fungus 2016, 7, 289-308. [CrossRef]

22. Wijayawardene, N.N.; Hyde, K.D.; Rajeshkumar, K.C.; Hawksworth, D.L.; Madrid, H.; Kirk, P.M.; Braun, U.; Singh, R.V.; Crous, P.W.; Kukwa, M.; et al. Notes for genera: Ascomycota. Fungal Divers. 2017, 86, 1-594. [CrossRef]

23. Wijayawardene, N.N.; Hyde, K.D.; Tibpromma, S.; Wanasinghe, D.N.; Thambugala, K.M.; Tian, Q.; Wang, Y. Towards incorporating asexual fungi in a natural classification: Checklist and notes 2012-2016. Mycosphere 2017, 8, 1457-1555. [CrossRef] 
24. Rossman, A.Y.; Seifert, K.A.; Samuels, G.J.; Minnis, A.M.; Schroers, H.J.; Lombard, L.; Crous, P.W.; Põldmaa, K.; Cannon, P.F.; Summerbell, R.C.; et al. Genera in Bionectriaceae, Hypocreaceae, and Nectriaceae (Hypocreales) proposed for acceptance or rejection. IMA Fungus 2013, 4, 41-51. [CrossRef] [PubMed]

25. Mortimer, P.E.; Jeewon, R.; Xu, J.-C.; Lumyong, S.; Wanasinghe, D.N. Morpho-Phylo Taxonomy of Novel Dothideomycetous Fungi Associated with Dead Woody Twigs in Yunnan Province, China. Front. Microbiol. 2021, 12, e654683. [CrossRef]

26. Wijayawardene, N.N.; Crous, P.W.; Kirk, P.M.; Hawksworth, D.L.; Boonmee, S.; Braun, U.; Dai, D.-Q.; D’Souza, M.J.; Diederich, P.; Dissanayake, A.J.; et al. Naming and outline of Dothideomycetes-2014 including proposals for the protection or suppression of generic names. Fungal Divers. 2014, 69, 1-55. [CrossRef]

27. Rossman, A.Y.; Crous, P.W.; Hyde, K.D.; Hawksworth, D.L.; Aptroot, A.; Bezerra, J.L.; Bhat, J.D.; Boehm, E.; Braun, U.; Boonmee, S.; et al. Recommended names for pleomorphic genera in Dothideomycetes. IMA Fungus 2015, 6, 507-523. [CrossRef] [PubMed]

28. Hongsanan, S.; Hyde, K.D.; Phookamsak, R.; Wanasinghe, D.N.; McKenzie, E.H.C.; Sarma, V.V.; Lücking, R.; Boonmee, S.; Bhat, J.D.; Liu, N.-G.; et al. Refined families of Dothideomycetes: Orders and families incertaesedis in Dothideomycetes. Fungal Divers. 2020, 105, 17-318. [CrossRef]

29. Hongsanan, S.; Hyde, K.D.; Phookamsak, R.; Wanasinghe, D.N.; McKenzie, E.H.C.; Sarma, V.V.; Boonmee, S.; Lücking, R.; Bhat, D.J.; Liu, N.G. Refined families of Dothideomycetes: Dothideomycetidae and Pleosporomycetidae. Mycosphere 2020, 11, $1533-2107$. [CrossRef]

30. Johnston, P.R.; Seifert, K.A.; Stone, J.K.; Rossman, A.Y.; Marvanová, L. Recommendations on generic names competing for use in Leotiomycetes (Ascomycota). IMA Fungus 2014, 5, 91-120. [CrossRef] [PubMed]

31. Zhang, N.; Luo, J.; Rossman, A.Y.; Aoki, T.; Chuma, I.; Crous, P.W.; Dean, R.; de Vries, R.; Donofrio, N.; Hyde, K.D.; et al. Generic names in Magnaporthales. IMA Fungus 2016, 7, 155-159. [CrossRef]

32. Baral, H.-O.; Weber, E.; Gams, W.; Hagedorn, G.; Liu, B.; Liu, X.; Marson, G.; Marvanová, L.; Stadler, M.; Weiß, M. Generic names in the Orbiliaceae (Orbiliomycetes) and recommendations on which names should be protected or suppressed. Mycol. Prog. 2018, 17, 5-31. [CrossRef]

33. Ekanayaka, A.H.; Hyde, K.D.; Jones, E.B.G.; Zhao, Q. Taxonomy and phylogeny of operculate Discomycetes: Pezizomycetes. Fungal Divers. 2018, 90, 161-243. [CrossRef]

34. Maharachchikumbura, S.S.N.; Hyde, K.D.; Jones, E.B.G.; McKenzie, E.H.C.; Huang, S.-K.; Abdel-Wahab, M.A.; Daranagama, D.A.; Dayarathne, M.; D'Souza, M.J.; Goonasekara, I.D.; et al. Towards a natural classification and backbone tree for Sordariomycetes. Fungal Divers. 2015, 72, 199-301. [CrossRef]

35. Maharachchikumbura, S.S.N.; Hyde, K.D.; Jones, E.B.G.; McKenzie, E.H.C.; Bhat, J.D.; Dayarathne, M.C.; Huang, S.-K.; Norphanphoun, C.; Senanayake, I.C.; Perera, R.H.; et al. Families of Sordariomycetes. Fungal Divers. 2016, 79, 1-317. [CrossRef]

36. Hyde, K.D.; Norphanphoun, C.; Maharachchikumbura, S.S.N.; Bhat, D.J.; Jones, E.B.G.; Bundhun, D.; Chen, Y.J.; Bao, D.F.; Boonmee, S.; Calabon, M.S.; et al. Refined families of Sordariomycetes. Mycosphere 2020, 11, 305-1059. [CrossRef]

37. Réblová, M.; Untereiner, W.A.; Štěpánek, V.; Gams, W. Disentangling Phialophora section Catenulatae: Disposition of taxa with pigmented conidiophores and recognition of a new subclass, Sclerococcomycetidae (Eurotiomycetes). Mycol. Prog. 2017, 16, 27-46. [CrossRef]

38. Smith, G.J.; Liew, E.C.Y.; Hyde, K.D. The Xylariales: A monophyletic order containing 7 families. Fungal Divers. 2003, 13, 185-218.

39. Senanayake, I.C.; Maharachchikumbura, S.; Hyde, K.D.; Bhat, J.D.; Jones, E.B.G.; McKenzie, E.H.C.; Dai, D.Q.; Daranagama, D.A.; Dayarathne, M.C.; Goonasekara, I.D.; et al. Towards unraveling relationships in Xylariomycetidae (Sordariomycetes). Fungal Divers. 2015, 73, 73-144. [CrossRef]

40. Healy, R.A.; Bonito, G.; Trappe, J.M. Calongea, a new genus of truffles in the Pezizaceae (Pezizales). Anales del JardinBotánico de Madrid 2009, 66, 25-32. [CrossRef]

41. Hawksworth, D.L.; Eriksson, O.E. The names of accepted orders of ascomycetes. Syst. Ascomycetum 1986, 5, 175-184.

42. Weir, A.; Blackwell, M. Molecular data support the Laboulbeniales as a separate class of Ascomycota, Laboulbeniomycetes. Mycol. Res. 2001, 105, 1182-1190. [CrossRef]

43. Moncalvo, J.-M.; Vilgalys, R.; Redhead, S.A.; Johnson, J.E.; James, T.Y.; Aime, M.C.; Hofstetter, V.; Verduin, S.J.; Larsson, E.; Baroni, T.J.; et al. One hundred and seventeen clades of euagarics. Mol. Phylogenet. Evol. 2002, 23, 357-400. [CrossRef]

44. Aime, M.C. Toward resolving family-level relationships in rust fungi (Uredinales). Mycoscience 2006, 47, 112-122. [CrossRef]

45. Aime, M.C.; Matheny, P.B.; Henk, D.A.; Frieders, E.M.; Nilsson, R.H.; Piepenbring, M.; McLaughlin, D.J.; Szabo, L.J.; Begerow, D.; Sampaio, J.P.; et al. An overview of the higher level classification of Pucciniomycotina based on combined analyses of nuclear large and small subunit RDNA sequences. Mycologia 2006, 98, 896-905. [CrossRef] [PubMed]

46. Perry, B.A.; Hansen, K.; Pfister, D.H. A phylogenetic overview of the family Pyronemataceae (Ascomycota, Pezizales). Mycol. Res. 2007, 111, 549-571. [CrossRef]

47. Hibbett, D.S.; Binder, M.; Bischoff, J.F.; Blackwell, M.; Cannon, P.F.; Eriksson, O.E.; Huhndorf, S.; James, T.; Kirk, P.M.; Lücking, R.; et al. A higher-level phylogenetic classification of the Fungi. Mycol. Res. 2007, 111, 509-547. [CrossRef]

48. Kirk, P.M.; Cannon, P.F.; Minter, D.W.; Stalpers, J.A. Dictionary of the Fungi, 10th ed.; CABI: Wallingford, UK, 2008.

49. Lumbsch, H.T.; Huhndorf, S.M. Myconet Volume 14. Part One. Outline of Ascomycota-2009. Part Two. Notes on Ascomycete Systematics. Nos. 4751-5113. Fieldiana Life Earth Sci. 2010, 1, 1-64. [CrossRef]

50. Oehl, F.; Alves a Silva, G.; Goto, B.T.; Costa Maia, L.; Sieverding, E. Glomeromycota: Two new classes andaneworder. Mycotaxon 2011, 116, 365-379. [CrossRef] 
51. Humber, R.A. Entomophthoromycota: A new phylum and reclassification for entomophthoroid fungi. Mycotaxon 2012, 120, 477-492. [CrossRef]

52. Wijayawardene, D.N.N.; McKenzie, E.H.C.; Hyde, K.D. Towards incorporating anamorphic fungi in a natural classification checklist and notes for 2011. Mycosphere 2012, 3, 157-228. [CrossRef]

53. McTaggart, A.R.; Shivas, R.G.; Geering, A.D.W.; Vánky, K.; Scharaschkin, T. Taxonomic revision of Ustilago, Sporisorium and Macalpinomyces. Persoonia 2012, 29, 116-132. [CrossRef]

54. Silva, G.; Maia, L.C.; Oehl, F. Phylogenetic systematics of the Gigasporales. Mycotaxon 2013, 122, 207-220. [CrossRef]

55. Kirk, P.M.; Stalpers, J.A.; Braun, U.; Crous, P.W.; Hansen, K.; Hawksworth, D.L.; Hyde, K.D.; Lücking, R.; Lumbsch, T.H.; Rossman, A.Y.; et al. A without-prejudice list of generic names of fungi for protection under the International Code of Nomenclature for algae, fungi, and plants. IMA Fungus 2013, 4, 381-443. [CrossRef]

56. Hansen, K.; Perry, B.A.; Dranginis, A.W.; Pfister, D.H. A phylogeny of the highly diverse cup-fungus family Pyronemataceae (Pezizomycetes, Ascomycota) clarifies relationships and evolution of selected life history traits. Mol. Phylogenet. Evol. 2013, 67, 311-335. [CrossRef] [PubMed]

57. Hyde, K.D.; Jones, E.B.G.; Liu, J.-K.; Ariyawansa, H.; Boehm, E.W.A.; Boonmee, S.; Braun, U.; Chomnunti, P.; Crous, P.W.; Dai, D.-Q.; et al. Families of Dothideomycetes. Fungal Divers. 2013, 63, 1-313. [CrossRef]

58. Hofstetter, V.; Redhead, S.A.; Kauff, F.; Moncalvo, J.-M.; Matheny, P.B.; Vilgalys, R. Taxonomic Revision and Examination of Ecological Transitions of the Lyophyllaceae (Basidiomycota, Agaricales) Based on a Multigene Phylogeny. Cryptogam. Mycol. 2014, 35, 399-425. [CrossRef]

59. Wang, Q.-M.; Yurkov, A.; Göker, M.; Lumbsch, H.; Leavitt, S.; Groenewald, M.; Theelen, B.; Liu, X.-Z.; Boekhout, T.; Bai, F.-Y. Phylogenetic classification of yeasts and related taxa within Pucciniomycotina. Stud. Mycol. 2015, 81, 149-189. [CrossRef]

60. Humber, R.A. Entomophthoromycota: A new overview of some of the oldest terrestrial fungi. In Biology of Microfungi; Springer International Publishing: Cham, Switzerland, 2016; pp. 127-145.

61. Benny, G.L.; Smith, M.E.; Kirk, P.M.; Tretter, E.D.; White, M.M. Challenges and future perspectives in the systematics of Kickxellomycotina, Mortierellomycotina, Mucoromycotina, and Zoopagomycotina. In Biology of Microfungi; Springer International Publishing: Cham, Switzerland, 2016; pp. 65-126.

62. Spatafora, J.W.; Chang, Y.; James, T.Y.; O’Donnell, K.; Roberson, R.W.; Taylor, T.N.; Uehling, J.; Vilgalys, R.; White, M.M.; Stajich, J.E.; et al. A phylum-level phylogenetic classification of Zygomycete fungi based on genome-scale data. Mycologia 2016, 108, 1028-1046. [CrossRef]

63. Galindo, L.J.; López-García, P.; Torruella, G.; Karpov, S.; Moreira, D. Phylogenomics of a new fungal phylum reveals multiple waves of reductive evolution across Holomycota. Nat. Commun. 2021, 12, 4973. [CrossRef]

64. Hibbett, D.S.; Abarenkov, K.; Koljalg, U.; Öpik, M.; Chai, B.; Cole, J.R.; Wang, Q.; Crous, P.; Robert, V.A.R.G.; Helgason, T.; et al. Sequence-based classification and identification of Fungi. Mycologia 2016, 108, 1049-1068.

65. Jaklitsch, W.M.; Gardiennet, A.; Voglmayr, H. Resolution of morphology-based taxonomic delusions: Acrocordiella, Basiseptospora, Blogiascospora, Clypeosphaeria, Hymenopleella, Lepteutypa, Pseudapiospora, Requienella, Seiridium and Strickeria. Persoonia 2016, 37, 82-105. [CrossRef]

66. Rossman, A.Y.; Udayanga, D.; Castlebury, L.A.; Hyde, K. Proposal to conserve the name Diaporthe eres against all other competing names (Ascomycota, Diaporthales, Diaporthaceae). Taxon 2014, 63, 934-935. [CrossRef]

67. Wijayawardene, N.N.; Hyde, K.D.; Wanasinghe, D.N.; Papizadeh, M.; Goonasekara, I.D.; Camporesi, E.; Bhat, D.J.; McKenzie, E.H.C.; Phillips, A.J.L.; Diederich, P.; et al. Taxonomy and phylogeny of dematiaceous coelomycetes. Fungal Divers. 2016, 77, 1-316. [CrossRef]

68. Desirò, A.; Rimington, W.R.; Jacob, A.; Pol, N.V.; Smith, M.E.; Trappe, J.M.; Bidartondo, M.I.; Bonito, G. Multigene phylogeny of Endogonales, an early diverging lineage of fungi associated with plants. IMA Fungus 2017, 8, 245-257. [CrossRef] [PubMed]

69. Lücking, R.; Hodkinson, B.P.; Leavitt, S.D. The 2016 classification of lichenized fungi in the Ascomycota and BasidiomycotaApproaching one thousand genera. Bryologist 2017, 119, 361-416. [CrossRef]

70. Malysheva, V.; Spirin, V. Taxonomy and phylogeny of the Auriculariales (Agaricomycetes, Basidiomycota) with stereoid basidiocarps. Fungal Biol. 2017, 121, 689-715. [CrossRef]

71. Hongsanan, S.; Maharachchikumbura, S.; Hyde, K.D.; Samarakoon, M.C.; Jeewon, R.; Zhao, Q.; Al-Sadi, A.; Bahkali, A.H. An updated phylogeny of Sordariomycetes based on phylogenetic and molecular clock evidence. Fungal Divers. 2017, 84, 25-41. [CrossRef]

72. Yang, T.; Groenewald, J.Z.; Cheewangkoon, R.; Jami, F.; Abdollahzadeh, J.; Lombard, L.; Crous, P.W. Families, genera, and species of Botryosphaeriales. Fungal Biol. 2017, 121, 322-346. [CrossRef]

73. Liu, J.-K.; Hyde, K.D.; Jeewon, R.; Phillips, A.; Maharachchikumbura, S.; Ryberg, M.; Liu, Z.-Y.; Zhao, Q. Ranking higher taxa using divergence times: A case study in Dothideomycetes. Fungal Divers. 2017, 84, 75-99. [CrossRef]

74. Justo, A.; Miettinen, O.; Floudas, D.; Ortiz-Santana, B.; Sjökvist, E.; Lindner, D.; Nakasone, K.; Niemelä, T.; Larsson, K.-H.; Ryvarden, L.; et al. A revised family-level classification of the Polyporales (Basidiomycota). Fungal Biol. 2017, 121, 798-824. [CrossRef]

75. Wijayawardene, N.N.; Hyde, K.D.; Lumbsch, T.; Liu, J.-K.; Maharachchikumbura, S.; Ekanayaka, A.H.; Tian, Q.; Phookamsak, R. Outline of Ascomycota: 2017. Fungal Divers. 2018, 88, 167-263. [CrossRef] 
76. Kraichak, E.; Huang, J.-P.; Nelsen, M.; Leavitt, S.D.; Lumbsch, H.T. A revised classification of orders and families in the two major subclasses of Lecanoromycetes (Ascomycota) based on a temporal approach. Bot. J. Linn. Soc. 2018, 188, 233-249. [CrossRef]

77. Letcher, P.M.; Powell, M.J. A taxonomic summary and revision of Rozella (Cryptomycota). IMA Fungus 2018, 9, 383-399. [CrossRef] [PubMed]

78. Aime, M.C.; Castlebury, L.; Abbasi, M.; Begerow, D.; Berndt, R.; Kirschner, R.; Marvanová, L.; Ono, Y.; Padamsee, M.; Scholler, M.; et al. Competing sexual and asexual generic names in Pucciniomycotina and Ustilaginomycotina (Basidiomycota) and recommendations for use. IMA Fungus 2018, 9, 75-89. [CrossRef] [PubMed]

79. Aime, M.C.; Bell, C.D.; Wilson, A.W. Deconstructing the evolutionary complexity between rust fungi (Pucciniales) and their plant hosts. Stud. Mycol. 2018, 89, 143-152. [CrossRef]

80. Goldmann, L.; Weir, A. Molecular phylogeny of the Laboulbeniomycetes (Ascomycota). Fungal Biol. 2018, 122, 87-100. [CrossRef]

81. Phillips, A.J.L.; Hyde, K.D.; Alves, A.; Liu, J.-K. Families in Botryosphaeriales: A phylogenetic, morphological and evolutionary perspective. Fungal Divers. 2019, 94, 1-22. [CrossRef]

82. Daranagama, D.A.; Hyde, K.D.; Sir, E.B.; Thambugala, K.M.; Tian, Q.; Samarakoon, M.C.; McKenzie, E.H.C.; Jayasiri, S.C.; Tibpromma, S.; Bhat, J.D.; et al. Towards a natural classification and backbone tree for Graphostromataceae, Hypoxylaceae, Lopadostomataceae and Xylariaceae. Fungal Divers. 2018, 88, 1-165. [CrossRef]

83. Sheikh, S.; Thulin, M.; Cavender, J.C.; Escalante, R.; Kawakami, S.-I.; Lado, C.; Landolt, J.C.; Nanjundiah, V.; Queller, D.C.; Strassmann, J.E.; et al. A New Classification of the Dictyostelids. Protist 2018, 169, 1-28. [CrossRef]

84. Bennett, R.; Thines, M. Revisiting Salisapiliaceae. Fungal Syst. Evol. 2019, 3, 171-185. [CrossRef]

85. Dayarathne, M.C.; Maharachchikumbura, S.S.N.; Jones, E.B.G.; Dong, W.; Devadatha, B.; Yang, J.; Ekanayaka, A.H.; De Silva, W.; Sarma, V.V.; Al-Sadi, A.M.; et al. Phylogenetic Revision of Savoryellaceae and Evidence for Its Ranking as a Subclass. Front. Microbiol. 2019, 10, 840. [CrossRef]

86. He, M.-Q.; Zhao, R.-L.; Hyde, K.D.; Begerow, D.; Kemler, M.; Yurkov, A.; McKenzie, E.H.C.; Raspé, O.; Kakishima, M.; SánchezRamírez, S.; et al. Notes, outline and divergence times of Basidiomycota. Fungal Divers. 2019, 99, 105-367. [CrossRef]

87. Johnston, P.R.; Quijada, L.; Carl, S.; López-Giráldez, F.; Wang, Z.; Townsend, J.P.; Smith, C.; Baral, H.-O.; Hosoya, T.; Baschien, C.; et al. A multigene phylogeny toward a new phylogenetic classification of Leotiomycetes. IMA Fungus 2019, 10, 1. [CrossRef] [PubMed]

88. Li, W.-J.; McKenzie, E.H.C.; Liu, J.-K.; Bhat, D.J.; Dai, D.-Q.; Camporesi, E.; Tian, Q.; Maharachchikumbura, S.S.N.; Luo, Z.-L.; Shang, Q.-J.; et al. Taxonomy and phylogeny of hyaline-spored Coelomycetes. Fungal Divers. 2020, 100, 279-801. [CrossRef]

89. Wijayawardene, N.N.; Dai, D.Q.; Tang, L.Z.; Fiuza, P.O.; Barbosa, F.R.; Cantillo-Perez, T.; Rajeshkumar, K.C. The genera of Coelomycetes; including genera of lichen forming, sexual morphs and synasexual morphs with coelomycetous morphs (A-C). MycoAsia 2020, 3, 1-92.

90. Aime, M.; McTaggart, A. A higher-rank classification for rust fungi, with notes on genera. Fungal Syst. Evol. 2021, 7, 21-47. [CrossRef] [PubMed]

91. Gautam, A.K.; Avasthi, S.; Verma, R.K.; Devadatha, B.; Jayawardena, R.S.; Sushma; Ranadive, K.R.; Kashyap, P.L.; Bhadauria, R.; Prasher, I.B.; et al. Indian Pucciniales: Taxonomic outline with important descriptive notes. Mycosphere 2021, 12, 89-162. [CrossRef]

92. Wijayawardene, N.N.; Hyde, K.D.; Anand, G.; Dissanayake, L.S.; Tang, L.Z.; Dai, D.Q. Towards incorporating asexually reproducing fungi in the natural classification and notes for pleomorphic genera. Mycosphere 2021, 12, 238-405. [CrossRef]

93. Aime, M.C.; Miller, A.N.; Aoki, T.; Bensch, K.; Cai, L.; Crous, P.W.; Hawksworth, D.L.; Hyde, K.D.; Kirk, P.M.; Lücking, R.; et al. How to publish a new fungal species, or name, version 3.0? IMA Fungus 2021, 12, e11. [CrossRef]

94. Heitman, J.; Howlett, B.J.; Crous, P.W.; Stukenbrock, E.H.; James, T.Y.; Gow, N.A.R. The Fungal Kingdom; John Wiley \& Sons: Hoboken, NJ, USA; American Society for Microbiology: Washington, DC, USA, 2017.

95. Blackwell, M.; Haelewaters, D.; Pfister, D.H. Laboulbeniomycetes: Evolution, natural history, and Thaxter's final word. Mycologia 2020, 112, 1048-1059. [CrossRef]

96. Genevieve, L.; Pierre-Luc, C.; Roxanne, G.-T.; Amélie, M.; Danny, B.; Vincent, M.; Hugo, G. Estimation of fungal diversity and identification of major abiotic drivers influencing fungal richness and communities in northern temperate and Boreal Quebec Forests. Forests 2019, 10, 1096. [CrossRef]

97. Wijayawardene, N.N.; Bahram, M.; Sánchez-Castro, I.; Dai, D.-Q.; Ariyawansa, K.G.S.U.; Jayalal, U.; Suwannarach, N.; Tedersoo, L. Current Insight into Culture-Dependent and Culture-Independent Methods in Discovering Ascomycetous Taxa. J. Fungi 2021, 7, 703. [CrossRef] [PubMed]

98. Willis, K.J. State of the World's Fungi; Report; Kew Publishing: Kew, UK, 2018.

99. Hawksworth, D.L. The magnitude of fungal diversity: The 1.5 million species estimate revisited. Mycol. Res. 2001, 105, 1422-1432. [CrossRef]

100. Hibbett, D.S.; Ohman, A.; Glotzer, D.; Nuhn, M.; Kirk, P.; Nilsson, R.H. Progress in molecular and morphological taxon discovery in Fungi and options for formal classification of environmental sequences. Fungal Biol. Rev. 2011, 25, 38-47. [CrossRef]

101. Dai, Y.-C.; Cui, B.; Si, J.; He, S.-H.; Hyde, K.D.; Yuan, H.-S.; Liu, X.-Y.; Zhou, L.-W. Dynamics of the worldwide number of fungi with emphasis on fungal diversity in China. Mycol. Prog. 2015, 14, 62. [CrossRef]

102. Bisby, G.; Ainsworth, G. The numbers of fungi. Trans. Br. Mycol. Soc. 1943, 26, 16-19. [CrossRef]

103. Martin, G.W. The numbers of fungi. Proc. Iowa Acad. Sci. 1951, 58, 175-178. 
104. Pascoe, I. History of systematic mycology in Australia. In History of Systematic Botany in Australia; Short, P.S., Ed.; Australian Syst. Bot. Soc.: South Yarra, Australia, 1990; pp. 259-264.

105. Hywel-Jones, N. A systematic survey of insect fungi from natural tropical forest in Thailand. In Aspects of Tropical Mycology; Isaac, S., Frankland, J.C., Watling, R., Whalley, A.J.S., Eds.; Cambridge University Press: Cambridge, UK, 1993; pp. $300-301$.

106. Hammond, P.M. The current magnitude of biodiversity. In Global Biodiversity Assessment; Heywood, V., Ed.; Cambridge University Press: Cambridge, UK, 1995; pp. 113-138.

107. Hammond, P.M. Species inventory. In Global Biodiversity: Status of the Earth's Living Resources; Groombridge, B., Ed.; Chapman and Hall: London, UK, 1992; pp. 17-39.

108. Smith, D.; Waller, J.M. Culture collections of microorganisms: Their importance in tropical plant pathology. Fitopatol. Bras. 1992, $17,1-8$.

109. Rossman, A.Y. Strategy for an all-taxa inventory of fungal biodiversity. In Biodiversity and Terrestrial Ecosystems; Peng, C.I., Chou, C.H., Eds.; Academia Sinica Monograph Series No. 14; Institute of BotanyAcademia Sinica: Taipei, Taiwan, $1994 ;$ pp. $169-194$.

110. Dreyfuss, M.M.; Chapela, I.H. Potential of fungi in the discovery of novel, low-molecular weight pharmaceuticals. In The Discovery of Natural Products with Therapeutic Potential; Gullo, V., Ed.; Butterworth Heinemann: London, UK, 1994 ; pp. 49-80.

111. Shivas, R.G.; Hyde, K.D. Biodiversity of plant pathogenic fungi in the tropics. In Biodiversity of Tropical Microfungi; Hyde, K.D., Ed.; Hong Kong University Press: Hong Kong, China, 1997; pp. 47-56.

112. May, R.M. The dimensions of life on earth. In Nature and Human Society: The Quest for a Sustainable World; Raven, P.H., Williams, T., Eds.; National Academy Press: Washington, DC, USA, 2000; pp. 30-45.

113. O'Brien, H.E.; Parrent, J.L.; Jackson, J.A.; Moncalvo, J.M.; Vilgalys, R. Fungal Community Analysis by Large-Scale Sequencing of Environmental Samples. Appl. Environ. Microbiol. 2005, 71, 5544-5550. [CrossRef]

114. Hyde, K.D.; Norphanphoun, C.; Chen, J.; Dissanayake, A.J.; Doilom, M.; Hongsanan, S.; Jayawardena, R.; Jeewon, R.; Perera, R.H.; Thongbai, B.; et al. Thailand's amazing diversity: Up to $96 \%$ of fungi in northern Thailand may be novel. Fungal Divers. 2018, 93, 215-239. [CrossRef]

115. Lücking, R.; Forno, M.D.; Sikaroodi, M.; Gillevet, P.M.; Bungartz, F.; Moncada, B.; Yánez-Ayabaca, A.; Chaves, J.L.; Coca, L.F.; Lawrey, J.D. A single macrolichen constitutes hundreds of unrecognized species. Proc. Natl. Acad. Sci. USA 2014, 111, 11091-11096. [CrossRef]

116. Lücking, R.; Johnston, M.K.; Kalb, K.; Mangold, A.; Manoch, L.; Mercado-Diaz, J.A.; Moncada, B.; Mongkolsuk, P.; Papong, K.B.; Parnmen, S.; et al. One hundred and seventy-five new species of Graphidaceae: Closing the gap or a drop in the bucket? Phytotaxa 2014, 189, 7-38. [CrossRef]

117. Aptroot, A.; Cáceres, M.E.S.; Johnston, M.K.; Lücking, R. How diverse is the lichenized fungal family Trypetheliaceae (Ascomycota: Dothideomycetes)? A quantitative prediction of global species richness. Lichenologist 2016, 48, 983-994. [CrossRef]

118. Lodge, D.J.; Ammirati, J.; O’Dell, T.E.; Mueller, G.M. Collecting and describing macrofungi. In Biodiversity of Fungi: Inventory and Monitoring Methods; Mueller, G.M., Bills, G.F., Foster, M.S., Eds.; Academic Press: New York, NY, USA, 2004 ; pp. $123-168$.

119. Straatsma, G.; Ayer, F.; Egli, S. Species richness, abundance, and phenology of fungal fruit bodies over 21 years in a Swiss forest plot. Mycol. Res. 2001, 105, 515-523. [CrossRef]

120. Schmit, J.P.; Murphy, J.F.; Mueller, G.M. Macrofungal diversity of a temperate oak forest: A test of species richness estimators. Can. J. Bot. 1999, 77, 1014-1027.

121. Huhndorf, S.M.; Lodge, D.J.; Wang, C.J.K.; Stokland, J. Macrofungi on woody substrata. In Biodiversity of Fungi: Inventory and Monitoring Methods; Mueller, G.M., Bills, G.F., Foster, M.S., Eds.; Academic Press: New York, NY, USA, $2004 ;$ pp. $123-168$.

122. Cantrell, S.A. Sampling methods to assess discomycete diversity in wet tropical forests. Caribb. J. Sci. 2004, 40, 8-16.

123. Lodge, D.J.; Cantrell, S. Diversity of litter agarics at Cuyabeno, Ecuador: Calibrating sampling efforts in tropical rainforest. Mycologist 1995, 9, 149-151. [CrossRef]

124. Polishook, J.D.; Bills, G.; Lodge, D.J. Microfungi from decaying leaves of two rain forest trees in Puerto Rico. J. Ind. Microbiol. Biotechnol. 1996, 17, 284-294. [CrossRef]

125. Rambelli, A.; Mulas, B.; Pasqualetti, M. Comparative studies on microfungi in tropical ecosystems in Ivory Coast forest litter: Behaviour on different substrata. Mycol. Res. 2004, 108, 325-336. [CrossRef]

126. Schnittler, M.; Stephenson, S.L. Myxomycete biodiversity in four different forest types in Costa Rica. Mycologia 2000, 92, 626-637. [CrossRef]

127. Bills, G.F.; Polishook, J.D. Selective isolation of fungi from dung of Odocoileus hemionus (mule deer). Nova Hedwigia 1993, 57, 195-206.

128. Krug, J.C.; Benny, G.L.; Keller, H.W. Coprophilous fungi. In Biodiversity of Fungi: Inventory and Monitoring Methods; Mueller, G.M., Bills, G.F., Foster, M.S., Eds.; Academic Press: New York, NY, USA, 2004; pp. 467-500.

129. Richardson, M.J. Diversity and occurrence of coprophilous fungi. Mycol. Res. 2001, 105, 387-402. [CrossRef]

130. Trappe, J.M.; Rossman, A.Y.; Tulloss, R.E.; O’Dell, T.E.; Thorn, R.G. Protocols for an All Taxa Biodiversity Inventory of Fungi in a Costa Rican Conservation Area. Mycologia 1998, 90, e1093. [CrossRef]

131. Hyde, K.D.; Soytong, K. The fungal endophyte dialema. Fungal Divers. 2008, 33, 163-173.

132. Bélanger, R.; Avis, T. Ecological processes and interactions in leaf surface fungi. In Phyllosphere Microbiology; Lindow, S.E., Hecht-Poinar, E.I., Elliot, V.J., Eds.; American Phytopathological Society Press: St. Paul, MN, USA, 2002; pp. $193-207$. 
133. Lindow, S.E.; Hecht-Poinar, E.I.; Elliot, V.J. Phyllosphere Microbiology; American Phytopathological Society Press: St. Paul, MN, USA, 2002.

134. Bills, G.F.; Polishook, J.D. Abundance and diversity of microfungi in leaf litter of a lowland rain forest in Costa Rica. Mycologia 1994, 86, 187-198. [CrossRef]

135. Bills, G.F.; Polishook, J.D. Microfungi from decaying leaves of Heliconia mariae (Heliconiaceae). Brenesia 1994, 41/42, 27-43.

136. Basu, S.; Bose, C.; Ojha, N.; Das, N.; Das, J.; Pal, M.; Khurana, S. Evolution of bacterial and fungal growth media. Bioinformation 2015, 11, 182-184. [CrossRef]

137. Hyde, K.D.; Hongsanan, S.; Jeewon, R.; Bhat, D.J.; McKenzie, E.H.C.; Jones, E.B.G.; Phookamsak, R.; Ariyawansa, H.; Boonmee, S.; Zhao, Q.; et al. Fungal diversity notes 367-490: Taxonomic and phylogenetic contributions to fungal taxa. Fungal Divers. 2016, 80, 1-270. [CrossRef]

138. Jeewon, R.; Hyde, K.D. Establishing species boundaries and new taxa among fungi: Recommendations to resolve taxonomic ambiguities. Mycosphere 2016, 7, 1669-1677. [CrossRef]

139. Manawasinghe, I.S.; Dissanayake, A.J.; Li, X.; Liu, M.; Wanasinghe, D.; Xu, J.; Zhao, W.; Zhang, W.; Zhou, Y.; Hyde, K.D.; et al. High Genetic Diversity and Species Complexity of Diaporthe Associated with Grapevine Dieback in China. Front. Microbiol. 2019, 10, e1936. [CrossRef]

140. Hyde, K.D.; Bahkali, A.H.; Moslem, M.A. Fungi-An unusual source for cosmetics. Fungal Divers. 2010, 43, 1-9. [CrossRef]

141. Senanayake, I.; Crous, P.; Groenewald, J.; Maharachchikumbura, S.; Jeewon, R.; Phillips, A.; Bhat, J.; Perera, R.; Li, Q.; Li, W.; et al. Families of Diaporthales based on morphological and phylogenetic evidence. Stud. Mycol. 2017, 86, 217-296. [CrossRef]

142. Senanayake, I.C.; Jeewon, R.; Chomnunti, P.; Wanasinghe, D.N.; Norphanphoun, C.; Karunarathna, A.; Pem, D.; Perera, R.H.; Camporesi, E.; McKenzie, E.H.C.; et al. Taxonomic circumscription of Diaporthales based on multigene phylogeny and morphology. Fungal Divers. 2018, 93, 241-443. [CrossRef]

143. Dissanayake, A.J.; Liu, M.; Zhang, W.; Chen, Z.; Udayanga, D.; Chukeatirote, E.; Li, X.H.; Yan, J.Y.; Hyde, K.D. Morphological and molecular characterization of Diaporthe species associated with grapevine trunk disease in China. Fungal Biol. 2015, 119, 283-294. [CrossRef] [PubMed]

144. Phukhamsakda, C.; McKenzie, E.H.C.; Phillips, A.J.L.; Jones, E.B.G.; Bhat, D.J.; Stadler, M.; Bhunjun, C.S.; Wanasinghe, D.N.; Thongbai, B.; Camporesi, E.; et al. Microfungi associated with Clematis (Ranunculaceae) with an integrated approach to delimiting species boundaries. Fungal Divers. 2020, 102, 1-203. [CrossRef]

145. Wibberg, D.; Stadler, M.; Lambert, C.; Bunk, B.; Spröer, C.; Rückert, C.; Kalinowski, J.; Cox, R.J.; Kuhnert, E. High quality genome sequences of thirteen Hypoxylaceae (Ascomycota) strengthen the phylogenetic family backbone and enable the discovery of new taxa. Fungal Divers. 2021, 106, 7-28. [CrossRef]

146. de Silva, N.I.; Maharachchikumbura, S.S.N.; Thambugala, K.M.; Bhat, D.J.; Karunarathna, S.C.; Tennakoon, D.S.; Phookamsak, R.; Jayawardena, R.S.; Lumyong, S.; Hyde, K.D. Morphomolecular taxonomic studies reveal a high number of endophytic fungi from Magnolia candolli and M. garrettii in China and Thailand. Mycosphere 2021, 11, 163-237. [CrossRef]

147. Shinohara, N.; Woo, C.; Yamamoto, N.; Hashimoto, K.; Yoshida-Ohuchi, H.; Kawakami, Y. Comparison of DNA sequencing and morphological identification techniques to characterize environmental fungal communities. Sci. Rep. 2021, 11, 2633. [CrossRef]

148. Walker, A.K.; Robicheau, B.M. Fungal diversity and community structure from coastal and barrier island beaches in the United States Gulf of Mexico. Sci. Rep. 2021, 11, 3889. [CrossRef]

149. Haelewaters, D.; Gorczak, M.; Kaishian, P.; De Kesel, A.; Blackwell, M. Laboulbeniomycetes, enigmatic fungi with a turbulent taxonomic history. In Encyclopedia of Mycology; Elsevier: Amsterdam, The Netherlands, 2021; pp. 263-283.

150. Hartmann, M.; Howes, C.G.; VanInsberghe, D.; Yu, H.; Bachar, D.; Christen, R.; Nilsson, R.H.; Hallam, S.J.; Mohn, W.W. Significant and persistent impact of timber harvesting on soil microbial communities in Northern coniferous forests. ISME J. 2012, 6, 2199-2218. [CrossRef]

151. Ihrmark, K.; Bödeker, I.T.M.; Cruz-Martinez, K.; Friberg, H.; Kubartova, A.; Schenck, J.; Strid, Y.; Stenlid, J.; Brandström-Durling, M.; Clemmensen, K.E.; et al. New primers to amplify the fungal ITS2 region-Evaluation by 454-sequencing of artificial and natural communities. FEMS Microbiol. Ecol. 2012, 82, 666-677. [CrossRef]

152. Davey, M.L.; Heegaard, E.; Halvorsen, R.; Ohlson, M.; Kauserud, H. Seasonal trends in the biomass and structure of bryophyteassociated fungal communities explored by 454 pyrosequencing. New Phytol. 2012, 195, 844-856. [CrossRef] [PubMed]

153. Peay, K.G.; Baraloto, C.; Fine, P. Strong coupling of plant and fungal community structure across western Amazonian rainforests. ISME J. 2013, 7, 1852-1861. [CrossRef] [PubMed]

154. Davey, M.L.; Heegaard, E.; Halvorsen, R.; Kauserud, H.; Ohlson, M. Amplicon-pyrosequencing-based detection of compositional shifts in bryophyte-associated fungal communities along an elevation gradient. Mol. Ecol. 2013, 22, 368-383. [CrossRef]

155. Talbot, J.M.; Bruns, T.D.; Taylor, J.W.; Smith, D.P.; Branco, S.; Glassman, S.I.; Erlandson, S.; Vilgalys, R.; Liao, H.-L.; Smith, M.E.; et al. Endemism and functional convergence across the North American soil mycobiome. Proc. Natl. Acad. Sci. USA 2014, 111, 6341-6346. [CrossRef] [PubMed]

156. Tedersoo, L.; Bahram, M.; Põlme, S.; Kõljalg, U.; Yorou, N.S.; Wijesundera, R.; Ruiz, L.V.; Vasco-Palacios, A.M.; Thu, P.Q.; Suija, A.; et al. Global diversity and geography of soil fungi. Science 2014, 346, e1256688. [CrossRef] [PubMed]

157. Kadowaki, K.; Sato, H.; Yamamoto, S.; Tanabe, A.; Hidaka, A.; Toju, H. Detection of the horizontal spatial structure of soil fungal communities in a natural forest. Popul. Ecol. 2014, 56, 301-310. [CrossRef] 
158. Geml, J.; Gravendeel, B.; Van Der Gaag, K.; Neilen, M.; Lammers, Y.; Raes, N.; Semenova, T.A.; De Knijff, P.; Noordeloos, M.E. The Contribution of DNA Metabarcoding to Fungal Conservation: Diversity Assessment, Habitat Partitioning and Mapping Red-Listed Fungi in Protected Coastal Salix repens Communities in the Netherlands. PLoS ONE 2014, 9, e99852. [CrossRef]

159. Davey, M.L.; Kauserud, H.; Ohlson, M. Forestry impacts on the hidden fungal biodiversity associated with bryophytes. FEMS Microbiol. Ecol. 2014, 90, 313-325. [CrossRef]

160. McHugh, T.A.; Schwartz, E. Changes in plant community composition and reduced precipitation have limited effects on the structure of soil bacterial and fungal communities present in a semiarid grassland. Plant Soil 2015, 388, 175-186. [CrossRef]

161. Op De Beeck, M.; Lievens, B.; Busschaert, P.; Declerck, S.; Vangronsveld, J.; Colpaert, J.V. Comparison and Validation of Some ITS Primer Pairs Useful for Fungal Metabarcoding Studies. PLoS ONE 2014, 9, e97629. [CrossRef]

162. Yamamoto, S.; Sato, H.; Tanabe, A.S.; Hidaka, A.; Kadowaki, K.; Toju, H. Spatial segregation and aggregation of ectomycorrhizal and root-endophytic fungi in the seedlings of two Quercusspecies. PLoS ONE 2014, 9, e96363. [CrossRef] [PubMed]

163. Walker, D.M.; Lawrence, B.R.; Esterline, D.; Graham, S.P.; Edelbrock, M.A.; Wooten, J.A. A metagenomics-based approach to the top-down effect on the detritivore food web: A salamanders influence on fungal communities within a deciduous forest. Ecol. Evol. 2014, 4, 4106-4116. [CrossRef] [PubMed]

164. Veach, A.; Dodds, W.K.; Jumpponen, A. Woody plant encroachment, and its removal, impact bacterial and fungal communities across stream and terrestrial habitats in a tallgrass prairie ecosystem. FEMS Microbiol. Ecol. 2015, 91, fiv109. [CrossRef] [PubMed]

165. Zhang, T.; Wei, X.-L.; Zhang, Y.-Q.; Liu, H.-Y.; Yu, L.-Y. Diversity and distribution of lichen-associated fungi in the Ny-Ålesund Region (Svalbard, High Arctic) as revealed by 454 pyrosequencing. Sci. Rep. 2015, 5, e14850. [CrossRef] [PubMed]

166. Elliott, D.R.; Caporn, S.J.M.; Nwaishi, F.; Nilsson, H.; Sen, R. Bacterial and Fungal Communities in a Degraded Ombrotrophic Peatland Undergoing Natural and Managed Re-Vegetation. PLoS ONE 2015, 10, e0124726. [CrossRef] [PubMed]

167. Geml, J.; Morgado, L.N.; Semenova, T.A.; Welker, J.M.; Walker, M.D.; Smets, E. Long-term warming alters richness and composition of taxonomic and functional groups of arctic fungi. FEMS Microbiol. Ecol. 2015, 91, fiv095. [CrossRef]

168. Hoppe, B.; Purahong, W.; Wubet, T.; Kahl, T.; Bauhus, J.; Arnstadt, T.; Hofrichter, M.; Buscot, F.; Krüger, D. Linking molecular deadwood-inhabiting fungal diversity and community dynamics to ecosystem functions and processes in Central European forests. Fungal Divers. 2016, 77, 367-379. [CrossRef]

169. Jarvis, S.G.; Woodward, S.; Taylor, A.F.S. Strong altitudinal partitioning in the distributions of ectomycorrhizal fungi along a short (300 m) elevation gradient. New Phytol. 2015, 206, 1145-1155. [CrossRef]

170. Chaput, D.L.; Hansel, C.M.; Burgos, W.D.; Santelli, C.M. Profiling Microbial Communities in Manganese Remediation Systems Treating Coal Mine Drainage. Appl. Environ. Microbiol. 2015, 81, 2189-2198. [CrossRef]

171. van der Wal, A.; Ottosson, E.; de Boer, W. Neglected role of fungal community composition in explaining variation in wood decay rates. Ecology 2015, 96, 124-133. [CrossRef]

172. Clemmensen, K.E.; Finlay, R.; Dahlberg, A.; Stenlid, J.; Wardle, D.; Lindahl, B.D. Carbon sequestration is related to mycorrhizal fungal community shifts during long-term succession in boreal forests. New Phytol. 2015, 205, 1525-1536. [CrossRef] [PubMed]

173. Gao, C.; Zhang, Y.; Shi, N.; Zheng, Y.; Chen, L.; Wubet, T.; Bruelheide, H.; Both, S.; Buscot, F.; Ding, Q.; et al. Community assembly of ectomycorrhizal fungi along a subtropical secondary forest succession. New Phytol. 2015, 205, 771-785. [CrossRef] [PubMed]

174. Liu, J.; Sui, Y.; Yu, Z.; Shi, Y.; Chu, H.; Jin, J.; Liu, X.; Wang, G. Soil carbon content drives the biogeographical distribution of fungal communities in the black soil zone of northeast China. Soil Biol. Biochem. 2015, 83, 29-39. [CrossRef]

175. Oja, J.; Kohout, P.; Tedersoo, L.; Kull, T.; Kõljalg, U. Temporal patterns of orchid mycorrhizal fungi in meadows and forests as revealed by 454 pyrosequencing. New Phytol. 2015, 205, 1608-1618. [CrossRef]

176. Goldmann, K.; Schöning, I.; Buscot, F.; Wubet, T. Forest Management Type Influences Diversity and Community Composition of Soil Fungi across Temperate Forest Ecosystems. Front. Microbiol. 2015, 6, 1300. [CrossRef] [PubMed]

177. Tedersoo, L.; Anslan, S.; Bahram, M.; Põlme, S.; Riit, T.; Liiv, I.; Kõljalg, U.; Kisand, V.; Nilsson, H.; Hildebrand, F.; et al. Shotgun metagenomes and multiple primer pair-barcode combinations of amplicons reveal biases in metabarcoding analyses of fungi. MycoKeys 2015, 10, 1-43. [CrossRef]

178. Rime, T.; Hartmann, M.; Brunner, I.; Widmer, F.; Zeyer, J.; Frey, B. Vertical distribution of the soil microbiota along a successional gradient in a glacier forefield. Mol. Ecol. 2015, 24, 1091-1108. [CrossRef]

179. Sterkenburg, E.; Bahr, A.; Durling, M.B.; Clemmensen, K.; Lindahl, B.D. Changes in fungal communities along a boreal forest soil fertility gradient. New Phytol. 2015, 207, 1145-1158. [CrossRef]

180. Štursová, M.; Bárta, J.; Šantrůčková, H.; Baldrian, P. Small-scale spatial heterogeneity of ecosystem properties, microbial community composition and microbial activities in a temperate mountain forest soil. FEMS Microbiol. Ecol. 2016, 92 , fiw185. [CrossRef]

181. Semenova, T.A.; Morgado, L.N.; Welker, J.M.; Walker, M.D.; Smets, E.; Geml, J. Compositional and functional shifts in arctic fungal communities in response to experimentally increased snow depth. Soil Biol. Biochem. 2016, 100, 201-209. [CrossRef]

182. Santalahti, M.; Sun, H.; Jumpponen, A.; Pennanen, T.; Heinonsalo, J. Vertical and seasonal dynamics of fungal communities in boreal Scots pine forest soil. FEMS Microbiol. Ecol. 2016, 92, fiw170. [CrossRef] [PubMed]

183. Rime, T.; Hartmann, M.; Frey, B. Potential sources of microbial colonizers in an initial soil ecosystem after retreat of an alpine glacier. ISME J. 2016, 10, 1625-1641. [CrossRef] [PubMed]

184. Roy-Bolduc, A.; Laliberté, E.; Hijri, M. High richness of ectomycorrhizal fungi and low host specificity in a coastal sand dune ecosystem revealed by network analysis. Ecol. Evol. 2016, 6, 349-362. [CrossRef] [PubMed] 
185. Roy-Bolduc, A.; Laliberté, E.; Boudreau, S.; Hijri, M. Strong linkage between plant and soil fungal communities along a successional coastal dune system. FEMS Microbiol. Ecol. 2016, 92, fiw156. [CrossRef] [PubMed]

186. Tedersoo, L.; Bahram, M.; Cajthaml, T.; Põlme, S.; Hiiesalu, I.; Anslan, S.; Harend, H.; Buegger, F.; Pritsch, K.; Koricheva, J.; et al. Tree diversity and species identity effects on soil fungi, protists and animals are context dependent. ISME J. 2016, 10, 346-362. [CrossRef]

187. Wilhelm, R.C.; Cardenas, E.; Leung, H.; Maas, K.; Hartmann, M.; Hahn, A.; Hallam, S.; Mohn, W.W. A metagenomic survey of forest soil microbial communities more than a decade after timber harvesting. Sci. Data 2017, 4, 170092. [CrossRef]

188. Urbina, H.; Scofield, D.G.; Cafaro, M.; Rosling, A. DNA-metabarcoding uncovers the diversity of soil-inhabiting fungi in the tropical island of Puerto Rico. Mycoscience 2016, 57, 217-227. [CrossRef]

189. Valverde, A.; De Maayer, P.; Oberholster, T.; Henschel, J.; Louw, M.K.; Cowan, D. Specific microbial communities associate with the rhizosphere of Welwitschia mirabilis, a Living Fossil. PLoS ONE 2016, 11, e0153353. [CrossRef]

190. Nacke, H.; Goldmann, K.; Schöning, I.; Pfeiffer, B.; Kaiser, K.; Castillo-Villamizar, G.A.; Schrumpf, M.; Buscot, F.; Daniel, R.; Wubet, T. Fine spatial scale variation of soil microbial communities under European Beech and Norway Spruce. Front. Microbiol. 2016, 7, 2067. [CrossRef]

191. Newsham, K.K.; Hopkins, D.; Carvalhais, L.C.; Fretwell, P.T.; Rushton, S.P.; O’Donnell, A.G.; Dennis, P.G. Relationship between soil fungal diversity and temperature in the maritime Antarctic. Nat. Clim. Chang. 2016, 6, 182-186. [CrossRef]

192. Nguyen, D.; Boberg, J.; Ihrmark, K.; Stenström, E.; Stenlid, J. Do foliar fungal communities of Norway spruce shift along a tree species diversity gradient in mature European forests? Fungal Ecol. 2016, 23, 97-108. [CrossRef]

193. Goldmann, K.; Schröter, K.; Pena, R.; Schöning, I.; Schrumpf, M.; Buscot, F.; Polle, A.; Wubet, T. Divergent habitat filtering of root and soil fungal communities in temperate beech forests. Sci. Rep. 2016, 6, e31439. [CrossRef] [PubMed]

194. Bahram, M.; Kohout, P.; Anslan, S.; Harend, H.; Abarenkov, K.; Tedersoo, L. Stochastic distribution of small soil eukaryotes resulting from high dispersal and drift in a local environment. ISME J. 2016, 10, 885-896. [CrossRef] [PubMed]

195. Gehring, C.A.; Hayer, M.; Flores-Rentería, L.; Krohn, A.F.; Schwartz, E.; Dijkstra, P. Cheatgrass invasion alters the abundance and composition of dark septate fungal communities in sagebrush steppe. Botany 2016, 94, 481-491. [CrossRef]

196. Gourmelon, V.; Maggia, L.; Powell, J.; Gigante, S.; Hortal, S.; Gueunier, C.; Letellier, K.; Carriconde, F. Environmental and Geographical Factors Structure Soil Microbial Diversity in New Caledonian Ultramafic Substrates: A Metagenomic Approach. PLoS ONE 2016, 11, e0167405. [CrossRef] [PubMed]

197. Bissett, A.; Fitzgerald, A.; Meintjes, T.; Mele, P.M.; Reith, F.; Dennis, P.G.; Breed, M.; Brown, B.; Brown, M.V.; Brugger, J.; et al. Introducing BASE: The Biomes of Australian Soil Environments soil microbial diversity database. GigaScience 2016, 5, 21. [CrossRef]

198. Cox, F.; Newsham, K.K.; Bol, R.; Dungait, J.A.J.; Robinson, C.H. Not poles apart: Antarctic soil fungal communities show similarities to those of the distant Arctic. Ecol. Lett. 2016, 19, 528-536. [CrossRef]

199. Oh, S.-Y.; Fong, J.J.; Park, M.S.; Lim, Y.W. Distinctive Feature of Microbial Communities and Bacterial Functional Profiles in Tricholoma matsutake Dominant Soil. PLoS ONE 2016, 11, e0168573. [CrossRef]

200. Frey, B.; Rime, T.; Phillips, M.; Stierli, B.; Hajdas, I.; Widmer, F.; Hartmann, M. Microbial diversity in European alpine permafrost and active layers. FEMS Microbiol. Ecol. 2016, 92, fiw018. [CrossRef]

201. de Gannes, V.; Bekele, I.; Dipchansingh, D.; Wuddivira, M.N.; De Cairies, S.; Boman, M.; Hickey, W.J. Microbial Community Structure and Function of Soil Following Ecosystem Conversion from Native Forests to Teak Plantation Forests. Front. Microbiol. 2016, 7, 1976. [CrossRef]

202. Li, Y.; Wang, S.; Jiang, L.; Zhang, L.; Cui, S.; Meng, F.; Wang, Q.; Li, X.; Zhou, Y. Changes of soil microbial community under different degraded gradients of alpine meadow. Agric. Ecosyst. Environ. 2016, 222, 213-222. [CrossRef]

203. Kielak, A.M.; Scheublin, T.R.; Mendes, L.W.; Van Veen, J.A.; Kuramae, E.E. Bacterial Community Succession in Pine-Wood Decomposition. Front. Microbiol. 2016, 7, 231. [CrossRef] [PubMed]

204. Ji, M.; van Dorst, J.; Bissett, A.; Brown, M.V.; Palmer, A.S.; Snape, I.; Siciliano, S.D.; Ferrari, B.C. Microbial diversity at Mitchell Peninsula, Eastern Antarctica: A potential biodiversity "hotspot". Polar Biol. 2016, 39, 237-249. [CrossRef]

205. Baldrian, P.; Zrůstová, P.; Tláskal, V.; Davidová, A.; Merhautová, V.; Vrška, T. Fungi associated with decomposing deadwood in a natural beech-dominated forest. Fungal Ecol. 2016, 23, 109-122. [CrossRef]

206. Barnes, C.J.; Maldonado, C.; Frøslev, T.G.; Antonelli, A.; Rønsted, N. Unexpectedly High Beta-Diversity of Root-Associated Fungal Communities in the Bolivian Andes. Front. Microbiol. 2016, 7, 1377. [CrossRef]

207. Porter, T.M.; Shokralla, S.; Baird, D.; Golding, G.B.; Hajibabaei, M. Ribosomal DNA and Plastid Markers Used to Sample Fungal and Plant Communities from Wetland Soils Reveals Complementary Biotas. PLoS ONE 2016, 11, e0142759. [CrossRef]

208. Zhou, J.; Deng, Y.; Shen, L.; Wen, C.; Yan, Q.; Ning, D.; Qin, Y.; Xue, K.; Wu, L.; He, Z.; et al. Temperature mediates continental-scale diversity of microbes in forest soils. Nat. Commun. 2016, 7, 12083. [CrossRef]

209. Zhou, X.; Tian, L.; Zhang, J.; Ma, L.; Li, X.; Tian, C. Rhizospheric Fungi and Their link with the nitrogen-fixing Frankia harbored in host plant Hippophaerhamnoides L. J. Basic Microbiol. 2017, 57, 1055-1064. [CrossRef]

210. Wang, W.; Zhai, Y.; Cao, L.; Tan, H.; Zhang, R. Endophytic bacterial and fungal microbiota in sprouts, roots and stems of rice (Oryza sativa L.). Microbiol. Res. 2016, 188-189, 1-8. [CrossRef]

211. Žif̌ćáková, L.; Větrovský, T.; Howe, A.; Baldrian, P. Microbial activity in forest soil reflects the changes in ecosystem properties between summer and winter: Seasonal dynamics of a soil microbial community. Environ. Microbiol. 2016, 18, 288-301. [CrossRef] 
212. Van Der Wal, A.; Gunnewiek, P.J.A.K.; Cornelissen, J.H.C.; Crowther, T.W.; De Boer, W. Patterns of natural fungal community assembly during initial decay of coniferous and broadleaf tree logs. Ecosphere 2016, 7, 01393. [CrossRef]

213. Varenius, K.; Lindahl, B.D.; Dahlberg, A. Retention of seed trees fails to lifeboat ectomycorrhizal fungal diversity in harvested Scots pine forests. FEMS Microbiol. Ecol. 2017, 93, fix105. [CrossRef] [PubMed]

214. van der Wal, A.; Klein Gunnewiek, P.; de Hollander, M.; de Boer, W. Fungal diversity and potential tree pathogens in decaying logs and stumps. For. Ecol. Manag. 2017, 406, 266-273. [CrossRef]

215. Wang, M.; Chen, M.; Yang, Z.; Chen, N.; Chi, X.; Pan, L.; Wang, T.; Yu, S.; Guo, X. Influence of Peanut Cultivars and Environmental Conditions on the Diversity and Community Composition of Pod Rot Soil Fungi in China. Mycobiology 2017, 45, 392-400. [CrossRef]

216. van der Wal, A.; kleinGunnewiek, P.; de Boer, W. Soil-wood interactions: Influence of decaying coniferous and broadleaf logs on composition of soil fungal communities. Fungal Ecol. 2017, 30, 132-134. [CrossRef]

217. Vasutova, M.; Edwards-Jonášová, M.; Baldrian, P.; Čermák, M.; Cudlín, P. Distinct environmental variables drive the community composition of mycorrhizal and saprotrophic fungi at the alpine treeline ecotone. Fungal Ecol. 2017, 27, 116-124. [CrossRef]

218. Vaz, A.B.; Fonseca, P.; Góes-Neto, A.; Leite, L.R.; Badotti, F.; Salim, A.C.; Araujo, F.M.; Cuadros-Orellana, S.; Duarte, Â.A.; Rosa, C.A.; et al. Using next-generation sequencing (NGS) to uncover diversity of wood-decaying fungi in neotropical Atlantic forests. Phytotaxa 2017, 295, 1-21. [CrossRef]

219. Yang, T.; Adams, J.; Shi, Y.; He, J.-S.; Jing, X.; Chen, L.; Tedersoo, L.; Chu, H. Soil fungal diversity in natural grasslands of the Tibetan Plateau: Associations with plant diversity and productivity. New Phytol. 2017, 215, 756-765. [CrossRef]

220. Wicaksono, C.Y.; Gutiérrez, J.A.; Nouhra, E.; Pastor, N.; Raes, N.; Pacheco, S.; Geml, J. Contracting montane cloud forests: A case study of the Andean alder (Alnus acuminata) and associated fungi in the Yungas. Biotropica 2017, 49, 141-152. [CrossRef]

221. Yang, T.; Adams, J.; Shi, Y.; Sun, H.; Cheng, L.; Zhang, Y.; Chu, H. Fungal community assemblages in a high elevation desert environment: Absence of dispersal limitation and edaphic effects in surface soil. Soil Biol. Biochem. 2017, 115, 393-402. [CrossRef]

222. Zhang, W.; Lu, Z.; Yang, K.; Zhu, J. Impacts of conversion from secondary forests to larch plantations on the structure and function of microbial communities. Appl. Soil Ecol. 2017, 111, 73-83. [CrossRef]

223. Zhang, Z.; Zhou, X.; Tian, L.; Ma, L.; Luo, S.; Zhang, J.; Li, X.; Tian, C. Fungal communities in ancient peatlands developed from different periods in the Sanjiang Plain, China. PLOS ONE 2017, 12, e0187575. [CrossRef] [PubMed]

224. Purahong, W.; Pietsch, K.A.; Lentendu, G.; Schöps, R.; Bruelheide, H.; Wirth, C.; Buscot, F.; Wubet, T. Characterization of Unexplored Deadwood Mycobiome in Highly Diverse Subtropical Forests Using Culture-independent Molecular Technique. Front. Microbiol. 2017, 8, 574. [CrossRef] [PubMed]

225. Poosakkannu, A.; Nissinen, R.; Männistö, M.; Kytöviita, M.-M. Microbial community composition but not diversity changes along succession in arctic sand dunes: Deschampsiaflexuosa associated microbiomes. Environ. Microbiol. 2017, 19, 698-709. [CrossRef]

226. Bergottini, V.; Hervé, V.; Sosa, D.; Otegui, M.; Zapata, P.D.; Junier, P. Exploring the diversity of the root-associated microbiome of Ilex paraguariensis St. Hil. (Yerba Mate). Appl. Soil Ecol. 2017, 109, 23-31. [CrossRef]

227. Dean, S.L.; Tobias, T.B.; Phippen, W.B.; Clayton, A.W.; Gruver, J.; Porras-Alfaro, A. A study of Glycine max (soybean) fungal communities under different agricultural practices. Plant Gene 2017, 11, 8-16. [CrossRef]

228. Fernández-Martínez, M.A.; Pérez-Ortega, S.; Pointing, S.B.; Green, T.G.A.; Pintado, A.; Rozzi, R.; Sancho, L.; Rios, A.D.L. Microbial succession dynamics along glacier forefield chronosequences in Tierra del Fuego (Chile). Polar Biol. 2017, 40, 1939-1957. [CrossRef]

229. Ge, Z.-W.; Brenneman, T.; Bonito, G.; Smith, M.E. Soil pH and mineral nutrients strongly influence truffles and other ectomycorrhizal fungi associated with commercial pecans (Carya illinoinensis). Plant Soil 2017, 418, 493-505. [CrossRef]

230. Gomes, S.I.F.; Aguirre-Gutiérrez, J.; Bidartondo, M.I.; Merckx, V.S.F.T. Arbuscular mycorrhizal interactions of mycoheterotrophic Thismia are more specialized than in autotrophic plants. New Phytol. 2017, 213, 1418-1427. [CrossRef]

231. Almario, J.; Jeena, G.; Wunder, J.; Langen, G.; Zuccaro, A.; Coupland, G.; Bucher, M. Root-associated fungal microbiota of nonmycorrhizal Arabis alpina and its contribution to plant phosphorus nutrition. Proc. Natl. Acad. Sci. USA 2017, 114, E9403-E9412. [CrossRef]

232. Anthony, M.A.; Frey, S.D.; Stinson, K.A. Fungal community homogenization, shift in dominant trophic guild, and appearance of novel taxa with biotic invasion. Ecosphere 2017, 8, e01951. [CrossRef]

233. Grau, O.; Geml, J.; Pérez-Haase, A.; Ninot, J.M.; Semenova-Nelsen, T.A.; Peñuelas, J. Abrupt changes in the composition and function of fungal communities along an environmental gradient in the high Arctic. Mol. Ecol. 2017, 26, 4798-4810. [CrossRef] [PubMed]

234. Hiiesalu, I.; Bahram, M.; Tedersoo, L. Plant species richness and productivity determine the diversity of soil fungal guilds in temperate coniferous forest and bog habitats. Mol. Ecol. 2017, 26, 4846-4858. [CrossRef] [PubMed]

235. Nguyen, D.; Boberg, J.; Cleary, M.; Bruelheide, H.; Hönig, L.; Koricheva, J.; Stenlid, J. Foliar fungi of Betula pendula: Impact of tree species mixtures and assessment methods. Sci. Rep. 2017, 7, 41801. [CrossRef]

236. Kolaříková, Z.; Kohout, P.; Krüger, C.; Janoušková, M.; Mrnka, L.; Rydlová, J. Root-associated fungal communities along a primary succession on a mine spoil: Distinct ecological guilds assemble differently. Soil Biol. Biochem. 2017, 113, 143-152. [CrossRef]

237. Kyaschenko, J.; Clemmensen, K.; Hagenbo, A.; Karltun, E.; Lindahl, B.D. Shift in fungal communities and associated enzyme activities along an age gradient of managed Pinus sylvestris stands. ISME J. 2017, 11, 863-874. [CrossRef] 
238. Oja, J.; Vahtra, J.; Bahram, M.; Kohout, P.; Kull, T.; Rannap, R.; Kõljalg, U.; Tedersoo, L. Local-scale spatial structure and community composition of orchid mycorrhizal fungi in semi-natural grasslands. Mycorrhiza 2017, 27, 355-367. [CrossRef]

239. Miura, T.; Sánchez, R.; Castañeda, L.E.; Godoy, K.; Barbosa, O. Is microbial terroir related to geographic distance between vineyards? Environ. Microbiol. Rep. 2017, 9, 742-749. [CrossRef]

240. Oono, R.; Rasmussen, A.; Lefèvre, E. distance decay relationships in foliar fungal endophytes are driven by rare taxa: Distance decay in fungal endophytes. Environ. Microbiol. 2017, 19, 2794-2805. [CrossRef]

241. Kamutando, C.N.; Vikram, S.; Kamgan-Nkuekam, G.; Makhalanyane, T.P.; Greve, M.; Le Roux, J.J.; Richardson, D.; Cowan, D.; Valverde, A. Soil nutritional status and biogeography influence rhizosphere microbial communities associated with the invasive tree Acacia dealbata. Sci. Rep. 2017, 7, 6472. [CrossRef]

242. Shen, Z.; Penton, C.R.; Lv, N.; Xue, C.; Yuan, X.; Ruan, Y.; Li, R.; Shen, Q. Banana Fusarium Wilt Disease Incidence Is Influenced by Shifts of Soil Microbial Communities under Different Monoculture Spans. Microb. Ecol. 2018, 75, 739-750. [CrossRef] [PubMed]

243. Smith, M.E.; Henkel, T.W.; Williams, G.C.; Aime, M.C.; Fremier, A.K.; Vilgalys, R. Investigating niche partitioning of ectomycorrhizal fungi in specialized rooting zones of the monodominant leguminous tree Dicymbecorymbosa. New Phytol. 2017, 215, 443-453. [CrossRef] [PubMed]

244. Tian, H.; Wang, H.; Hui, X.; Wang, Z.; Drijber, R.A.; Liu, J. Changes in soil microbial communities after 10 years of winter wheat cultivation versus fallow in an organic-poor soil in the Loess Plateau of China. PLoS ONE 2017, 12, e0184223. [CrossRef] [PubMed]

245. Tu, B.; Domene, X.; Yao, M.; Li, C.; Zhang, S.; Kou, Y.; Wang, Y.; Li, X. Microbial diversity in Chinese temperate steppe: Unveiling the most influential environmental drivers. FEMS Microbiol. Ecol. 2017, 93, fix031. [CrossRef] [PubMed]

246. Sharma-Poudyal, D.; Schlatter, D.; Yin, C.; Hulbert, S.; Paulitz, T. Long-term no-till: A major driver of fungal communities in dryland wheat cropping systems. PLoS ONE 2017, 12, e0184611. [CrossRef]

247. Cross, H.; Sønstebø, J.H.; Nagy, N.E.; Timmermann, V.; Solheim, H.; Børja, I.; Kauserud, H.; Carlsen, T.; Rzepka, B.; Wasak, K.; et al. Fungal diversity and seasonal succession in ash leaves infected by the invasive ascomycete Hymenoscyphus fraxineus. New Phytol. 2017, 213, 1405-1417. [CrossRef]

248. Kazartsev, I.; Shorohova, E.; Kapitsa, E.; Kushnevskaya, H. Decaying Piceaabies log bark hosts diverse fungal communities. Fungal Ecol. 2018, 33, 1-12. [CrossRef]

249. Bickford, W.A.; Goldberg, D.E.; Kowalski, K.P.; Zak, D.R. Root endophytes and invasiveness: No difference between native and non-native Phragmites in the Great Lakes Region. Ecosphere 2018, 9, 02526. [CrossRef]

250. Cline, L.C.; Schilling, J.S.; Menke, J.; Groenhof, E.; Kennedy, P.G. Ecological and functional effects of fungal endophytes on wood decomposition. Funct. Ecol. 2018, 32, 181-191. [CrossRef]

251. Cregger, M.A.; Veach, A.; Yang, Z.K.; Crouch, M.J.; Vilgalys, R.; Tuskan, G.A.; Schadt, C.W. The Populus holobiont: Dissecting the effects of plant niches and genotype on the microbiome. Microbiome 2018, 6, e31. [CrossRef]

252. Marasco, R.; Mosqueira, M.J.; Fusi, M.; Ramond, J.-B.; Merlino, G.; Booth, J.M.; Maggs-Kölling, G.; Cowan, D.A.; Daffonchio, D. Rhizosheath microbial community assembly of sympatric desert speargrasses is independent of the plant host. Microbiome 2018, 6, e215. [CrossRef] [PubMed]

253. Glynou, K.; Nam, B.; Thines, M.; Maciá-Vicente, J.G. Facultative root-colonizing fungi dominate endophytic assemblages in roots of nonmycorrhizal Microthlaspi species. New Phytol. 2018, 217, 1190-1202. [CrossRef] [PubMed]

254. Montagna, M.; Berruti, A.; Bianciotto, V.; Cremonesi, P.; Giannico, R.; Gusmeroli, F.; Lumini, E.; Pierce, S.; Pizzi, F.; Turri, F.; et al. Differential biodiversity responses between kingdoms (plants, fungi, bacteria and metazoa) along an Alpine succession gradient. Mol. Ecol. 2018, 27, 3671-3685. [CrossRef] [PubMed]

255. Schlegel, M.; Queloz, V.; Sieber, T.N. The Endophytic Mycobiome of European Ash and Sycamore Maple Leaves-Geographic Patterns, Host Specificity and Influence of Ash Dieback. Front. Microbiol. 2018, 9, e2345. [CrossRef]

256. Schneider-Maunoury, L.; Leclercq, S.; Clément, C.; Covès, H.; Lambourdière, J.; Sauve, M.; Richard, F.; Selosse, M.-A.; Taschen, E. Is Tuber melanosporum colonizing the roots of herbaceous, non-ectomycorrhizal plants? Fungal Ecol. 2018, 31, 59-68. [CrossRef]

257. Schön, M.E.; Nieselt, K.; Garnica, S. Belowground fungal community diversity and composition associated with Norway spruce along an altitudinal gradient. PLoS ONE 2018, 13, e0208493. [CrossRef]

258. Rasmussen, P.U.; Hugerth, L.W.; Blanchet, F.G.; Andersson, A.; Lindahl, B.D.; Tack, A.J.M. Multiscale patterns and drivers of arbuscular mycorrhizal fungal communities in the roots and root-associated soil of a wild perennial herb. New Phytol. 2018, 220, 1248-1261. [CrossRef]

259. Rogers, T.J.; Leppanen, C.; Brown, V.; Fordyce, J.A.; LeBude, A.; Ranney, T.; Simberloff, D.; Cregger, M.A. Exploring variation in phyllosphere microbial communities across four hemlock species. Ecosphere 2018, 9, e02524. [CrossRef]

260. Purahong, W.; Wubet, T.; Kahl, T.; Arnstadt, T.; Hoppe, B.; Lentendu, G.; Baber, K.; Rose, T.; Kellner, H.; Hofrichter, M.; et al. Increasing $\mathrm{N}$ deposition impacts neither diversity nor functions of deadwood-inhabiting fungal communities, but adaptation and functional redundancy ensure ecosystem function. Environ. Microbiol. 2018, 20, 1693-1710. [CrossRef]

261. Qian, X.; Chen, L.; Guo, X.; He, D.; Shi, M.; Zhang, D. Shifts in community composition and co-occurrence patterns of phyllosphere fungi inhabiting Mussaenda shikokiana along an elevation gradient. PeerJ 2018, 6, e5767. [CrossRef]

262. Park, M.S.; Eimes, J.A.; Oh, S.H.; Suh, H.J.; Oh, S.-Y.; Lee, S.; Park, K.H.; Kwon, H.J.; Kim, S.-Y.; Lim, Y.W. Diversity of fungi associated with roots of Calanthe orchid species in Korea. J. Microbiol. 2018, 56, 49-55. [CrossRef] [PubMed]

263. Mirmajlessi, S.M.; Bahram, M.; Mänd, M.; Najdabbasi, N.; Mansouripour, S.; Loit, E. Survey of Soil Fungal Communities in Strawberry Fields by Illumina Amplicon Sequencing. Eurasian Soil Sci. 2018, 51, 682-691. [CrossRef] 
264. Purahong, W.; Wubet, T.; Lentendu, G.; Hoppe, B.; Jariyavidyanont, K.; Arnstadt, T.; Baber, K.; Otto, P.; Kellner, H.; Hofrichter, M.; et al. Determinants of deadwood-inhabiting fungal communities in temperate forests: Molecular evidence from a large scale deadwood decomposition experiment. Front. Microbiol. 2018, 9, 2120. [CrossRef] [PubMed]

265. Si, P.; Shao, W.; Yu, H.; Yang, X.; Gao, D.; Qiao, X.; Wang, Z.; Wu, G. Rhizosphere Microenvironments of Eight Common Deciduous Fruit Trees Were Shaped by Microbes in Northern China. Front. Microbiol. 2018, 9, e3147. [CrossRef]

266. Saitta, A.; Anslan, S.; Bahram, M.; Brocca, L.; Tedersoo, L. Tree species identity and diversity drive fungal richness and community composition along an elevational gradient in a Mediterranean ecosystem. Mycorrhiza 2018, 28, 39-47. [CrossRef]

267. Santalahti, M.; Sun, H.; Sietiö, O.-M.; Köster, K.; Berninger, F.; Laurila, T.; Pumpanen, J.; Heinonsalo, J. Reindeer grazing alter soil fungal community structure and litter decomposition related enzyme activities in boreal coniferous forests in Finnish Lapland. Appl. Soil Ecol. 2018, 132, 74-82. [CrossRef]

268. Sukdeo, N.; Teen, E.; Rutherford, P.M.; Massicotte, H.B.; Egger, K.N. Selecting fungal disturbance indicators to compare forest soil profile re-construction regimes. Ecol. Indic. 2018, 84, 662-682. [CrossRef]

269. Zhu, S.; Wang, Y.; Xu, X.; Liu, T.; Wu, D.; Zheng, X.; Tang, S.; Dai, Q. Potential use of high-throughput sequencing of soil microbial communities for estimating the adverse effects of continuous cropping on ramie (Boehmeria nivea L. Gaud). PLoS ONE 2018, 13, e0197095. [CrossRef]

270. Zhang, J.; Zhang, B.; Liu, Y.; Guo, Y.; Shi, P.; Wei, G. Distinct large-scale biogeographic patterns of fungal communities in bulk soil and soybean rhizosphere in China. Sci. Total Environ. 2018, 644, 791-800. [CrossRef]

271. Zhang, B.; Zhang, Y.; Li, X.; Zhang, Y. Successional changes of fungal communities along the biocrust development stages. Biol. Fertil. Soils 2018, 54, 285-294. [CrossRef]

272. Sun, R.; Li, W.; Dong, W.; Tian, Y.; Hu, C.; Liu, B. Tillage changes vertical distribution of soil bacterial and fungal communities. Front. Microbiol. 2018, 9, 699. [CrossRef] [PubMed]

273. Weißbecker, C.; Wubet, T.; Lentendu, G.; Kühn, P.; Scholten, T.; Bruelheide, H.; Buscot, F. Experimental evidence of functional group-dependent effects of tree diversity on soil fungi in subtropical forests. Front. Microbiol. 2018, 9, 2312. [CrossRef] [PubMed]

274. Purahong, W.; Mapook, A.; Wu, Y.T.; Chen, C.T. Characterization of the Castanopsis carlesii deadwood mycobiome by pacbio sequencing of the full-length fungal nuclear ribosomal Internal Transcribed Spacer (ITS). Front. Microbiol. 2019, 10, 983. [CrossRef] [PubMed]

275. Egidi, E.; Delgado-Baquerizo, M.; Plett, J.; Wang, J.; Eldridge, D.J.; Bardgett, R.D.; Maestre, F.T.; Singh, B.K. A few Ascomycota taxa dominate soil fungal communities worldwide. Nat. Commun. 2019, 10, 2369. [CrossRef] [PubMed]

276. Frøslev, T.G.; Kjøller, R.; Bruun, H.H.; Ejrnæs, R.; Hansen, A.J.; Læssøe, T.; Heilmann-Clausen, J. Man against machine: Do fungal fruitbodies and eDNA give similar biodiversity assessments across broad environmental gradients? Biol. Conserv. 2019, 233, 201-212. [CrossRef]

277. Ogwu, M.C.; Takahashi, K.; Dong, K.; Song, H.-K.; Moroenyane, I.; Waldman, B.; Adams, J.M. Fungal elevational rapoport pattern from a high mountain in Japan. Sci. Rep. 2019, 9, 6570. [CrossRef]

278. Ovaskainen, O.; Abrego, N.; Somervuo, P.; Palorinne, I.; Hardwick, B.; Pitkänen, J.-M.; Andrew, N.R.; Niklaus, P.A.; Schmidt, N.M.; Seibold, S.; et al. Monitoring fungal communities with the global spore sampling project. Front. Ecol. Evol. $2020,7,511$. [CrossRef]

279. Qian, X.; Li, H.; Wang, Y.; Wu, B.; Wu, M.; Chen, L.; Li, X.; Zhang, Y.; Wang, X.; Shi, M.; et al. Leaf and root endospheres harbor lower fungal diversity and less complex fungal co-occurrence patterns than rhizosphere. Front. Microbiol. 2019, 10, 1015. [CrossRef]

280. Ramirez, K.S.; Snoek, L.B.; Koorem, K.; Geisen, S.; Bloem, L.J.; ten Hooven, F.; Kostenko, O.; Krigas, N.; Manrubia, M.; Caković, D.; et al. Range-expansion effects on the belowground plant microbiome. Nat. Ecol. Evol. 2019, 3, 604-611. [CrossRef]

281. Pellitier, P.T.; Zak, D.R.; Salley, S. Environmental filtering structures fungal endophyte communities in tree bark. Mol. Ecol. 2019, 28, 5188-5198. [CrossRef]

282. Semenova-Nelsen, T.A.; Platt, W.J.; Patterson, T.R.; Huffman, J.; Sikes, B.A. Frequent fire reorganizes fungal communities and slows decomposition across a heterogeneous pine savanna landscape. New Phytol. 2019, 224, 916-927. [CrossRef] [PubMed]

283. Sheng, Y.; Cong, J.; Lu, H.; Yang, L.; Liu, Q.; Li, D.; Zhang, Y. Broad-leaved forest types affect soil fungal community structure and soil organic carbon contents. Microbiology Open 2019, 8, e874. [CrossRef] [PubMed]

284. Shigyo, N.; Umeki, K.; Hirao, T. Seasonal dynamics of soil fungal and bacterial communities in cool-temperate montane forests. Front. Microbiol. 2019, 10, 1944. [CrossRef] [PubMed]

285. Schröter, K.; Wemheuer, B.; Pena, R.; Schöning, I.; Ehbrecht, M.; Schall, P.; Ammer, C.; Daniel, R.; Polle, A. Assembly processes of trophic guilds in the root mycobiome of temperate forests. Mol. Ecol. 2019, 28, 348-364. [CrossRef]

286. Singh, J.; Silva, K.J.P.; Fuchs, M.; Khan, A. Potential role of weather, soil and plant microbial communities in rapid decline of apple trees. PLoS ONE 2019, 14, e0213293. [CrossRef]

287. Song, H.; Singh, D.; Tomlinson, K.W.; Yang, X.; Ogwu, M.C.; Slik, J.W.F.; Adams, J.M. Tropical forest conversion to rubber plantation in southwest China results in lower fungal beta diversity and reduced network complexity. FEMS Microbiol. Ecol. 2019, 95, fiz092. [CrossRef]

288. U’Ren, J.M.; Lutzoni, F.; Miadlikowska, J.; Zimmerman, N.B.; Carbone, I.; May, G.; Arnold, A.E. Host availability drives distributions of fungal endophytes in the imperilled boreal realm. Nat. Ecol. Evol. 2019, 3, 1430-1437. [CrossRef] 
289. Unuk, T.; Martinović, T.; Finžgar, D.; Šibanc, N.; Grebenc, T.; Kraigher, H. Root-associated fungal communities from two phenologically contrasting silver fir (Abies alba Mill.) groups of trees. Front. Plant Sci. 2019, 10, 214. [CrossRef]

290. Araya, J.P.; González, M.; Cardinale, M.; Schnell, S.; Stoll, A. Microbiome dynamics associated with the atacama flowering desert. Front. Microbiol. 2020, 10, 3160. [CrossRef]

291. Álvarez-Garrido, L.; Viñegla, B.; Hortal, S.; Powell, J.R.; Carreira, J.A. Distributional shifts in ectomycorrizhal fungal communities lag behind climate-driven tree upward migration in a conifer forest-high elevation shrubland ecotone. Soil Biol. Biochem. 2019, 137, e107545. [CrossRef]

292. Wei, Z.; Yu, D. Rhizosphere fungal community structure succession of Xinjiang continuously cropped cotton. Fungal Biol. 2018, 123, 42-50. [CrossRef] [PubMed]

293. Pan, H.; Chen, M.; Feng, H.; Wei, M.; Song, F.; Lou, Y.; Cui, X.; Wang, H.; Zhuge, Y. Organic and inorganic fertilizers respectively drive bacterial and fungal community compositions in a fluvo-aquic soil in northern China. Soil Tillage Res. 2020, 198, 104540. [CrossRef]

294. Detheridge, A.P.; Cherrett, S.; Clasen, L.A.; Medcalf, K.; Pike, S.; Griffith, G.W.; Scullion, J. Depauperate soil fungal populations from the St. Helena endemic Commidendrum robustum are dominated by Capnodiales. Fungal Ecol. 2020, 45, e100911. [CrossRef]

295. Li, S.-P.; Wang, P.; Chen, Y.; Wilson, M.C.; Yang, X.; Ma, C.; Lu, J.; Chen, X.-Y.; Wu, J.; Shu, W.-S.; et al. Island biogeography of soil bacteria and fungi: Similar patterns, but different mechanisms. ISME J. 2020, 14, 1886-1896. [CrossRef] [PubMed]

296. Barghoorn, E.S.; Linder, D.H. Marine fungi: Their taxonomy and biology. Farlowia 1944, 1, 395-467. [CrossRef]

297. Roth, F.J., Jr.; Orpurt, P.A.; Ahearn, D.G. Occurrence and distribution of fungi in a subtropical marine environment. Can. J. Bot. 1964, 42, 375-383. [CrossRef]

298. Höhnk, W. Über den pilzlichen Befall kalkigerHartteile von Meerestieren. Ber. Dtsch. Wiss. Komm. Meeresforsch. 1969, 20, 129-140.

299. Gaertner, A.N. mit Pollen koderbare marine Pilzediesseits und jenseits des Island-Faroer-RiickensimOberflachenwasser und im Sediment. Veroeff. Inst. Meeresforsch. Bremerhav. 1968, 11, 65-82.

300. Kohlmeyer, J.; Volkmann-Kohlmeyer, B. Illustrated Key to the Filamentous Higher Marine Fungi. Bot. Mar. 1991, $34,1-61$. [CrossRef]

301. Raghukumar, C.; Raghukumar, S. Barotolerance of fungi isolated from deep-sea sediments of the Indian Ocean. Aquat. Microb. Ecol. 1998, 15, 153-163. [CrossRef]

302. Nagahama, T.; Hamamoto, M.; Nakase, T.; Horikoshi, K. Rhodotorula lamellibrachii sp. nov., a new yeast species from a tubeworm collected at the deep-sea floor in Sagami bay and its phylogenetic analysis. Antonie Leeuwenhoek 2001, 80, 317-323. [CrossRef] [PubMed]

303. Edgcomb, V.P.; Kysela, D.T.; Teske, A.; de Vera Gomez, A.; Sogin, M.L. Benthic eukaryotic diversity in the Guaymas Basin hydrothermal vent environment. Proc. Natl. Acad. Sci. USA 2002, 99, 7658-7662. [CrossRef] [PubMed]

304. Lopez-Garcia, P.; Philippe, H.; Gail, F.; Moreira, D. Autochthonous eukaryotic diversity in hydrothermal sediment and experimental microcolonizers at the Mid-Atlantic Ridge. Proc. Natl. Acad. Sci. USA 2003, 100, 697-702. [CrossRef] [PubMed]

305. Raghukumar, C.; Raghukumar, S.; Sheelu, G.; Gupta, S.; Nagendernath, B.; Rao, B. Buried in time: Culturable fungi in a deep-sea sediment core from the Chagos Trench, Indian Ocean. Deep Sea Res. Part I Oceanogr. Res. Pap. 2004, 51, 1759-1768. [CrossRef]

306. Biddle, J.; House, C.H.; Brenchley, J.E. Microbial stratification in deeply buried marine sediment reflects changes in sulfate/methane profiles. Geobiology 2005, 3, 287-295. [CrossRef]

307. Damare, S.; Raghukumar, C.; Raghukumar, S. Fungi in deep-sea sediments of the Central Indian Basin. Deep Sea Res. Part I Oceanogr. Res. Pap. 2006, 53, 14-27. [CrossRef]

308. Takishita, K.; Tsuchiya, M.; Reimer, J.D.; Maruyama, T. Molecular evidence demonstrating the basidiomycetous fungus Cryptococcus curvatus is the dominant microbial eukaryote in sediment at the Kuroshima Knoll methane seep. Extremophiles 2006, 10, 165-169. [CrossRef]

309. Damare, S.; Raghukumar, C.; Muraleedharan, U.D.; Raghukumar, S. Deep-sea fungi as a source of alkaline and cold-tolerant proteases. Enzym. Microb. Technol. 2006, 39, 172-181. [CrossRef]

310. Bass, D.; Howe, A.; Brown, N.; Barton, H.; Demidova, M.; Michelle, H.; Li, L.; Sanders, H.; Watkinson, S.C.; Willcock, S.; et al. Yeast forms dominate fungal diversity in the deep oceans. Proc. R. Soc. B Boil. Sci. 2007, 274, 3069-3077. [CrossRef]

311. Lai, X.; Cao, L.; Tan, H.; Fang, S.; Huang, Y.; Zhou, S. Fungal communities from methane hydrate-bearing deep-sea marine sediments in South China Sea. ISME J. 2007, 1, 756-762. [CrossRef]

312. López-García, P.; Vereshchaka, A.; Moreira, D. Eukaryotic diversity associated with carbonates and fluid-seawater interface in Lost City hydrothermal field. Environ. Microbiol. 2007, 9, 546-554. [CrossRef]

313. Damare, S.; Raghukumar, C. Fungi and Macroaggregation in Deep-Sea Sediments. Microb. Ecol. 2008, 56, 168-177. [CrossRef] [PubMed]

314. Connell, L.; Barrett, A.; Templeton, A.; Staudigel, H. Fungal Diversity Associated with an Active Deep Sea Volcano: Vailulu'u Seamount, Samoa. Geomicrobiol. J. 2009, 26, 597-605. [CrossRef]

315. Dupont, J.; Magnin, S.; Rousseau, F.; Zbinden, M.; Frebourg, G.; Samadi, S.; de Forges, B.R.; Jones, E.G. Molecular and ultrastructural characterization of two ascomycetes found on sunken wood off Vanuatu Islands in the deep Pacific Ocean. Mycol. Res. 2009, 113, 1351-1364. [CrossRef] [PubMed]

316. Le Calvez, T.; Burgaud, G.; Mahé, S.; Barbier, G.; Vandenkoornhuyse, P. Fungal Diversity in Deep-Sea Hydrothermal Ecosystems. Appl. Environ. Microbiol. 2009, 75, 6415-6421. [CrossRef] 
317. Burgaud, G.; Le Calvez, T.; Arzur, D.; Vandenkoornhuyse, P.; Barbier, G. Diversity of culturable marine filamentous fungi from deep-sea hydrothermal vents. Environ. Microbiol. 2009, 11, 1588-1600. [CrossRef]

318. Burgaud, G.; Arzur, D.; Durand, L.; Cambon-Bonavita, M.-A.; Barbier, G. Marine culturable yeasts in deep-sea hydrothermal vents: Species richness and association with fauna: Culturable yeasts from hydrothermal vents. FEMS Microbiol. Ecol. 2010, 73, 121-133. [CrossRef]

319. Nagano, Y.; Nagahama, T.; Hatada, Y.; Nunoura, T.; Takami, H.; Miyazaki, J.; Takai, K.; Horikoshi, K. Fungal diversity in deep-sea sediments-The presence of novel fungal groups. Fungal Ecol. 2010, 3, 316-325. [CrossRef]

320. Sauvadet, A.-L.; Gobet, A.; Guillou, L. Comparative analysis between protist communities from the deep-sea pelagic ecosystem and specific deep hydrothermal habitats. Environ. Microbiol. 2010, 12, 2946-2964. [CrossRef]

321. Singh, P.; Raghukumar, C.; Verma, P.; Shouche, Y. Phylogenetic diversity of culturable fungi from the deep-sea sediments of the Central Indian Basin and their growth characteristics. Fungal Divers. 2010, 40, 89-102. [CrossRef]

322. Bhadury, P.; Bik, H.; Lambshead, J.D.; Austen, M.C.; Smerdon, G.R.; Rogers, A.D. Molecular Diversity of Fungal Phylotypes Co-Amplified Alongside Nematodes from Coastal and Deep-Sea Marine Environments. PLoS ONE 2011, 6, e26445. [CrossRef] [PubMed]

323. Edgcomb, V.P.; Beaudoin, D.; Gast, R.; Biddle, J.F.; Teske, A. Marine subsurface eukaryotes: The fungal majority: Marine subsurface eukaryotes. Environ. Microbiol. 2011, 13, 172-183. [CrossRef] [PubMed]

324. Eloe, E.A.; Shulse, C.N.; Fadrosh, D.W.; Williamson, S.J.; Allen, E.E.; Bartlett, D.H. Compositional differences in particle-associated and free-living microbial assemblages from an extreme deep-ocean environment: Microbial diversity in the puertorico trench. Environ. Microbiol. Rep. 2011, 3, 449-458. [CrossRef] [PubMed]

325. Nagahama, T.; Takahashi, E.; Nagano, Y.; Abdel-Wahab, M.A.; Miyazaki, M. Molecular evidence that deep-branching fungi are major fungal components in deep-sea methane cold-seep sediments. Environ. Microbiol. 2011, 13, 2359-2370. [CrossRef]

326. Quaiser, A.; Zivanovic, Y.; Moreira, D.; López-García, P. Comparative metagenomics of bathypelagic plankton and bottom sediment from the Sea of Marmara. ISME J. 2010, 5, 285-304. [CrossRef]

327. Singh, P.; Raghukumar, C.; Verma, P.; Shouche, Y. Fungal Community Analysis in the Deep-Sea Sediments of the Central Indian Basin by Culture-Independent Approach. Microb. Ecol. 2011, 61, 507-517. [CrossRef]

328. Singh, P.; Raghukumar, C.; Meena, R.M.; Verma, P.; Shouche, Y. Fungal diversity in deep-sea sediments revealed by culturedependent and culture-independent approaches. Fungal Ecol. 2012, 5, 543-553. [CrossRef]

329. Thaler, A.D.; Van Dover, C.L.; Vilgalys, R. Ascomycete phylotypes recovered from a Gulf of Mexico methane seep are identical to an uncultured deep-sea fungal clade from the Pacific. Fungal Ecol. 2012, 5, 270-273. [CrossRef]

330. Kimes, N.E.; Callaghan, A.V.; Aktas, D.F.; Smith, W.L.; Sunner, J.; Golding, B.T.; Drozdowska, M.; Hazen, T.C.; Suflita, J.M.; Morris, P.J. Metagenomic analysis and metabolite profiling of deep-sea sediments from the Gulf of Mexico following the Deepwater Horizon oil spill. Front. Microbiol. 2013, 4, 50. [CrossRef]

331. Orsi, W.; Biddle, J.; Edgcomb, V. Deep Sequencing of Subseafloor Eukaryotic rRNA Reveals Active Fungi across Marine Subsurface Provinces. PLoS ONE 2013, 8, e56335. [CrossRef]

332. Zhang, T.; Zhang, Y.-Q.; Liu, H.-Y.; Wei, Y.-Z.; Li, H.-L.; Su, J.; Zhao, L.-X.; Yu, L.-Y. Diversity and cold adaptation of culturable endophytic fungi from bryophytes in the Fildes Region, King George Island, maritime Antarctica. FEMS Microbiol. Lett. 2013, 341, 52-61. [CrossRef] [PubMed]

333. Bernhard, J.M.; Kormas, K.; Pachiadaki, M.; Rocke, E.; Beaudoin, D.J.; Morrison, C.; Visscher, P.; Cobban, A.; Starczak, V.R.; Edgcomb, V. Benthic protists and fungi of Mediterranean deep hypsersaline anoxic basin redoxcline sediments. Front. Microbiol. 2014, 5, 605. [CrossRef] [PubMed]

334. Rédou, V.; Ciobanu, M.C.; Pachiadaki, M.G.; Edgcomb, V.; Alain, K.; Barbier, G.; Burgaud, G. In-depth analyses of deep subsurface sediments using 454-pyrosequencing reveals a reservoir of buried fungal communities at record-breaking depths. FEMS Microbiol. Ecol. 2014, 90, 908-921. [CrossRef] [PubMed]

335. Wei, W.; Isobe, K.; Shiratori, Y.; Nishizawa, T.; Ohte, N.; Otsuka, S.; Senoo, $\mathrm{K}_{\text {. }} \mathrm{N}_{2} \mathrm{O}$ emission from cropland field soil through fungal denitrification after surface applications of organic fertilizer. Soil Biol. Biochem. 2014, 69, 157-167. [CrossRef]

336. Zhang, D.; Ge, H.; Zou, J.-H.; Tao, X.; Chen, R.; Dai, J. Periconianone A, a new 6/6/6 carbocyclic sesquiterpenoid from endophytic fungus Periconia sp. with neural anti-inflammatory activity. Org. Lett. 2014, 16, 1410-1413. [CrossRef]

337. Rédou, V.; Navarri, M.; Meslet-Cladière, L.; Barbier, G.; Burgaud, G. Species richness and adaptation of marine fungi from deep-subsea floor sediments. Appl. Environ. Microbiol. 2015, 81, 3571-3583. [CrossRef]

338. Edgcomb, V.P.; Pachiadaki, M.; Mara, P.; Kormas, K.; Leadbetter, E.R.; Bernhard, J. Gene expression profiling of microbial activities and interactions in sediments under haloclines of E. Mediterranean deep hypersaline anoxic basins. ISME J. 2016, 10, $2643-2657$. [CrossRef]

339. Tisthammer, K.H.; Cobian, G.; Amend, A.S. Global biogeography of marine fungi is shaped by the environment. Fungal Ecol. 2016, 19, 39-46. [CrossRef]

340. Boraks, A.; Amend, A.S. Fungi in soil and understory have coupled distribution patterns. Peer] 2021, 9, e11915. [CrossRef]

341. Zhang, T.; Wang, N.-F.; Liu, H.-Y.; Zhang, Y.-Q.; Yu, L.-Y. Soil pH is a Key Determinant of Soil Fungal Community Composition in the Ny-Ålesund Region, Svalbard (High Arctic). Front. Microbiol. 2016, 7, 227. [CrossRef]

342. Ali, S.H.; Alias, S.A.; Siang, H.Y.; Smykla, J.; Pang, K.L.; Guo, S.Y.; Peter, C. Studies on diversity of soil microbfungi in the Hornsund area, Spitsbergen. Pol. Polar Res. 2013, 34, 39-54. 
343. Pachiadaki, M.; Rédou, V.; Beaudoin, D.J.; Burgaud, G.; Edgcomb, V.P. Fungal and Prokaryotic Activities in the Marine Subsurface Biosphere at Peru Margin and Canterbury Basin Inferred from RNA-Based Analyses and Microscopy. Front. Microbiol. 2016, 7, 846. [CrossRef] [PubMed]

344. Bochdansky, A.B.; Clouse, M.A.; Herndl, G.J. Eukaryotic microbes, principally fungi and labyrinthulomycetes, dominate biomass on bathypelagic marine snow. ISME J. 2017, 11, 362-373. [CrossRef] [PubMed]

345. Vera, J.; Gutiérrez, M.H.; Palfner, G.; Pantoja, S. Diversity of culturable filamentous Ascomycetes in the eastern South Pacific Ocean off Chile. World J. Microbiol. Biotechnol. 2017, 33, 157. [CrossRef]

346. Nagano, Y.; Miura, T.; Nishi, S.; Lima, A.; Nakayama, C.R.; Pellizari, V.; Fujikura, K. Fungal diversity in deep-sea sediments associated with asphalt seeps at the Sao Paulo Plateau. Deep Sea Res. Part II Top. Stud. Oceanogr. 2017, 146, 59-67. [CrossRef]

347. Orsi, W.D.; Richards, T.A.; Francis, W.R. Predicted microbial secretomes and their target substrates in marine sediment. Nat. Microbiol. 2018, 3, 32-37. [CrossRef]

348. Wei, X.; Guo, S.; Gong, L.-F.; He, G.; Pang, K.-L.; Luo, Z.-H. Cultivable Fungal Diversity in Deep-Sea Sediment of the East Pacific Ocean. Geomicrobiol. J. 2018, 35, 790-797. [CrossRef]

349. Barone, G.; Rastelli, E.; Corinaldesi, C.; Tangherlini, M.; Danovaro, R.; Dell'Anno, A. Benthic deep-sea fungi in submarine canyons of the Mediterranean Sea. Prog. Oceanogr. 2018, 168, 57-64. [CrossRef]

350. Xu, W.; Gong, L.F.; Pang, K.L.; Luo, Z.H. Fungal diversity in deep-sea sediments of a hydrothermal vent system in the Southwest Indian Ridge. Deep Sea Res. Part I Oceanogr. Res. Pap. 2018, 131, 16-26. [CrossRef]

351. Li, J.; Meng, B.; Chai, H.; Yang, X.; Song, W.; Li, S.; Lu, A.; Zhang, T.; Sun, W. Arbuscular Mycorrhizal Fungi Alleviate Drought Stress in C3 (Leymus chinensis) and C4 (Hemarthria altissima) Grasses via Altering Antioxidant Enzyme Activities and Photosynthesis. Front. Plant Sci. 2019, 10, 499. [CrossRef]

352. Vargas-Gastélum, L.; Chong-Robles, J.; Lago-Lestón, A.; Darcy, J.L.; Amend, A.S.; Riquelme, M. Targeted ITS1 sequencing unravels the mycodiversity of deep-sea sediments from the Gulf of Mexico. Environ. Microbiol. 2019, 21, 4046-4061. [CrossRef] [PubMed]

353. Wei, F.; Zhao, L.; Xu, X.; Feng, H.; Shi, Y.; Deakin, G.; Feng, Z.; Zhu, H. Cultivar-Dependent Variation of the Cotton Rhizosphere and Endosphere Microbiome Under Field Conditions. Front. Plant Sci. 2019, 10, 1659. [CrossRef]

354. Velez, P.; Gasca-Pineda, J.; Riquelme, M. Cultivable fungi from deep-sea oil reserves in the Gulf of Mexico: Genetic signatures in response to hydrocarbons. Mar. Environ. Res. 2020, 153, 104816. [CrossRef] [PubMed]

355. Wieser, A.; Schneider, L.; Jung, J.; Schubert, S. MALDI-TOF MS in microbiological diagnostics-Identification of microorganisms and beyond (mini review). Appl. Microbiol. Biotechnol. 2012, 93, 965-974. [CrossRef] [PubMed]

356. Rossman, A.Y.; Samuels, G.J. Towards a single scientific name for species of fungi. Inoculum 2005, 56, 3-6.

357. Stadler, M.; Læssøe, T.; Fournier, J.; Decock, C.; Schmieschek, B.; Tichy, H.-V.; Persoh, D. A polyphasic taxonomy of Daldinia (Xylariaceae). Stud. Mycol. 2014, 77, 1-143. [CrossRef]

358. Bhunjun, C.S.; Dong, Y.; Jayawardena, R.; Jeewon, R.; Phukhamsakda, C.; Bundhun, D.; Hyde, K.D.; Sheng, J. A polyphasic approach to delineate species in Bipolaris. Fungal Divers. 2020, 102, 225-256. [CrossRef]

359. Crous, P.W.; Hawksworth, D.L.; Wingfield, M.J. Identifying and Naming Plant-Pathogenic Fungi: Past, Present, and Future. Annu. Rev. Phytopathol. 2015, 53, 247-267. [CrossRef]

360. Bhunjun, C.S.; Phukhamsakda, C.; Jayawardena, R.S.; Jeewon, R.; Promputtha, I.; Hyde, K.D. Investigating species boundaries in Colletotrichum. Fungal Divers. 2021, 107, 107-127. [CrossRef]

361. Hebert, P.D.N.; Cywinska, A.; Ball, S.L.; Dewaard, J.R. Biological identifications through DNA barcodes. Proc. R. Soc. B Boil. Sci. 2003, 270, 313-321. [CrossRef]

362. Lücking, R.; Aime, M.C.; Hawksworth, D.L.; Hyde, K.D.; Irinyi, L.; Jeewon, R.; Johnston, P.R.; Kirk, P.M.; Malosso, E.; May, T.W.; et al. Unambiguous identification of fungi: Where do we stand and how accurate and precise is fungal DNA barcoding? IMA Fungus 2020, 11, 14. [CrossRef] [PubMed]

363. Lindahl, J.F.; Grace, D. The consequences of human actions on risks for infectious diseases: A review. Infect. Ecol. Epidemiol. 2015, 5, 30048. [CrossRef] [PubMed]

364. Taylor, J.W.; Jacobson, D.J.; Kroken, S.; Kasuga, T.; Geiser, D.M.; Hibbett, D.S.; Fisher, M. Phylogenetic Species Recognition and Species Concepts in Fungi. Fungal Genet. Biol. 2000, 31, 21-32. [CrossRef] [PubMed]

365. Ariyawansa, H.A.; Hyde, K.D.; Jayasiri, S.C.; Buyck, B.; Chethana, K.T.; Dai, D.Q.; Dai, Y.C.; Daranagama, D.A.; Jayawardena, R.S.; Lücking, R.; et al. Fungal diversity notes 111-252-Taxonomic and phylogenetic contributions to fungal taxa. Fungal Divers. 2015, 75, 27-274. [CrossRef]

366. Lawrence, D.P.; Gannibal, P.; Peever, T.L.; Pryor, B.M. The sections of Alternaria: Formalizing species-group concepts. Mycologia 2013, 105, 530-546. [CrossRef]

367. Woudenberg, J.; Groenewald, J.; Binder, M.; Crous, P. Alternaria redefined. Stud. Mycol. 2013, 75, 171-212. [CrossRef]

368. Woudenberg, J.H.C.; van der Merwe, N.A.; Jurjević, Ž.; Groenewald, J.Z.; Crous, P.W. Diversity and movement of indoor Alternaria alternata across the mainland USA. Fungal Genet. Biol. 2015, 81, 62-72. [CrossRef]

369. Kim, M.-S.; Klopfenstein, N.B.; Hanna, J.W.; McDonald, G.I. Characterization of North American Armillaria species: Genetic relationships determined by ribosomal DNA sequences and AFLP markers. For. Pathol. 2006, 36, 145-164. [CrossRef]

370. Coetzee, M.P.A.; Wingfeld, B.D.; Wingfeld, M.J. Armillaria root-rot pathogens: Species boundaries and global distribution. Pathogens 2018, 7, 83. [CrossRef] 
371. Dissanayake, A.J.; Phillips, A.J.L.; Li, X.H.; Hyde, K.D. Botryosphaeriaceae: Current status of genera and species. Mycosphere 2016, 7, 1001-1073. [CrossRef]

372. Li, G.J.; Hyde, K.D.; Zhao, R.L.; Hongsanan, S.; Abdel-Aziz, F.A.; Abdel-Wahab, M.A.; Alvarado, P.; Alves-Silva, G.; Ammirati, J.F.; Ariyawansa, H.A.; et al. Fungal diversity notes 253-366: Taxonomic and phylogenetic contributions to fungal taxa. Fungal Divers. 2016, 78, 1-237. [CrossRef]

373. Chen, Q.; Jiang, J.R.; Zhang, G.Z.; Cai, L.; Crous, P.W. Resolving the Phoma enigma. Stud. Mycol. 2015, 82, 137-217. [CrossRef] [PubMed]

374. Chen, Q.; Hou, L.W.; Duan, W.J.; Crous, P.W.; Cai, L. Didymellaceae revisited. Stud. Mycol. 2017, 87, 105-159. [CrossRef] [PubMed]

375. Jayasiri, S.C.; Hyde, K.D.; Jones, E.B.; Jeewon, R.; Ariyawansa, H.A.; Bhat, J.D.; Camporesi, E.; Kang, J.C. Taxonomy and multigene phylogenetic evaluation of novel species in Boeremia and Epicoccum with new records of Ascochyta and Didymella (Didymellaceae). Mycosphere 2017, 8, 1080-1101. [CrossRef]

376. Berner, D.; Cavin, C.; Woudenberg, J.H.; Tunali, B.; Büyük, O.; Kansu, B. Assessment of Boeremiaexigua var. rhapontica, as a biological control agent of Russian knapweed (Rhaponticum repens). Biol. Control 2015, 81, 65-75. [CrossRef]

377. Manamgoda, D.S.; Cai, L.; McKenzie, E.H.C.; Crous, P.W.; Madrid, H.; Chukeatirote, E.; Shivas, R.G.; Tan, Y.P.; Hyde, K.D. A phylogenetic and taxonomic re-evaluation of the Bipolaris-Cochliobolus-Curvularia Complex. Fungal Divers. 2012, 56, 131-144. [CrossRef]

378. Phillips, A.J.L.; Alves, A.; Abdollahzadeh, J.; Slippers, B.; Wingfield, M.J.; Groenewald, J.Z.; Crous, P.W. The Botryosphaeriaceae: Genera and species known from culture. Stud. Mycol. 2013, 76, 51-167. [CrossRef]

379. Hyde, K.D.; Nilsson, R.H.; Alias, S.A.; Ariyawansa, H.A.; Blair, J.E.; Cai, L.; De Cock, A.W.A.M.; Dissanayake, A.J.; Glockling, S.L.; Goonasekara, I.D.; et al. One stop shop: Backbones trees for important phytopathogenic genera: I. Fungal Divers. 2014, 67, 21-125. [CrossRef]

380. Crous, P.W.; Kang, J.C.; Schoch, C.L.; Mchua, G.R.A. Phylogenetic relationships of Cylindrocladium pseudogracile and Cylindrocladium rumohrae with morphologically similar taxa, based on morphology and DNA sequences of internal transcribed spacers and ß-tubulin. Can. J. Bot. 1999, 77, 1813-1820. [CrossRef]

381. Schoch, C.L.; Crous, P.W.; Wingfield, B.D.; Wingfield, M.J. Phylogeny of Calonectria based on comparisons of $\beta$-tubulin DNA sequences. Mycol. Res. 2001, 105, 1045-1052. [CrossRef]

382. Lombard, L.; Crous, P.; Wingfield, B.; Wingfield, M. Species concepts in Calonectria (Cylindrocladium). Stud. Mycol. 2010, 66, 1-13. [CrossRef] [PubMed]

383. Lombard, L.; Crous, P.W.; Wingfield, B.D.; Wingfield, M.J. Phylogeny and systematics of the genus Calonectria. Stud. Mycol. 2010, 66, 31-69. [CrossRef] [PubMed]

384. Lombard, L.; Wingfield, M.; Alfenas, A.; Crous, P. The forgotten Calonectria collection: Pouring old wine into new bags. Stud. Mycol. 2016, 85, 159-198. [CrossRef] [PubMed]

385. Groenewald, J.; Nakashima, C.; Nishikawa, J.; Shin, H.-D.; Park, J.-H.; Jama, A.; Groenewald, M.; Braun, U.; Crous, P. Species concepts in Cercospora: Spotting the weeds among the roses. Stud. Mycol. 2013, 75, 115-170. [CrossRef] [PubMed]

386. Albu, S.; Sharma, S.; Bluhm, B.H.; Price, P.P.; Schneider, R.W.; Doyle, V.P. Draft Genome Sequence of Cercospora cf. sigesbeckiae, a Causal Agent of Cercospora Leaf Blight on Soybean. Genome Announc. 2017, 5, e00708-17. [CrossRef]

387. Guatimosim, E.; Schwartsburd, P.; Barreto, R.; Crous, P. Novel fungi from an ancient niche: Cercosporoid and related sexual morphs on ferns. Persoonia 2016, 37, 106-141. [CrossRef]

388. Bakhshi, M.; Arzanlou, M.; Babai-Ahari, A.; Groenewald, J.Z.; Braun, U.; Crous, P.W. Application of the consolidated species concept to Cercospora spp. from Iran. Persoonia 2015, 34, 65-86. [CrossRef]

389. Bakhshi, M.; Arzanlou, M.; Babai-Ahari, A.; Groenewald, J.Z.; Crous, P.W. Novel primers improve species delimitation in Cercospora. IMA Fungus 2018, 9, 299-332. [CrossRef]

390. Jiang, M.; Kirschner, R. Unraveling two East Asian species of Clinoconidium (Cryptobasidiaceae). Mycoscience 2016, 57, 440-447. [CrossRef]

391. Kakishima, M.; Ji, J.-X.; Nagao, H.; Wang, Q.; Denchev, C.M. Clinoconidium globosum, nom. nov. (Cryptobasidiaceae) producing galls on fruits of Cinnamomum daphnoides in Japan. Phytotaxa 2017, 299, 267-272. [CrossRef]

392. Kakishima, M.; Nagao, H.; Ji, J.-X.; Sun, Y.; Denchev, C.M. Clinoconidium onumae, comb. nov. (Cryptobasidiaceae) producing galls on shoot buds of Cinnamomum tenuifolium in Japan. Phytotaxa 2017, 313, 175-184. [CrossRef]

393. Schoch, C.L.; Seifert, K.A.; Huhndorf, S.; Robert, V.; Spouge, J.L.; Levesque, C.A.; Chen, W.; Fungal Barcoding Consortium. Nuclear ribosomal internal transcribed spacer (ITS) region as a universal DNA barcode marker for Fungi. Proc. Natl. Acad. Sci. USA 2012, 109, 6241-6246. [CrossRef] [PubMed]

394. Doyle, V.P.; Oudemans, P.; Rehner, S.A.; Litt, A. Habitat and Host Indicate Lineage Identity in Colletotrichum gloeosporioides s.1. from Wild and Agricultural Landscapes in North America. PLoS ONE 2013, 8, e62394. [CrossRef]

395. Gunjan, S.; Navinder, K.; Weir, B.S.; Hyde, K.D.; Shenoy, B.D. Apmat gene can resolve Colletotrichum species: A case study with Mangifera indica. Fungal Divers. 2013, 61, 117-138.

396. Silva, D.N.; Talhinas, P.; Várzea, V.; Cai, L.; Paulo, O.S.; Batista, D. Application of the Apn2/MAT locus to improve the systematics of the Colletotrichum gloeosporioides complex: An example from coffee (Coffea spp.) hosts. Mycologia 2012, 104, 396-409. [CrossRef]

397. Castlebury, L.A.; Rossman, A.Y.; Jaklitsch, W.J.; Vasilyeva, L.N. A preliminary overview of the Diaporthales based on large subunit nuclear ribosomal DNA sequences. Mycologia 2002, 94, 1017-1031. [CrossRef] 
398. Van Niekerk, J.M.; Groenewald, J.Z.E.; Verkley, G.J.; Fourie, P.H.; Wingfield, M.J.; Crous, P.W. Systematic reappraisal of Coniella and Pilidiella, with specific reference to species occurring on Eucalyptus and Vitis in South Africa. Mycol. Res. 2004, 108, 283-303. [CrossRef]

399. Phookamsak, R.; Liu, J.-K.; McKenzie, E.H.C.; Manamgoda, D.S.; Ariyawansa, H.; Thambugala, K.M.; Dai, D.-Q.; Camporesi, E.; Chukeatirote, E.; Wijayawardene, N.N.; et al. Revision of Phaeosphaeriaceae. Fungal Divers. 2014, 68, 159-238. [CrossRef]

400. Alvarez, L.; Groenewald, J.; Crous, P. Revising the Schizoparmaceae: Coniella and its synonyms Pilidiella and Schizoparme. Stud. Mycol. 2016, 85, 1-34. [CrossRef]

401. Chethana, K.W.T.; Zhou, Y.; Zhang, W.; Liu, M.; Xing, Q.K.; Li, X.H.; Yan, J.Y.; Hyde, K.D. Coniellavitis sp. nov. Is the Common Pathogen of White Rot in Chinese Vineyards. Plant Dis. 2017, 101, 2123-2136. [CrossRef]

402. Manamgoda, D.; Rossman, A.; Castlebury, L.; Crous, P.; Madrid, H.; Chukeatirote, E.; Hyde, K. The genus Bipolaris. Stud. Mycol. 2014, 79, 221-288. [CrossRef] [PubMed]

403. Hyde, K.D.; Norphanphoun, C.; Abreu, V.P.; Bazzicalupo, A.; Chethana, K.W.T.; Clericuzio, M.; Dayarathne, M.C.; Dissanayake, A.J.; Ekanayaka, A.H.; He, M.-Q.; et al. Fungal diversity notes 603-708: Taxonomic and phylogenetic notes on genera and species. Fungal Divers. 2017, 87, 1-235. [CrossRef]

404. Marin-Felix, Y.; Groenewald, J.Z.; Cai, L.; Chen, Q.; Marincowitz, S.; Barnes, I.; Bensch, K.; Braun, U.; Camporesi, E.; Damm, U.; et al. Genera of phytopathogenic fungi: GOPHY 1. Stud. Mycol. 2017, 86, 99-216. [CrossRef] [PubMed]

405. Lombard, L.; Cheewangkoon, R.; Crous, P.W. New Cylindrocladiella spp. from Thailand soils. Mycosphere 2017, 8, 1088-1104. [CrossRef]

406. Marin-Felix, Y.; Hernández-Restrepo, M.; Wingfield, M.; Akulov, A.; Carnegie, A.; Cheewangkoon, R.; Gramaje, D.; Groenewald, J.; Guarnaccia, V.; Halleen, F.; et al. Genera of phytopathogenic fungi: GOPHY 2. Stud. Mycol. 2019, 92, 47-133. [CrossRef] [PubMed]

407. Réblová, M.; Untereiner, W.A.; Réblová, K. Novel evolutionary lineagesrevealed in the Chaetothyriales (Fungi) based on multigene phylogenetic analyses and comparison of ITS secondary structure. PLoS ONE 2013, 8, e63547. [CrossRef]

408. Feng, P.; Lu, Q.; Najafzadeh, M.J.; van den Ende, A.G.; Sun, J.; Li, R.; Xi, L.; Vicente, V.A.; Lai, W.; Lu, C.; et al. Cyphellophora and its relatives in Phialophora: Biodiversity and possible role in human infection. Fungal Divers. 2014, 65, 17-45. [CrossRef]

409. Alves, A.; Linaldeddu, B.T.; Deidda, A.; Scanu, B.; Phillips, A.J.L. The complex of Diplodia species associated with Fraxinus and some other woody hosts in Italy and Portugal. Fungal Divers. 2014, 67, 143-156. [CrossRef]

410. Abdollahzadeh, J.; Javadi, A.; Zare, R.; Phillips, A. A phylogenetic study of Dothiorella and Spencermartinsia species associated with woody plants in Iran, New Zealand, Portugal and Spain. Persoonia 2014, 32, 1-12. [CrossRef]

411. Jayawardena, R.; Ariyawansa, H.; Singtripop, C.; Li, Y.M.; Yan, J.; Li, X.; Nilthong, S.; Hyde, K.D. A re-assessment of Elsinoaceae (Myriangiales, Dothideomycetes). Phytotaxa 2014, 176, 120-138. [CrossRef]

412. Fan, X.; Barreto, R.; Groenewald, J.; Bezerra, J.; Pereira, O.; Cheewangkoon, R.; Mostert, L.; Tian, C.; Crous, P. Phylogeny and taxonomy of the scab and spot anthracnose fungus Elsinoe (Myriangiales, Dothideomycetes). Stud. Mycol. 2017, 87, 1-41. [CrossRef]

413. Da Silva, C.S.; Pereira, M.B.; Pereira, J. New accounts on Hypoxylaceae and Xylariaceae from Brazil. Rodriguésia 2020, $71,03012018$. [CrossRef]

414. Kruse, J.; Piatek, M.; Lutz, M.; Thines, M. Broad host range species in specialised pathogen groups should be treated with suspicion-A case study on Entyloma infecting Ranunculus. Persoonia 2018, 41, 175-201. [CrossRef] [PubMed]

415. Rooney-Latham, S.; Lutz, M.; Blomquist, C.L.; Romberg, M.K.; Scheck, H.J.; Piątek, M. Entyloma helianthi: Identification and characterization of the casual agent of sunflower white leaf smut. Mycologia 2017, 109, 520-528. [CrossRef] [PubMed]

416. Ghobad-Nejhad, M.; Hallenberg, N. Erythricium atropatanum sp. nov. (Corticiales) from Iran, based on morphological and molecular data. Mycol. Prog. 2011, 10, 61-66. [CrossRef]

417. Thynne, E.; McDonald, M.C.; Evans, M.; Wallwork, H.; Neate, S.; Solomon, P.S. Re-classification of the causal agent of white grain disorder on wheat as three separate species of Eutiarosporella. Australas. Plant Pathol. 2015, 44, 527-539. [CrossRef]

418. Burgess, T.I.; Tan, Y.P.; Garnas, J.; Edwards, J.; Scarlett, K.A.; Shuttleworth, L.A.; Daniel, R.; Dann, E.K.; Parkinson, L.; Dinh, Q.; et al. Current status of the Botryosphaeriaceae in Australia. Australas. Plant Pathol. 2019, 48, 35-44. [CrossRef]

419. Santana, M.D.C.; Amalfi, M.; Robledo, G.; da Silveira, R.M.B.; Decock, C. Fomitiporia neotropica, a new species from South America evidenced by multilocus phylogenetic analyses. Mycol. Prog. 2014, 13, 601-615. [CrossRef]

420. Chen, H.; Cui, B.-K. Multi-locus phylogeny and morphology reveal five new species of Fomitiporia (Hymenochaetaceae) from China. Mycol. Prog. 2017, 16, 687-701. [CrossRef]

421. Morera, G.; Robledo, G.; Ferreira-Lopes, V.; Urcelay, C. South American Fomitiporia (Hymenochaetaceae, Basidiomycota) 'jump on'exotic living trees revealed by multi-gene phylogenetic analysis. Phytotaxa 2017, 321, 277-286. [CrossRef]

422. Zhou, L.W. Fulvifomes hainanensis sp. nov. and F. indicus comb. nov. (Hymenochaetales, Basidiomycota) evidenced by a combination of morphology and phylogeny. Mycoscience 2014, 55, 70-77. [CrossRef]

423. Zhou, L.-W. Fulvifomes imbricatus and F. thailandicus (Hymenochaetales, Basidiomycota): Two new species from Thailand based on morphological and molecular evidence. Mycol. Prog. 2015, 14, 89. [CrossRef]

424. Ji, X.H.; Wu, F.; Dai, Y.C.; Vlasák, J. Two new species of Fulvifomes (Hymenochaetales, Basidiomycota) from America. MycoKeys 2017, 22, 1-13. [CrossRef] 
425. Salvador-Montoya, C.A.; Popoff, O.F.; Reck, M.; Drechsler-Santos, E.R. Taxonomic delimitation of Fulvifomes robiniae (Hymenochaetales, Basidiomycota) and related species in America: F. squamosus sp. nov. Plant Syst. Evol. 2018, 304, 445-459. [CrossRef]

426. Laurence, M.H.; Summerell, B.A.; Burgess, L.W.; Liew, E.C.Y. Fusarium burgessii sp. nov. representing a novel lineage in the genus Fusarium. Fungal Divers. 2011, 49, 101-112. [CrossRef]

427. O'Donnell, K.; Rooney, A.P.; Proctor, R.H.; Brown, D.W.; McCormick, S.P.; Ward, T.J.; Frandsen, R.J.N.; Lysøe, E.; Rehner, S.A.; Aoki, T.; et al. RPB1 and RPB2 phylogeny supports an early Cretaceous origin and a strongly supported clade comprising all agriculturally and medically important fusaria. Fungal Genet. Biol. 2013, 52, 20-31. [CrossRef]

428. O’Donnell, K.; Sutton, D.A.; Fothergill, A.; McCarthy, D.; Rinaldi, M.G.; Brandt, M.E.; Zhang, N.; Geiser, D.M. Molecular Phylogenetic Diversity, Multilocus Haplotype Nomenclature, and In Vitro Antifungal Resistance within the Fusarium solani Species Complex. J. Clin. Microbiol. 2008, 46, 2477-2490. [CrossRef]

429. Coetzee, M.P.A.; Marincowitz, S.; Muthelo, V.G.; Wingfield, M.J. Ganoderma species, including new taxa associated with root rot of the iconic Jacaranda mimosifolia in Pretoria, South Africa. IMA Fungus 2015, 6, 249-256. [CrossRef]

430. Xing, J.-H.; Song, J.; Decock, C.; Cui, B. Morphological characters and phylogenetic analysis reveal a new species within the Ganoderma lucidum complex from South Africa. Phytotaxa 2016, 266, 115-124. [CrossRef]

431. Xing, J.H.; Sun, Y.F.; Han, Y.L.; Cui, B.K.; Dai, Y.C. Morphological and molecular identifcation of two new Ganoderma species on Casuarina equisetifolia from China. MycoKeys 2018, 34, 93-108. [CrossRef]

432. Tchoumi, J.M.T.; Coetzee, M.P.A.; Rajchenberg, M.; Roux, J. Taxonomy and species diversity of Ganoderma species in the Garden Route National Park of South Africa inferred from morphology and multilocus phylogenies. Mycologia 2019, 111, 730-747. [CrossRef] [PubMed]

433. Luangharn, T.; Karunarathna, S.C.; Mortimer, P.E.; Hyde, K.D.; Xu, J. Additions to the knowledge of Ganoderma in Thailand: Ganoderma casuarinicola, a new record; and Ganoderma thailandicum sp. nov. MycoKeys 2019, 59, 47-65. [CrossRef] [PubMed]

434. Ye, L.; Karunarathna, S.C.; Mortimer, P.E.; Li, H.; Qiu, M.-H.; Peng, X.-R.; Luangharn, T.; Li, Y.-J.; Promputtha, I.; Hyde, K.D.; et al. Ganoderma weixiensis (Polyporaceae, Basidiomycota), a new member of the G. lucidum complex from Yunnan Province, China. Phytotaxa 2019, 423, 75-86. [CrossRef]

435. Cabarroi-Hernández, M.; Villalobos-Arámbula, A.R.; Torres-Torres, M.G.; Decock, C.; Guzmán-Dávalos, L. The Ganoderma weberianum-resinaceum lineage: Multilocus phylogenetic analysis and morphology confrm G. mexicanum and G. parvulum in the Neotropics. MycoKeys 2019, 59, 95-131. [CrossRef] [PubMed]

436. Braun, U.; Bradshaw, M.; Zhao, T.-T.; Cho, S.-E.; Shin, H.-D. Taxonomy of the Golovinomyces cynoglossi complex (Erysiphales, Ascomycota) disentangled by phylogenetic analyses and reassessments of morphological traits. Mycobiology 2018, 46, 192-204. [CrossRef] [PubMed]

437. Braun, U.; Shin, H.; Takamatsu, S.; Meeboon, J.; Kiss, L.; Lebeda, A.; Kitner, M.; Götz, M. Phylogeny and taxonomy of Golovinomyces orontii revisited. Mycol. Prog. 2019, 18, 335-357. [CrossRef]

438. Takamatsu, S.; Matsuda, S.; Grigaliunaite, B. Comprehensive phylogenetic analysis of the genus Golovinomyces (Ascomycota: Erysiphales) reveals close evolutionary relationships with its host plants. Mycologia 2013, 105, 1135-1152. [CrossRef]

439. Qiu, P.-L.; Liu, S.-Y.; Li, Y.; Wang, L.-L.; Braun, U.; Bradshaw, M.; Rooney-Latham, S.; Takamatsu, S.; Bulgakov, T.; Tang, S.-R.; et al. Multi-locus phylogeny and taxonomy of an unresolved, heterogeneous species complex within the genus Golovinomyces (Ascomycota, Erysiphales), including G. ambrosiae, G. circumfusus and G. spadiceus. BMC Microbiol. 2020, 20, e51. [CrossRef]

440. Qiu, P.L.; Qi, X.F.; Li, Y.; Braun, U.; Liu, S.Y. Epitypifcation and molecular confrmation of Erysiphe cucurbitacearum as a synonym of Golovinomyces tabaci. Mycoscience 2020, 61, 30-36. [CrossRef]

441. Chen, J.-J.; Cui, B.; Zhou, L.-W.; Korhonen, K.T.; Dai, Y.-C. Phylogeny, divergence time estimation, and biogeography of the genus Heterobasidion (Basidiomycota, Russulales). Fungal Divers. 2015, 71, 185-200. [CrossRef]

442. Cabral, A.; Groenewald, J.Z.; Rego, M.C.N.F.; Oliveira, H.; Crous, P.W. Cylindrocarpon root rot: Multi-gene analysis reveals novel species within the Ilyonectria radicicola species complex. Mycol. Prog. 2012, 11, 655-688. [CrossRef]

443. Cabral, A.; Rego, C.; Crous, P.W.; Oliveira, H. Virulence and cross-infection potential of Ilyonectria spp. to grapevine. Phytopathol. Mediterr. 2012, 52, 340-354.

444. Cabral, A.; Rego, C.; Nascimento, T.; Oliveira, H.; Groenewald, J.Z.; Crous, P.W. Multi-gene analysis and morphology reveal novel Ilyonectria species associated with black foot disease of grapevines. Fungal Biol. 2012, 116, 62-80. [CrossRef] [PubMed]

445. Lombard, L.; Bezuidenhout, C.M.; Crous, P.W. Ilyonectria black foot rot associated with Proteaceae. Australas. Plant Pathol. 2013, 42, 337-349. [CrossRef]

446. Lombard, L.; Van Der Merwe, N.A.; Groenewald, J.Z.; Crous, P.W. Lineages in Nectriaceae: Re-evaluating the generic status of Ilyonectria and allied genera. Phytopathol. Mediterr. 2014, 53, 515-532.

447. Diederich, P.; Lawrey, J.D.; Sikaroodi, M.; Gillevet, P.M. A new lichenicolous teleomorph is related to plant pathogens in Laetisaria and Limonomyces (Basidiomycota, Corticiales). Mycologia 2011, 103, 525-533. [CrossRef]

448. Zhang, W.; Nan, Z.B.; Liu, G.D. First Report of Limonomyces roseipellis causing pink patch on bermudagrass in South China. Plant Dis. 2013, 97, 561. [CrossRef]

449. Crous, P.W.; Slippers, B.; Wingfield, M.J.; Rheeder, J.; Marasas, W.F.O.; Philips, A.J.L.; Alves, A.; Burgess, T.; Barber, P.; Groenewald, J.Z. Phylogenetic lineages in the Botryosphaeriaceae. Stud. Mycol. 2006, 55, 235-254. [CrossRef] 
450. Sarr, M.P.; Ndiaye, M.; Groenewald, J.Z.; Crous, P.W. Genetic diversity in Macrophomina phaseolina, the causal agent of charcoal rot. Phytopathol. Mediterr. 2014, 53, 250-268.

451. LoBuglio, K.F.; Pfister, D.H. Placement of Medeolaria farlowii in the Leotiomycetes, and comments on sampling within the class. Mycol. Prog. 2010, 9, 361-368. [CrossRef]

452. Pfister, D.H.; Agnello, C.; Lantieri, A.; LoBuglio, K.F. The Caloscyphaceae (Pezizomycetes, Ascomycota), with a new genus. Mycol. Prog. 2013, 12, 667-674. [CrossRef]

453. Hongsanan, S.; Tian, Q.; Persoh, D.; Zeng, X.-Y.; Hyde, K.D.; Chomnunti, P.; Boonmee, S.; Bahkali, A.H.; Wen, T.-C. Meliolales. Fungal Divers. 2015, 74, 91-141. [CrossRef]

454. Justavino, D.R.; Kirschner, R.; Piepenbring, M. New species and new records of Meliolaceae from Panama. Fungal Divers. 2015, 70, 73-84. [CrossRef]

455. Nguyen, T.T.; Duong, T.; Lee, H. Characterization of two new records of Mucoralean species isolated from gut of soldier fy larva in Korea. Mycobiology 2016, 44, 310-313. [CrossRef]

456. Nguyen, T.T.; Jung, H.Y.; Lee, Y.S.; Voigt, K.; Lee, H.B. Phylogenetic status of two undescribed zygomycete species from Korea: Actinomucor elegans and Mucor minutus. Mycobiology 2017, 45, e34. [CrossRef]

457. Walther, G.; Pawłowska, J.; Alastruey-Izquierdo, A.; Wrzosek, M.; Rodriguez-Tudela, J.; Dolatabadi, S.; Chakrabarti, A.; de Hoog, G. DNA barcoding in Mucorales: An inventory of biodiversity. Persoonia 2013, 30, 11-47. [CrossRef]

458. Walther, G.; Wagner, L.; Kurzai, O. Updates on the Taxonomy of Mucorales with an Emphasis on Clinically Important Taxa. J. Fungi 2019, 5, 106. [CrossRef]

459. Wagner, L.; Stielow, J.; De Hoog, G.; Bensch, K.; Schwartze, V.U.; Voigt, K.; Alastruey-Izquierdo, A.; Kurzai, O.; Walther, G. A new species concept for the clinically relevant Mucor circinelloides complex. Persoonia 2020, 44, 67-97. [CrossRef]

460. Heluta, V.; Takamatsu, S.; Harada, M.; Voytyuk, S. Molecular phylogeny and taxonomy of Eurasian Neoerysiphe species infecting Asteraceae and Geranium. Persoonia 2010, 24, 81-92. [CrossRef]

461. Gregorio-Cipriano, R.; González, D.; Félix-Gastélum, R.; Chacón, S. Neoerysiphesechii (Ascomycota: Erysiphales): A new species of powdery mildew found on Sechium edule and Sechium mexicanum (Cucurbitaceae) in Mexico. Botany 2020, 98, 185-195. [CrossRef]

462. Braun, U.; Cook, R.T.A. Taxonomic Manual of the Erysiphales (Powdery Mildews); CBS Biodiversity Series No. 11; Centraalbureau voor Schimmelcultures: Utrecht, The Netherlands, 2012.

463. Chen, C.; Verkley, G.J.; Sun, G.; Groenewald, J.Z.; Crous, P. Redefining common endophytes and plant pathogens in Neofabraea, Pezicula, and related genera. Fungal Biol. 2016, 120, 1291-1322. [CrossRef]

464. Choi, S.; Paul, N.; Lee, K.-H.; Kim, H.-J.; Sang, H. Morphology, Molecular Phylogeny, and Pathogenicity of Neofusicoccum parvum, Associated with Leaf Spot Disease of a New Host, the Japanese Bay Tree (Machilus thunbergii). Forests 2021, 12, 440. [CrossRef]

465. Prasannath, K.; Shivas, R.G.; Galea, V.J.; Akinsanmi, O.A. Neopestalotiopsis Species Associated with Flower Diseases of Macadamia integrifolia in Australia. J. Fungi 2021, 7, 771. [CrossRef]

466. Maharachchikumbura, S.S.; Larignon, P.; Al-Sadi, A.M.; Zuo-Yi, L.I.U. Characterization of Neopestalotiopsis, Pestalotiopsis and Truncatella species associated with grapevine trunk diseases in France. Phytopathol. Mediterr. 2017, 55, 380-390.

467. Jayawardena, R.; Liu, M.; Maharachchikumbura, S.S.N.; Zhang, W.; Xing, Q.; Hyde, K.D.; Nilthong, S.; Li, X.; Yan, J. Neopestalotiopsis vitis sp. nov. causing grapevine leaf spot in China. Phytotaxa 2016, 258, 63-74. [CrossRef]

468. Abdel-Wahab, M.A.; Bahkali, A.H.; El-Gorban, A.M.; Hodhod, M.S. Natural products of Nothophoma multilocularis sp. nov. an endophyte of the medicinal plant Rhazya stricta. Mycosphere 2017, 8, 1185-1200. [CrossRef]

469. Valenzuela-Lopez, N.; Cano-Lira, J.F.; Guarro, J.; Sutton, D.A.; Wiederhold, N.; Crous, P.W.; Stchigel, A.M. Coelomycetous Dothideomycetes with emphasis on the families Cucurbitariaceae and Didymellaceae. Stud. Mycol. 2018, 90, 1-69. [CrossRef]

470. Chethana, K.W.T.; Jayawardene, R.S.; Zhang, W.; Zhou, Y.Y.; Liu, M.; Hyde, K.D.; Li, X.H.; Wang, J.; Zhang, K.C.; Yan, J.Y. Molecular characterization and pathogenicity of fungal taxa associated with cherry leaf spot disease. Mycosphere 2019, 10, 490-530. [CrossRef]

471. Zhang, L.X.; Yin, T.; Pan, M.; Tian, C.M.; Fan, X.L. Occurrence and identifcation of Nothophoma spiraeae sp. nov. in China. Phytotaxa 2020, 430, 147-156.

472. Maharachchikumbura, S.; Guo, L.-D.; Chukeatirote, E.; Bahkali, A.; Hyde, K.D. Pestalotiopsis—Morphology, phylogeny, biochemistry and diversity. Fungal Divers. 2011, 50, 167-187. [CrossRef]

473. Keith, L.M.; Velasquez, M.E.; Zee, F.T. Identification and Characterization of Pestalotiopsis spp. Causing Scab Disease of Guava, Psidium guajava, in Hawaii. Plant Dis. 2006, 90, 16-23. [CrossRef]

474. Gramaje, D.; León, M.; Pérez-Sierra, A.; Burgess, T.; Armengol, J. New Phaeoacremonium species isolated from sandalwood trees in Western Australia. IMA Fungus 2014, 5, 67-77. [CrossRef] [PubMed]

475. da Silva, M.A.; Correia, K.C.; Barbosa, M.A.G.; Câmara, M.P.S.; Gramaje, D.; Michereff, S.J. Characterization of Phaeoacremonium isolates associated with Petri disease of table grape in Northeastern Brazil, with description of Phaeoacremonium nordesticola sp. nov. Eur. J. Plant Pathol. 2017, 149, 695-709. [CrossRef]

476. Spies, C.; Moyo, P.; Halleen, F.; Mostert, L. Phaeoacremonium species diversity on woody hosts in the Western Cape Province of South Africa. Persoonia 2018, 40, 26-62. [CrossRef] [PubMed]

477. Drechsler-Santos, E.R.; Robledo, G.L.; Lima-Júnior, N.C.; Malosso, E.; Reck, M.A.; Gibertoni, T.B.; Cavalcanti, M.A.D.Q.; Rajchenberg, M. Phellinotus, a new neotropical genus in the Hymenochaetaceae (Basidiomycota, Hymenochaetales). Phytotaxa 2016, 261, 218-239. [CrossRef] 
478. Tomšovský, M.; Vampola, P.; Sedlák, P.; Byrtusová, Z.; Jankovský, L. Delimitation of central and northern European species of the Phellinus igniarius group (Basidiomycota, Hymenochaetales) based on analysis of ITS and translation elongation factor 1 alpha DNA sequences. Mycol. Prog. 2010, 9, 431-445. [CrossRef]

479. Brazee, N.J. Phylogenetic Relationships among Species of Phellinus sensu stricto, Cause of White Trunk Rot of Hardwoods, from Northern North America. Forests 2015, 6, 4191-4211. [CrossRef]

480. Zhou, L.-W.; Vlasák, J.; Qin, W.-M.; Dai, Y.-C. Global diversity and phylogeny of the Phellinus igniarius complex (Hymenochaetales, Basidiomycota) with the description of five new species. Mycologia 2016, 108, 192-204. [CrossRef]

481. Zhu, L.; Ji, X.; Si, J.; Cui, B.-K. Morphological characters and phylogenetic analysis reveal a new species of Phellinus with hooked hymenial setae from Vietnam. Phytotaxa 2018, 356, 91-99. [CrossRef]

482. Slippers, B.; Boissin, E.; Phillips, A.; Groenewald, J.; Lombard, L.; Wingfield, M.; Postma, A.; Burgess, T.; Crous, P. Phylogenetic lineages in the Botryosphaeriales: A systematic and evolutionary framework. Stud. Mycol. 2013, 76, 31-49. [CrossRef]

483. Wu, S.-P.; Liu, Y.-X.; Yuan, J.; Wang, Y.; Hyde, K.D.; Liu, Z.-Y. Phyllosticta species from banana (Musa sp.) in Chongqing and Guizhou Provinces, China. Phytotaxa 2014, 188, 135-144. [CrossRef]

484. Blair, J.E.; Coffey, M.D.; Park, S.-Y.; Geiser, D.M.; Kang, S. A multi-locus phylogeny for Phytophthora utilizing markers derived from complete genome sequences. Fungal Genet. Biol. 2008, 45, 266-277. [CrossRef]

485. Martin, F.N.; Blair, J.E.; Coffey, M.D. A combined mitochondrial and nuclear multilocus phylogeny of the genus Phytophthora. Fungal Genet. Biol. 2014, 66, 19-32. [CrossRef] [PubMed]

486. Zhang, W.; Manawasinghe, I.S.; Zhao, W.; Xu, J.; Brooks, S.; Zhao, X.; Xu, J.P.; Brooks, S.; Zhao, X.; Hyde, K.D.; et al. Multiple gene genealogy reveals high genetic diversity and evidence for multiple origins of Chinese Plasmopara viticola population. Sci. Rep. 2017, 7, 17304. [CrossRef] [PubMed]

487. Tennakoon, D.S.; Phookamsak, R.; Wanasinghe, D.N.; Yang, J.B.; Lumyong, S.; Hyde, K.D. Morphological and phylogentic insights resolve Plenodomus sinensis (Leptosphariaceae) as a new species. Phytotaxa 2017, 324, 73-82. [CrossRef]

488. Maharachchikumbura, S.; Guo, L.-D.; Cai, L.; Chukeatirote, E.; Wu, W.P.; Sun, X.; Crous, P.W.; Bhat, D.J.; McKenzie, E.H.C.; Bahkali, A.; et al. A multi-locus backbone tree for Pestalotiopsis, with a polyphasic characterization of 14 new species. Fungal Divers. 2012, 56, 95-129. [CrossRef]

489. Maharachchikumbura, S.S.; Guo, L.-D.; Liu, Z.-Y.; Hyde, K.D. Pseudopestalotiopsis ignota and Ps. camelliae spp. nov. associated with grey blight disease of tea in China. Mycol. Prog. 2016, 15, 22. [CrossRef]

490. Pordel, A.; Khodaparast, S.A.; McKenzie, E.H.C.; Javan-Nikkhah, M. Two new species of Pseudopyricularia from Iran. Mycol. Prog. 2017, 16, 729-736. [CrossRef]

491. Klaubauf, S.; Tharreau, D.; Fournier, E.; Groenewald, J.; Crous, P.; de Vries, R.; Lebrun, M.-H. Resolving the polyphyletic nature of Pyricularia (Pyriculariaceae). Stud. Mycol. 2014, 79, 85-120. [CrossRef]

492. Crous, P.W.; Wingfeld, M.J.; Burgess, T.I.; Hardy, G.E.S.T.J.; Barber, P.A.; Alvarado, P.; Barnes, C.W.; Buchanan, P.K.; Heykoop, M.; Moreno, G. Fungal planet description sheets: 558-624. Persoonia 2017, 38, 240-384. [CrossRef]

493. Quaedvlieg, W.; Verkley, G.; Shin, H.-D.; Barreto, R.; Alfenas, A.; Swart, W.; Groenewald, J.; Crous, P. Sizing up Septoria. Stud. Mycol. 2013, 75, 307-390. [CrossRef] [PubMed]

494. Abe, A.; Asano, K.; Sone, T. A Molecular Phylogeny-Based Taxonomy of the Genus Rhizopus. Biosci. Biotechnol. Biochem. 2010, 74, 1325-1331. [CrossRef] [PubMed]

495. Gryganskyi, A.P.; Golan, J.; Dolatabadi, S.; Mondo, S.; Robb, S.; Idnurm, A.; Muszewska, A.; Steczkiewicz, K.; Masonjones, S.; Liao, H.-L.; et al. Phylogenetic and Phylogenomic Definition of Rhizopus Species. G3 Genes I Genom. I Genet. 2018, 8, $2007-2018$. [CrossRef] [PubMed]

496. Vebliza, Y.; Sjamsuridzal, W.; Oetari, A.; Santoso, I.; Roosheroe, I.G. Re-identifcation of five strains of Rhizopus arrhizus from tempeh based on ITS regions of rDNA sequence data. AIP Conf. Proc. 2018, 2023, e02016.

497. Hsieh, H.-M.; Lin, C.R.; Fang, M.J.; Rogers, J.D.; Fournier, J.; Lechat, C.; Ju, Y.-M. Phylogenetic status of Xylaria subgenus Pseudoxylaria among taxa of the subfamily Xylarioideae (Xylariaceae) and phylogeny of the taxa involved in the subfamily. Mol. Phylogenet. Evol. 2010, 54, 957-969. [CrossRef]

498. Bahl, J.; Jeewon, R.; Hyde, K.D. Phylogeny of Rosellinia capetribulensis sp. nov. and its allies (Xylariaiceae). Mycologia 2005, 97, 1102-1110. [CrossRef]

499. Daranagama, D.A.; Camporesi, E.; Tian, Q.; Liu, X.; Chamyuang, S.; Stadler, M.; Hyde, K.D. Anthostomella is polyphyletic comprising several genera in Xylariaceae. Fungal Divers. 2015, 73, 203-238. [CrossRef]

500. Wendt, L.; Sir, E.B.; Kuhnert, E.; Heitkamper, S.; Lambert, C.; Hladki, A.I.; Romero, A.I.; Luangsa-ard, J.J.; Srikitikulchai, P.; Peršoh, D.; et al. Resurrection and emendation of the Hypoxylaceae, recognised from a multigene phylogeny of the Xylariales. Mycol. Prog. 2018, 17, 115-154. [CrossRef]

501. Keirnan, E.C.; Tan, Y.P.; Laurence, M.H.; Mertin, A.A.; Liew, E.C.Y.; Summerell, B.A.; Shivas, R.G. Cryptic diversity found in Didymellaceae from Australian native legumes. MycoKeys 2021, 78, 1-20. [CrossRef]

502. Jayasiri, S.C.; Hyde, K.D.; Jones, E.B.G.; McKenzie, E.H.C.; Jeewon, R.; Phillips, A.J.L.; Bhat, D.J.; Wanasinghe, D.N.; Liu, J.K.; Lu, Y.Z.; et al. Diversity, morphology and molecular phylogeny of Dothideomycetes on decaying wild seed pods and fruits. Mycosphere 2019, 10, 1-186. [CrossRef]

503. Hou, L.W.; Hernández-Restrepo, M.; Groenewald, J.; Cai, L.; Crous, P.W. Citizen science project reveals high diversity in Didymellaceae (Pleosporales, Dothideomycetes). MycoKeys 2020, 65, 49-99. [CrossRef] 
504. Moslemi, A.; Ades, P.K.; Groom, T.; Nicolas, M.E.; Taylor, P.W. Alternaria infectoria and Stemphylium herbarum, two new pathogens of pyrethrum (Tanacetum cinerariifolium) in Australia. Australas. Plant Pathol. 2017, 46, 91-101. [CrossRef]

505. Woudenberg, J.H.C.; Hanse, B.; van Leeuwen, G.C.M.; Groenewald, J.Z.; Crous, P.W. Stemphylium revisited. Stud. Mycol. 2017, 87, 77-103. [CrossRef] [PubMed]

506. Brahmanage, R.S.; Hyde, K.D.; Li, X.H.; Jayawardena, R.S.; McKenzie, E.H.C.; Yan, J.Y. Are pathogenic isolates of Stemphylium host specifc and cosmopolitan? Plant Pathol. Quarant. 2018, 8, 153-164. [CrossRef]

507. Senwanna, C.; Wanasinghe, D.N.; Bulgakov, T.S.; Wang, Y.; Bhat, D.J.; Tang, A.M.C.; Mortimer, P.E.; Xu, J.; Hyde, K.D.; Phookamsak, R. Towards a natural classification of Dothidotthia and Thyrostroma in Dothidotthiaceae (Pleosporineae, Pleosporales). Mycosphere 2019, 10, 701-738. [CrossRef]

508. Crous, P.W.; Schumache, R.K.; Akulov, A.; Thangavel, R.; Hernández Restrepo, M.; Carnegie, A.J.; Cheewangkoon, R.; Wingfeld, M.J.; Summerel, B.A.; Quaedvlieg, W.; et al. New and interesting fungi. 2. Fungal Syst. Evol. 2019, 3, 57-134. [CrossRef]

509. Shivas, R.G.; Barrett, M.D.; Barrett, R.L.; McTaggart, A.R. Tilletia micrairae. Persoonia 2009, 22, 171-172.

510. Shivas, R.G.; Beasley, D.R.; McTaggart, A.R. Online identification guides for Australian smut fungi (Ustilaginomycotina) and rust fungi (Pucciniales). IMA Fungus 2014, 5, 195-202. [CrossRef]

511. McTaggart, A.R.; Shivas, R.G. Tilletia challinorae McTaggart \& RG Shivas, sp. nov. Persoonia 2009, $23,36$.

512. Li, Y.M.; Shivas, R.G.; Cai, L. Three new species of Tilletia on Eriachne from north-western Australia. Mycoscience 2014, 55, 361-366. [CrossRef]

513. Vánky, K.; Lutz, M. Tubisorus, a new genus of smut fungi (Ustilaginomycetes) for Sporisorium pachycarpum. Mycol. Balc. 2011, 8, 129-135.

514. Zhang, J.; Dou, Z.; Zhou, Y.; He, W.; Zhang, X.; Zhang, Y. Venturia sinensis sp. nov. a new ventuarialean ascomycete from Khingan Mountains. SaudiJ. Biol. Sci. 2016, 23, 592-597. [CrossRef] [PubMed]

515. Zhang, Y.; Crous, P.; Schoch, C.; Bahkali, A.; Guo, L.; Hyde, K.D. A molecular, morphological and ecological re-appraisal of Venturiales-A new order of Dothideomycetes. Fungal Divers. 2011, 51, 249-277. [CrossRef] [PubMed] 